



\section{Chemical and physical hazards in the Dutch poultry meat chain}

J.L. Banach ${ }^{1}$, E.D. van Asselt ${ }^{1}$, R. Hoogenboom ${ }^{1}$, L. Razenberg ${ }^{2}$, P.E. Boon ${ }^{2}$, P. van Horne ${ }^{3}$, M.J.B. Mengelers ${ }^{2}$, H.J. van der Fels-Klerx ${ }^{1}$

1 RIKILT Wageningen University \& Research

2 National Institute for Public Health and the Environment (RIVM)

3 Wageningen Economic Research

This research has been carried out by RIKILT Wageningen University \& Research, institute within the legal entity Wageningen Research Foundation funded by the Netherlands Food and Consumer Product Safety Authority (NVWA) (project number 1257335401).

Wageningen, July 2017

RIKILT report 2017.001 
Banach, J.L., E.D. van Asselt, R. Hoogenboom, L. Razenberg, P.E. Boon, P. van Horne, M.J.B. Mengelers and H.J. van der Fels-Klerx, 2017. Chemical and physical hazards in the Dutch poultry meat chain. RIKILT Wageningen University \& Research, RIKILT report 2017.001. 70 pp.; 9 fig.; 7 tab.; 151 ref.

Project number: 1257335401

Project title: Gevaaranalyse Witvleesketen

Project leader: H.J. van der Fels-Klerx

This report can be downloaded for free at https://doi.org/10.18174/401913 or at www.wur.eu/rikilt (under RIKILT publications).

(C) 2017 RIKILT Wageningen University \& Research, institute within the legal entity Wageningen Research Foundation. Hereinafter referred to as RIKILT.

a) publish parts of this report;

b) use this report or title of this report in conducting legal procedures, for advertising, acquisition or other commercial purposes;

c) use the name of RIKILT other than as the author of this report.

P.O. Box 230, 6700 AA Wageningen, The Netherlands, T +31 (0)317 4802 56, E info.RIKILT@wur.nl, www.wur.eu/rikilt. RIKILT is part of Wageningen University \& Research.

This report from RIKILT has been produced with the utmost care. However, RIKILT does not accept liability for any claims based on the contents of this report.

RIKILT report 2017.001

Distribution list:

- J. Cornelese (NVWA)

- M. Schrap (NVWA)

- G. Visser (NVWA)

- D. Sijm (NVWA) 


\section{Contents}

$\begin{array}{ll}\text { Summary } & 5\end{array}$

1

$\begin{array}{ll}\text { Introduction } & 7\end{array}$

$\begin{array}{lll}1.1 & \text { Project Background } & 7\end{array}$

$\begin{array}{lll}1.2 & \text { Poultry Chain Background } & 7\end{array}$

1.2.1 Supply chain of broiler meat 8

1.2.2 Marketing structure of poultry (broiler) meat $\quad 10$

2

\section{Materials and methods}

2.1 Literature study and expert input

2.2 Data analysis

3.1 Chemical and physical hazards

3.1.1 Potential chemical hazards 13

3.1.2 Potential physical hazards $\quad 26$

$\begin{array}{ll}3.1 .3 \text { Results alerting and monitoring data } & 27\end{array}$

3.1.4 Main chemical hazards $\quad 30$

3.2 Human health effects of the main chemical hazards 31

3.2.1 Dioxins and polychlorinated biphenyls (PCBs) 31

3.2.2 Chloramphenicol 33

$\begin{array}{ll}3.2 .3 \text { Nitrofurans } & 34\end{array}$

3.2.4 Nitroimidazoles 36

3.2.5 Polybrominated diphenyl ethers (PBDEs) 38

3.2.6 Hexabromocyclododecanes (HBCDDs) 39

3.3 Possible intervention measures $\quad 41$

3.3.1 Intervention measures at primary production $\quad 41$

3.3.2 Intervention measures for further processing $\quad 42$

3.4 Trends in the poultry meat chain $\quad 43$

3.4.1 Broiler farms $\quad 43$

3.4.2 Production, Trade, and Consumption 43

3.4.3 Consequences for hazards $\quad 46$

$4 \quad$ Conclusions and recommendations $\quad 48$

$\begin{array}{lll}4.1 & \text { Conclusions } & 48\end{array}$

4.2 Recommendations $\quad 51$

$\begin{array}{lll}\text { Annex } 1 & \text { Poultry Chain } & 61\end{array}$

$\begin{array}{lll}\text { Annex } 2 & \text { RASFF notifications } & 62\end{array}$ 



\section{Summary}

The Netherlands Food and Consumer Product Safety Authority (NVWA) watches over the safety of food and feed products. For this purpose, the NVWA monitors the presence of possible hazards for human and animal health in food and feed. In order to prioritize its monitoring activities, in accordance with Regulation (EC) 882/2004, the NVWA aims to apply risk-based control focusing on the most important food safety hazards.

The aim of the current study was to provide an overview of possible chemical and physical hazards in the poultry supply chain (from farm to retail) and identify the most important chemical and physical hazards for human health. For these most important hazards, the possible human health effects were also evaluated. Furthermore, intervention measures for reducing the presence of these hazards were studied as well as trends that may affect food safety in the poultry chain in the future.

A scientific literature review was performed, datasets (from the Rapid Alert System for Food and Feed and Dutch monitoring data) were analyzed, and experts were consulted. The focus was on broiler meat, but also the meat of other poultry, such as turkey and ducks, was considered if literature and/or data were available.

Results showed that various groups of chemical and physical hazards might occur in the poultry meat production chain. Most information was available for broilers and broiler meat, though occurrence data for several contaminants that are possibly relevant in poultry and poultry meat, specifically brominated flame retardants, were scarce. Occurrence data for other poultry types, like turkey and duck, were also scarce. Therefore, it is recommended to allocate research to obtain more information on the presence of specific chemical hazards in broilers, as well as other poultry types (although volumes for these meat sources are only a fraction of the total volumes of broiler meat produced in the Netherlands).

Most chemical hazards are introduced at the farm level, where poultry can become contaminated due to the intake of contaminated feed, the outdoor and indoor environment, and equipment.

Furthermore, due to the administration of veterinary drugs, residues of pharmacologically active substances could be present in poultry products. During further processing, contamination may occur due to the use of biocides, such as residues from agents used for cleaning the slaughtering and processing lines. In processed poultry products, food additives may be used. In addition, substances migrating from packaging materials and/or formed during processing (like heat-generated contaminants) may be introduced at later stages of the chain. For the latter hazards, arising from poultry processing, monitoring data is lacking and should continue to be collected so as to monitor their future presence.

Based on the literature review, alerting and monitoring data, and expert opinion, the following chemical hazards were considered most important for the Dutch poultry meat production chain: dioxins and dioxin-like polychlorinated biphenyls (DL-PCBs), and prohibited and unauthorized veterinary drugs (mainly antimicrobial substances). Also, other veterinary drug residues, particularly in poultry products imported from non-European Union (EU) countries, are considered relevant. To a lesser extent, NDL-PCBs and emerging contaminants like brominated flame retardants (BFRs) were considered relevant, but more data on the latter group of compounds should be collected. Limited data is also available for plant toxins and perfluoralkylated substances (PFASs), though these two groups of compounds are considered to be of lesser relevance to poultry meat products. However, more data should be collected to validate this. The presence of bones and feathers in poultry products is considered to be the most important physical hazard; this hazard is, however, well controlled by slaughtering and processing plants. 
Chemical hazards can be prevented and controlled by applying quality assurance schemes such as GLOBALG.A.P. (Good Agricultural Practices) at the farm and HACCP (Hazard Analysis and Critical Control Points) at poultry processing. Furthermore, most Dutch poultry farmers are certified to the IKB-system. In order to maintain a high level of food safety, such quality assurance systems have to adapt to future trends in developments. The most important drivers that may affect food safety are a further intensification of the chain, consumer demands for "animal-friendly" production, global economy and trade, and climate change.

In the Netherlands, the number of poultry farms is decreasing, while the farm size is increasing. This will result in a further intensification of the poultry meat production chain. This may have positive effects on food safety as farmers will invest to improve their farm and will be more aware of possible food safety issues. On the other hand, an increased farm size may result in an increased occurrence of animal diseases and, subsequently, the use of veterinary drugs. Increased numbers of poultry will also affect the animal feed market; this may have some consequences for the quality and safety of these products. With a larger farm size, farmers are also expected to mix feed ingredients at their own farm rather than purchasing complete feeds. Further globalization may hamper the transparency in the chain, especially in the feed sector. This may increase possibilities for food and feed fraud. Climate change is expected to affect animal and plant diseases as well as the subsequent use of pesticides, veterinary drugs, etc.

As most chemical hazards are introduced at the farm level through feed, the environment, and the use of veterinary medicinal products, and since future developments may have consequences for the poultry farm, it is advised to focus monitoring on the farm and feed supply. At the farm level, changes in production systems, as a result of increased awareness for sustainability and animal welfare, should be closely followed in order to evaluate their consequences for food safety. Further processing should not be ignored, and some level of inspection should be arranged for contaminants that may be introduced further along the chain. Furthermore, imported products from outside the EU may need to have increased monitoring, especially for residues of veterinary drugs. 


\section{Introduction}

\section{$1.1 \quad$ Project Background}

The Netherlands Food and Consumer Product Safety Authority (NVWA) monitors the health of animals and plants, animal welfare, and the safety of food and consumer products. Risk-based monitoring can help to increase the efficiency of monitoring activities. An important aspect in setting up risk-based monitoring plans is to identify the most important food and feed safety hazards throughout the whole chain (i.e. from farm to supermarket to consumer or "farm to fork"). In this context, the risk is defined as the combined probability of hazard occurrence in the chain and the effects of these hazards on human health (World Health Organization (WHO) and Food Agriculture Organization of the United Nations (FAO), 2015). The definition of risk in the General Food Law (Regulation (EC) 178/2002) is slightly different: 'risk means the function of the probability of an adverse health effect and the severity of that effect, consequential to a hazard.' Currently, the NVWA is performing a risk evaluation of various food supply chains, of which chemical and physical hazards in the poultry meat chain is the focus of the present research.

The aim of the current study was to identify the main chemical and physical hazards in the poultry meat chain, from farm to retail, and to estimate the potential human health effects of these hazards, as based on literature review, data analyses, and expert input. This information can be used as input for prioritizing monitoring of chemical and physical hazards in the poultry meat chain. The focus of this study was on chicken (broilers) although turkeys, duck, quail, guinea fowl, pheasant, amongst other game birds, were considered in the literature search and data analysis. The health hazards posed by microbiological hazards in the poultry meat chain were outside the scope of the present research.

The main aim was elaborated in the following tasks:

1. Literature study of the chemical and physical hazards that may occur in the poultry meat chain including their points of introduction in the chain (sections 3.1 and 3.2).

2. Analysis of data on chemical and physical hazards from the Rapid Alert System for Food and Feed (RASFF) and KAP (Quality Program for Agricultural Products). Furthermore, notifications of the main hazards (from the results of task 1 ) are collected from risk assessments made by the RIVM-RIKILT Front Office Food and Product Safety, hereafter referred to as the Front Office (section 3.1).

3. Literature review on the human health effects and the human intake of the main hazards, resulting from task 1 and 2 (section 3.2).

4. Identification of intervention measures that can prevent or reduce the occurrence of the main chemical and physical hazards as identified in task 1 (section 3.3).

5. Evaluation of trends in developments within the poultry chain up to 2025 that may influence the presence of food safety hazards (section 3.4).

Several authors contributed to the conception of the report. RIKILT (co-)authors were responsible for the tasks 1, 2, 4, and 5. RIVM co-authors were responsible for task 3, while the involved expert from Wageningen Economic Research was mainly responsible for task 5.

\subsection{Poultry Chain Background}

In the Netherlands, poultry meat refers primarily to broiler meat (or colloquially chicken). Broiler meat production occurs in a chain with several consecutive stages, each one with a specialized task. Within this chain, there is cooperation between breeding companies, farms with broiler breeders, hatcheries, broiler farms, slaughterhouses, and further processors. In addition, poultry meat is produced from turkeys and ducks. Moreover, the category of poultry meat includes the meat of laying hens in addition to broiler meat. According to the former Dutch Product Boards for Livestock, Meat and Eggs 
$(\mathrm{PVE})^{1}$ the distribution of poultry meat production in the Netherlands is approximated as such: broiler $(90 \%)$, turkey $(3 \%)$, duck (2\%), and chickens/roosters, i.e. laying hens and broiler breeders, $(4 \%)$ (Dutch Product Boards for Livestock, 2013). Below, the Dutch broiler meat supply chain and market are described in further detail.

\subsubsection{Supply chain of broiler meat}

The poultry production chain for broilers is depicted in Figure 1. A more detailed depiction of the poultry meat chain including influences from animal feed, waste management, and marketing structure can be found in Annex 1 (van Bokhorst-van de Veen et al., 2015).

At the beginning of the supply chain are the breeding organizations. From the grandparent stock of broilers, these organizations produce the pure lines. Worldwide, two breeding companies, Aviagen and Cobb-Vantress Inc., dominate the market. These companies have grandparent stocks and hatcheries in the Netherlands. A third company (Hubbard) gained some market share with slower growing broilers (Beter Leven Kenmerk) and provided broiler parent stocks from France. These companies transport the day-old broiler breeders to the rearing farms where they are raised to become young broiler breeders.

At the rearing farms, the broiler breeders are grown until 20 weeks. In the Netherlands, there are around 60 to 70 rearing farms, which produce six million broiler breeders per year (Wisman, 2014). When the broiler breeders are mature, they are transported to broiler breeder farms. At the broiler breeder farms, eggs are produced. Twice a week, these eggs are transported to a hatchery. Part of this production is directly exported. In the Netherlands, there are between 200 and 220 broiler breeder farms, which house approximately six million broiler breeders, producing approximately 1000 million eggs per year for broiler production (Dutch Product Board for Poultry and Eggs (PPE), 2013; Wisman, 2014).

At the broiler hatchery, the chicks hatch, and then one-day-old chicks are transported to specialized broiler farms. As of 2013, there were seventeen broiler hatcheries in the Netherlands where about 650 million eggs are hatched per year (Dutch Product Board for Poultry and Eggs (PPE), 2013). Out of the 1000 million hatching eggs, approximately $50 \%$ are hatched for the domestic market, $15 \%$ are hatched for export, and 35\% are directly exported, mainly to Russia. In broiler meat production, both male and female broilers are included; splitting of one-day-old chickens according to sex is negligible.

At the broiler farms, the birds are kept five to seven weeks for conventional broilers, eight weeks for the animal-friendly chicks ("scharrelkuikens") and animal-friendly broilers, and 10 weeks for organic broilers. When the broilers have a live weight of 1.8 to $2.6 \mathrm{~kg}$, they are sold to the slaughterhouse. From the 2012 agricultural census, a total of 44.6 million animals were present on 560 broiler farms, while the total yearly production was approximately 998,000 tons live weight (Dutch Product Board for Poultry and Eggs (PPE), 2013; Dutch Product Boards for Livestock, 2013; Wisman, 2014). From the 560 broiler farms, there are 12 organic broiler farms in the Netherlands that produce yearly nearly 240,000 organic broilers. Therefore, organic broiler meat contributes to $0.5 \%$ of the total yearly broiler meat production in the Netherlands (Landbouw-Economisch Institut (LEI), 2015).

At broiler farms, the birds are caught manually and put in containers/crates, which are loaded onto trucks to transport them to the slaughterhouse (Mitchell and Kettlewel, 2009). In 2012, there were 19 slaughterhouses in the Netherlands of which about 843,600 tons (slaughter weight) of broiler meat were produced (Dutch Product Board for Poultry and Eggs (PPE), 2013; Dutch Product Boards for Livestock, 2013). Two companies, Plukon Royale Group and 2 Sisters Storteboom B.V., comprise half of the market. Both companies have various slaughterhouse locations in the Netherlands and are also active in other EU countries. Dutch slaughterhouses also receive live broilers from abroad, mainly from Germany (Dutch Product Boards for Livestock, 2013), while Dutch broilers are also slaughtered in Germany and Belgium. Slaughterhouses buy live broilers, which are slaughtered, and sold as semifinished products to processors or are further processed at the slaughterhouse into consumer products directly to be sold at retail (e.g., supermarkets) or for use at food services (e.g., restaurants, catering) (van Horne, 2007). In the Netherlands, about 264 companies process poultry products post-slaughter (Dutch Product Boards for Livestock, 2013).

\footnotetext{
1 The Product Boards for Livestock, Meat and Eggs (PVE) is the name for two joint Dutch product boards: the Product Board for Livestock and Meat (PVV) and the Product Board for Poultry and Eggs (PPE).
} 


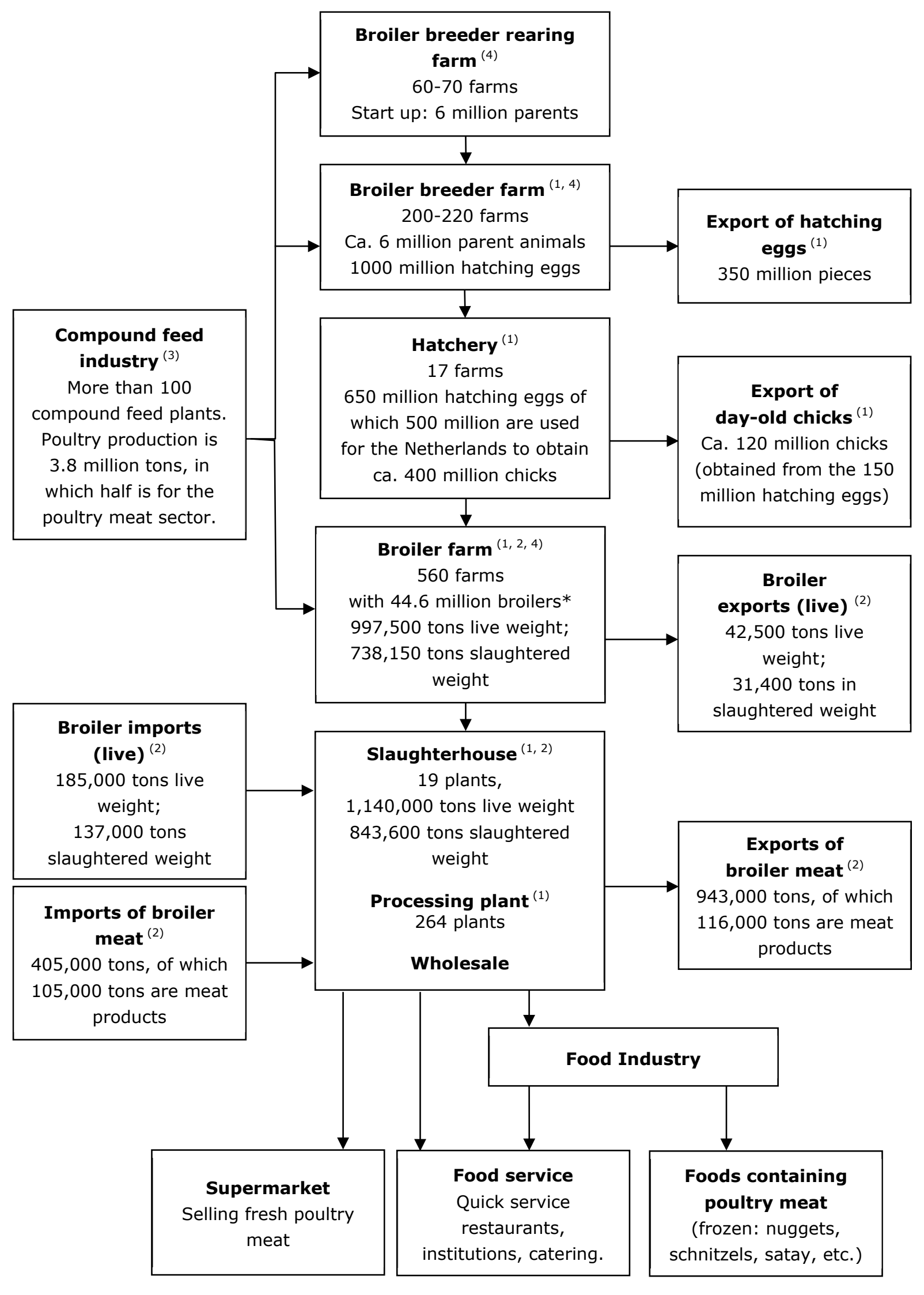

*Value represents the agricultural census at one timepoint (or of one cycle).

Figure 1 The Netherlands broiler meat chain. Sources: (1) Dutch Product Board for Poultry and Eggs (PPE) (2013), (2) Dutch Product Boards for Livestock (2013), (3) Hoste (2014), and (4) Wisman (2014). 


\subsubsection{Marketing structure of poultry (broiler) meat}

Some details of the Netherlands marketing structure of the broiler sector in 2012 are shown in Figure 1; this includes figures for total imports and exports for both broilers and broiler meat as well as figures on broiler populations and animals slaughtered (Dutch Product Boards for Livestock, 2013). Besides domestic production, the Netherlands imports and exports poultry meat. Imports of poultry meat, for example, cooked and/or salted poultry meat, canned food, and meat products, decreased about 2\% between 2011 and 2012 to an estimated 584,000 tons in 2012, and there were fewer deliveries from Brazil (Dutch Product Boards for Livestock, 2013). In 2012, a total of 405,000 tons of broiler meat were imported, mainly from Brazil and Thailand (Dutch Product Boards for Livestock, 2013). Imported, frozen poultry meat is used by the processing industry for producing prepared meat products. These products are purchased by quick service restaurants, institutions, and retailers to be sold in supermarkets (in the frozen section).

The import of broiler meat from third countries can be divided into three main categories: salted, boiled, and natural chicken breast fillet. In 2013, imports of broiler meat from third countries were approximately 250,000 tons. In total, about 150,000 tons of salted fillet (GN code 0210.9939 ) came from Brazil (70\%) and Thailand (25\%). Imports of boiled fillet (GN code 1602.3219) were about 60,000 tons and came from Thailand (65\%) and Brazil (25\%). Imports of natural breast fillet were about 35,000 tons (GN code 0207.1410) and came from Brazil (60\%) as well as Chile, Thailand, and Argentina.

Dutch trade exports of poultry meat have increased by 2\% between 2011 and 2012, while European Union (EU) exports to Germany, Belgium, and France also increased. In total, export in 2012 was approximately 943,000 tons (Dutch Product Boards for Livestock, 2013). Poultry meat is exported as a fresh product to neighboring countries like Germany and the United Kingdom. The domestic consumption of poultry meat in 2013 was 306,000 tons, which is approximately $18.5 \mathrm{~kg}$ per person (Dutch Product Board for Poultry and Eggs (PPE), 2014).

In the Netherlands, higher transport costs as well as an increase in feed prices, start-up costs for dayold chicks, and energy costs in 2012 resulted in diminished profits in spite of about a $4 \%$ price increase from 2011. An overview of gross domestic product (GDP) for poultry meat products in 2012 is depicted in Table 1 (Dutch Product Boards for Livestock, 2013).

Table 1 The Netherlands estimated GDP for poultry meat products in 2012 (Dutch Product Boards for Livestock, 2013).

\begin{tabular}{|c|c|c|}
\hline Product & $\begin{array}{l}\text { Estimated Tons } \\
\text { (based on slaughter weight) }\end{array}$ & $\begin{array}{l}\text { Percentage changed } \\
\text { (since 2011) }\end{array}$ \\
\hline Poultry & 810,000 & $\uparrow 3 \%$ \\
\hline Turkey & 27,200 & $\downarrow 2 \%$ \\
\hline Other poultry ${ }^{(1)}$ & 45,000 & stabilized \\
\hline
\end{tabular}

(1) Other poultry includes chickens, ducks, geese, and guinea fowl.

In the Netherlands, there are no longer turkey slaughterhouses. Instead, Dutch produced turkey is slaughtered in Germany. There are two slaughterhouses for duck although almost all duck production is exported. Also, there is one slaughterhouse for "spent" laying hens and one for broiler breeders. 


\section{$2 \quad$ Materials and methods}

\subsection{Literature study and expert input}

Information from scientific literature was retrieved using the bibliographic database Scopus and Google Scholar. Additionally, articles and reports from EUR-Lex legal texts, official websites of the EU (e.g., the European Food Safety Authority (EFSA)), and those suggested by experts were retrieved. These references were evaluated for their relevance based on title, abstract, and keywords. The following keywords were used: chemical and/or physical -contaminants, -hazards, -pollutants in the poultry chain. Furthermore, scientific reports or papers from international institutions and organizations such as the European Commission (EC), the United States Department of Agriculture (USDA), the New Zealand Food Safety Authority (NZFSA), the World Health Organization (WHO), and the Food and Agricultural Organization (FAO), among other trustworthy sources, were also included in the search. Also, keywords for selected hazards (e.g., dioxins and dioxin-like polychlorinated biphenyls (DL-PCBs), non-dioxin-like polychlorinated biphenyls (NDL-PCBs), chloramphenicol, nitrofurans, nitroimidazoles, brominated flame retardants and perfluoralkylated substances were investigated to obtain additional background information. Furthermore, experts from Wageningen University \& Research Centre provided input on the major chemical and physical hazards and possible intervention measures within the poultry meat chain.

\subsection{Data analysis}

In order to indicate the incidence of possible hazards (as part of tasks 1 and 2), monitoring data were analyzed. For this purpose, the RASFF portal was utilized to extract data notified from 01/01/2009 until 01/01/2015. RASFF types of notifications included alerts, border rejections, and information (including attention and follow-up). The product category poultry meat and poultry meat products were analyzed, and specific hazards related to chemical and physical hazards were identified. In addition, the product category meat and meat products (other than poultry) was investigated in a similar fashion for specific products (as noted in the subject column in RASFF) including chicken, turkey, duck, quail, guinea fowl, and pheasant. Furthermore, data from the Dutch national monitoring program on chemical contaminants in food and feed were retrieved. These data are stored in the KAP database, a database that is part of a Quality Program for Agricultural Products, which involves extensive cooperation between the Dutch government (i.a. NVWA) and agribusiness. ${ }^{2}$ KAP data from 2009-2011 were used as these were the most recent data in the KAP database. These data showed that 2,212 samples were taken for meat from broilers, hens, and other types of poultry meat. Most of the samples were taken from broilers $(76 \%)$, the majority of which were tested for the presence of veterinary drugs (Fig. 2). For the years 2012-2014, only limited data on halogenated carbon compounds (dioxins, PCBs, and brominated flame retardants), pesticides, and mycotoxins were available in the KAP database. These data were, therefore, not further evaluated. Data of some individual compounds from the National Monitoring Plan (NMP) were used for 2011-2016, if available.

${ }^{2}$ https://chemkap.rivm.nl/ 


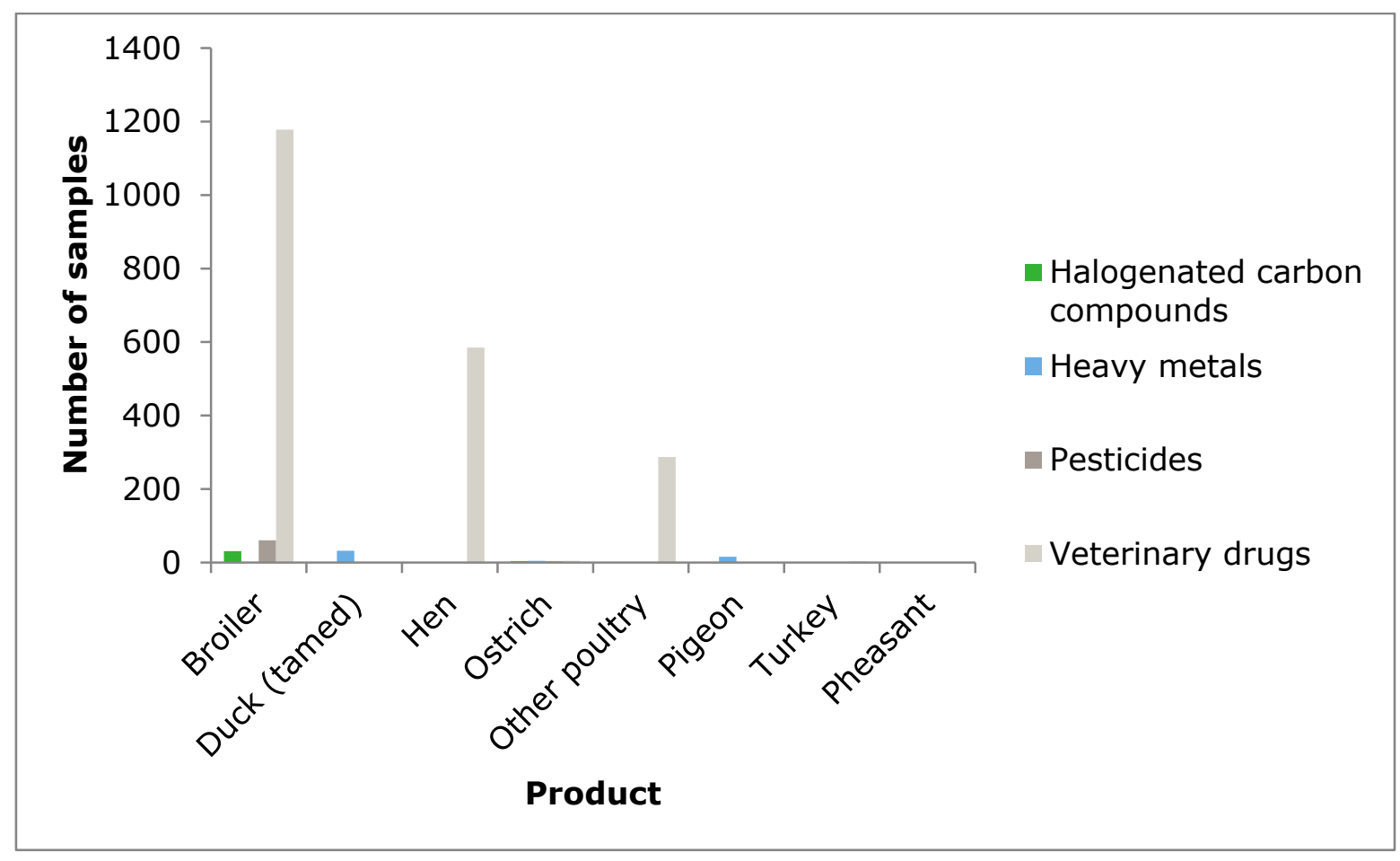

Figure 2 The number of samples in the KAP-database from 2009-2011 [data of the NVWA annual national plan on poultry products from 2011 onwards were not stored in KAP].

Furthermore, three databases that contain information on incidentally occurring chemical hazards in the food supply chain were reviewed. These databases included notifications reported in the Notification Support System of the NVWA (Meldingenondersteuningssysteem, MOS), the National Poisons Information Centre (Nationaal Vergiftigingen Informatie Centrum, NVIC), and from risk assessments made by the Front Office. Information collected from the NVWA and NVIC were summarized on a quarterly basis from 2010 up to and including 2012 (National Institute of Public Health and the Environment (RIVM), 2010-2012). For the present poultry meat chain analysis, all available information on the trend analysis project was screened for chemical hazards occurring in poultry meat and poultry meat products. Information collected from the Front Office were summarized on a yearly basis since 2006 (Front Office, 2010-2014). The available information was screened for chemical hazards occurring in poultry meat and poultry meat products from 2010 up to and including 2014. 


\section{$3 \quad$ Results}

Based on the information from the literature search, chemical and physical hazards at the various stages in the poultry meat chain, further divided into "primary production" and "further processing" (i.e. processing, retail, manufacture, and consumer), were investigated.

\subsection{Chemical and physical hazards}

\subsubsection{Potential chemical hazards}

Chemical hazards could potentially be introduced throughout the chain and end up in poultry meat or related products. At primary production (farm level), contamination of poultry could occur due to use of contaminated feed and water or via the uptake of chemical compounds from the contaminated environment. Via the administration of veterinary medicines, residues of pharmacologically active substances may be present in meat. During further processing, contamination may result from the use of biocides, such as residues from agents used for cleaning the slaughtering and processing lines. In processed poultry products food additives may be used. In addition, substances migrating from packaging materials and processing contaminants may be introduced at later stages of the chain (FSANZ, 2005). Another cause of contamination is fraud, which may occur at various stages along the chain. Previous cases of food fraud in poultry have been reported in the UK; these entailed diverting unfit poultry meat into the food chain, for example by bleaching, or illegally repackaging and selling poultry meat that was unknown in origin (Tähkäpää et al., 2015). Although food fraud in the poultry meat chain could potentially be of a concern, as it can contribute to the appearance or reappearance of (new) hazards, specific fraud-related hazards are outside the scope of the present research.

Table 2 provides an overview of possible chemical substances that may enter into the poultry meat chain during primary production and further processing; the column "hazard category" refers to the group of chemical hazards. The column "hazard types" indicates the most likely hazards/hazard groups within each category, possibly relevant for poultry meat. The different hazard categories with their hazard types are further discussed in the following sections.

\subsubsection{Primary production}

Chemical hazards that may be introduced to poultry during primary production (farm level) include those from feed and water, those related to the poultry housing system, and transport. The use of veterinary medicines for treatment may result in residues of pharmacologically active substances in meat. Poultry is mainly fed with compound feed that is specially produced for this animal category. Poultry feed may be contaminated with, amongst others, various persistent organic pollutants, heavy metals, mycotoxins, plant toxins, and/or pesticide residues. Since compound feed for poultry produced in the Netherlands has to fulfill high-quality standards, the presence of these contaminants is well controlled and expected to be low. Furthermore, cleaning and disinfection may introduce chemical hazards. For example, formaldehyde is used for fumigation of the broiler farms. Disadvantages of the use of formaldehyde for cleaning animal facilities are primarily related to human safety and environmental impact - safer alternatives are warranted. Disinfection is performed by specialized companies who are IKB-PSB (Pluimvee Service bedrijven) certified (Le Blansch and Heesen, 2016). 
Table 2 Potential chemical hazards in the poultry meat chain, adapted from two literature sources (EFSA Panels on Biological Hazards (BIOHAZ) et al., 2012; Food Standards Australia New Zealand (FSANZ), 2005).

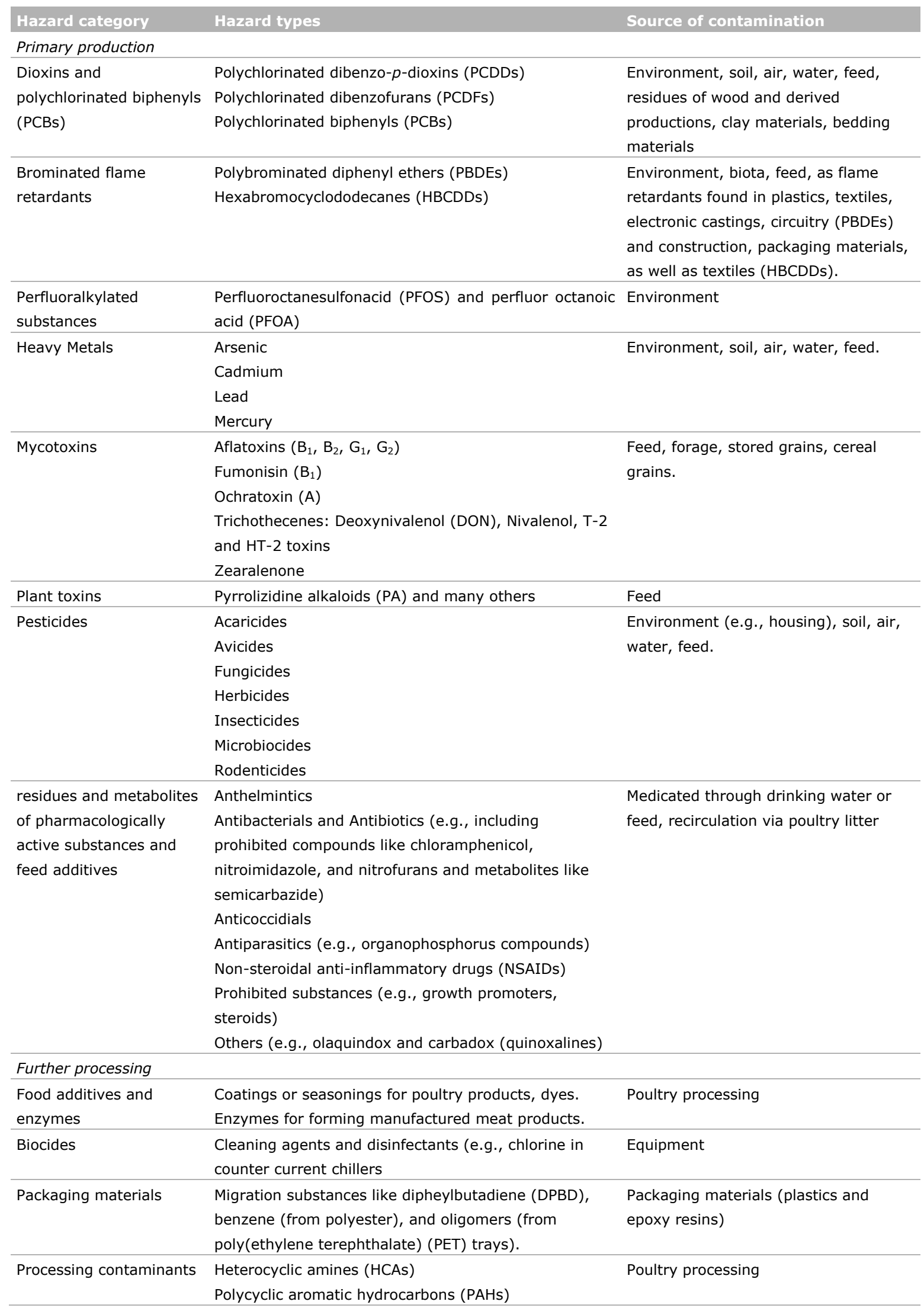




\section{Environmental and feed contaminants}

\subsection{Dioxins and polychlorinated biphenyls (PCBs)}

In Regulation (EC) $1881 / 2006$ it is stated that "dioxins" comprise 75 polychlorinated dibenzo-p-dioxins (PCDDs) congeners and 135 polychlorinated dibenzofurans (PCDFs) congeners, of which 17 are of toxicological concern (7 PCDDs and 10 PCDFs) (European Commission, 2006a). Polychlorinated biphenyls (PCBs) include 209 congeners, of which 12 congeners exhibit toxicological properties similar to dioxins, and hence are termed dioxin-like polychlorinated biphenyls (DL-PCBs) (European Commission, 2006a; Food Standards Australia New Zealand (FSANZ), 2005; Hoogenboom, 2012).

Dioxins and DL-PCBs are persistent organic pollutants (POPs) with a high chemical stability, e.g., they are not destroyed by microbial, photochemical, or chemical degradation, or by thermal treatment. They are lipophilic compounds that have the potential to bio-magnify, bio-accumulate, and persist especially in fatty tissues of animals - in the food chain causing potential adverse effects to human health (European Food Safety Authority (EFSA), 2012b; Ghimpeţeanu et al., 2014; Reyes-Herrera and Donoghue, 2012; World Health Organization (WHO), 2014a).

Animal feed is considered to contribute considerably to the presence of these compounds in animalderived products (Malisch and Kotz, 2014). In various historical incidents, dioxins and DL-PCBs have been introduced via contaminated animal feed traced back to clay, contaminated fat, citrus pulp pellets, or improperly dried ingredients used for animal feed production (Hoogenboom et al., 2015). Within the Netherlands, incidents of dioxin and DL-PCB contaminations of feed ingredients occurred in 2004 with potato peels contaminated with kaolinic clay, in 2006 with contaminated hydrochloric acid for gelatin production from pig bones, and in 2010 with contaminated corn (Hoogenboom et al., 2015). In addition to feed, also the soil in the courtyard, the housing, and the use of certain litter may be important sources.

The EU has provided statutory limits for dioxins and DL-PCBs in food and feed. According to Regulation (EC) $1881 / 2006$, the current maximum level (ML) for dioxins (WHO-PCDD/F-TEQ) in poultry meat and fat is $1.75 \mathrm{pg} \mathrm{TEQ} / \mathrm{g}$ fat and in poultry liver is $0.30 \mathrm{pg} / \mathrm{g}$ wet weight liver, while the $\mathrm{ML}$ for the sum of dioxins and DL-PCBs (WHO-PCDD/F-PCB-TEQ) in poultry meat and fat is $3.0 \mathrm{pg} \mathrm{TEQ} / \mathrm{g}$ fat and in poultry liver is $0.50 \mathrm{pg}$ TEQ/g wet weight liver. In addition, the EU set action levels for dioxins and for DL-PCBs, being 1.25 and 0.75 pg TEQ/g fat, respectively, for meat (Recommendation 2011/516/EU, later replaced by Recommendation 2013/711/EU (later amended by Recommendation 2014/663/EU)). The EU also established maximum levels and action thresholds for animal feed (Directive 2002/32/EC). Exceedance of action levels and thresholds should be followed up by tracing the source of the contamination, but products can still be put on the market. Products exceeding MLs should not be put on the market. Limits were established according to the principle strict but feasible, i.e. based on the levels reported to EFSA and as such that 5-10\% should exceed the limits. This approach should result in a further decrease of the levels, allowing a reduction of the limits and decreased exposure of consumers.

Dioxins and DL-PCBs accumulate in food-producing animals and transfer to milk, meat, and eggs (de Jong et al., 2015). For example, in the 1999 Belgian dioxin crisis, levels of $780 \mathrm{ng} \mathrm{TEQ} / \mathrm{kg}$ in chicken feed, $960 \mathrm{ng}$ TEQ/kg in chicken fat, and $710 \mathrm{ng}$ TEQ/kg in egg fat were detected (Hoogenboom, 2012). Hoogenboom et al. (2004) carried out a study to evaluate the potential carryover of dioxins and categories of PCBs (non-ortho, mono-ortho, and indicator PCBs) to broilers fed with 10-fold diluted feed from the Belgian crisis, to determine the kinetics of such compounds. In this study, threeweek-old broilers were fed for one week with contaminated feed, followed by clean feed for either one or three weeks. Resulting levels in fat totaled $402 \mathrm{ng} \mathrm{TEQ} / \mathrm{kg}$ fat consisting of $102 \mathrm{ng} T E Q / \mathrm{kg}$ fat of dioxins, $84 \mathrm{ng}$ TEQ/kg fat of non-ortho PCBs, and $216 \mathrm{ng} \mathrm{TEQ} / \mathrm{kg}$ fat of mono-ortho PCBs (based on TEFs from 1998). Following a one or three week clean feed diet, total levels decreased to 217 and $109 \mathrm{ng} \mathrm{TEQ} / \mathrm{kg}$ fat, respectively, primarily due to the growth of the animals. Similarly, indicator PCBs (congeners 28, 52, 101, 118, 138, 153, and 180; except 118 now termed NDL-PCBs), decreased from an initial $6.2 \mathrm{mg} / \mathrm{kg}$ fat to 3.2 and $1.5 \mathrm{mg} / \mathrm{kg}$ fat. The ratio of indicator PCBs to dioxin TEQs remained stable. In general, carryover rates of dioxins and DL-PCBs congeners vary based on absorption, excretion, and metabolism in animals. Also, there is the possibility for selective accumulation of 
certain congeners in the liver, and this may be more severe, for example during incidents, due to the induction of cytochrome P450 1A in the liver and the binding of certain dioxins and PCBs to this protein (de Jong et al., 2015).

Adamse et al. (2015) reviewed the dioxins and DL-PCBs levels in animal derived products for the period 2001-2011, based on Dutch monitoring data. A total of 65 poultry (fat) samples were analyzed in this period with GC/HRMS (Table 3). Accordingly, the median (P50) concentration for polychlorinated dibenzo- $p$-dioxins and polychlorinated dibenzofurans (PCDD/Fs), DL-PCBS, and their sum in poultry (fat) products was $0.18,0.05$, and $0.24 \mathrm{pg} \mathrm{TEQwH02005} / \mathrm{g}$ fat respectively. These levels were lower than the P50-values based on European data reported to EFSA (Table 3). This was even more clear for the P95, which is important for establishing the limits.

Table 3 Distribution of PCDD/FS and DL-PCB levels (in pg TEQ ${ }_{w H O 2005} / g$ fat [ $\mu$ b]) comparing EFSA data with the Dutch dataset (calculated based on EU monitoring data from 2001-2011), as reported in Adamse et al. (2015).

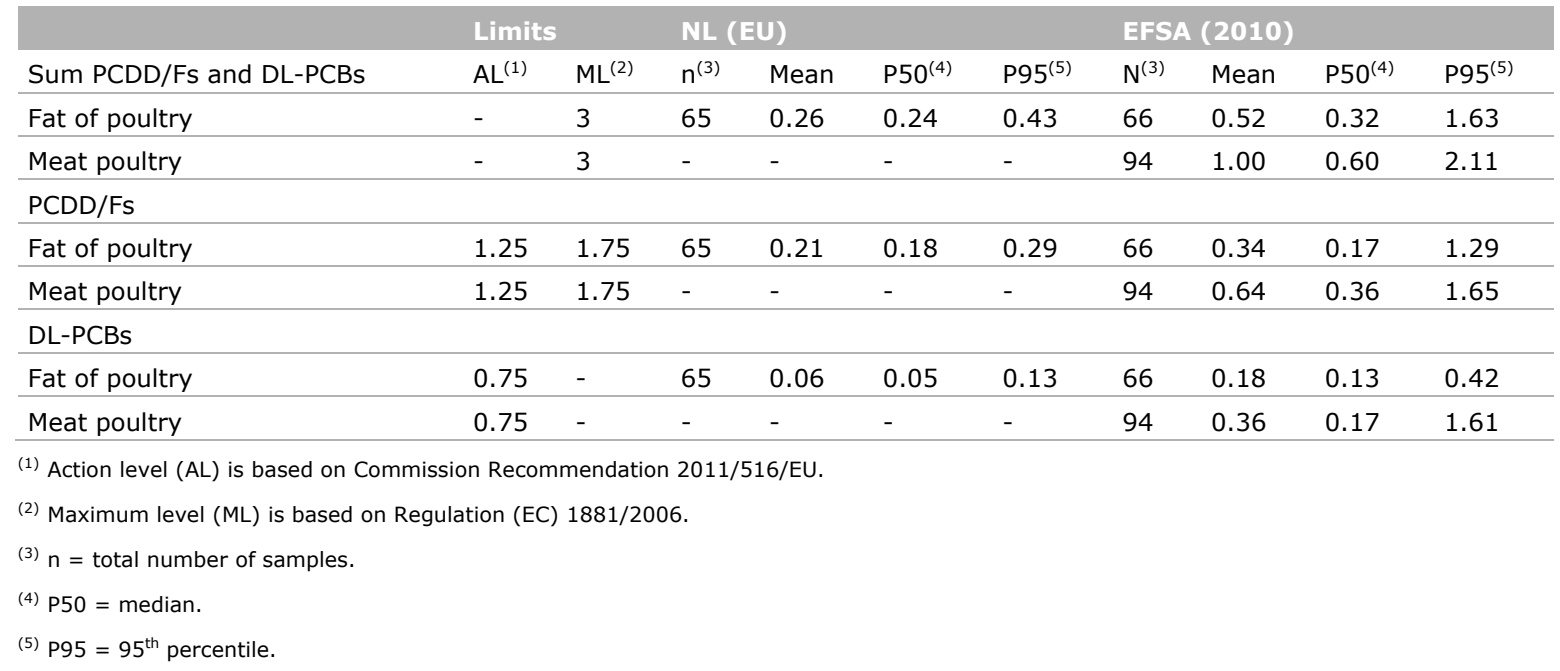

Recently, Ghimpeteanu et al. (2014) reviewed dioxin and DL-PCB contamination in poultry liver in relation to food safety and consumer health. Dioxins and DL-PCBs were shown to accumulate selectively in poultry livers; however, data on poultry liver contamination remains scarce, and the data that are available indicate that the background levels in poultry liver are of no concern (i.e. below the European ML) (Ghimpeţeanu et al., 2014). Nevertheless, these authors suggest that more information, in particular for DL-PCBS, is required for a reliable risk assessment.

Non-dioxin-like polychlorinated biphenyls (NDL-PCBs)

NDL-PCBs refer to PCB congeners that do not show similar structural and toxicological properties as dioxins and DL-PCBs. The NDL-PCBs are di-ortho or more chlorosubstituted with the exception of PCB28, which is mono-ortho (European Food Safety Authority (EFSA), 2010). NDL-PCBs induce different responses including neurological, neuroendocrine, endocrine, immunological, and carcinogenic effects (EFSA Panel on Contaminants in the Food Chain (CONTAM), 2005c; European Food Safety Authority (EFSA), 2010). However, in the case of mixtures, EFSA concluded that the effects observed at lower levels are probably caused by the presence of DL-PCBS and PCDFs, which are formed by oxidation of PCBs. As a result, EFSA was unable to establish a separate health-based guidance value for NDL-PCBs. In order to harmonize the various limits in different member states, the EU introduced MLs for the sum of 6 NDL-PCBs $n$ 2012. For poultry, the $M L$ is $40 \mathrm{ng} / \mathrm{g}$ fat $(E C / 1881 / 2006)$.

Similar to dioxins and DL-PCBs, NDL-PCBs can accumulate in meat, liver, and especially in fatty tissues. NDL-PCBs can also transfer to milk and eggs; in particular, PCBs 138 and 153 have been shown to have to the highest carryover rates, in the order of 50-60\% (EFSA Panel on Contaminants in the Food Chain (CONTAM), 2005c). Like dioxins and DL-PCBs, a steady state in fattening animals, like poultry, is not reached since the animals are continuously growing and slaughtered at a young age. 
Based on data provided to EFSA by member states, the sum of six NDL-PCBs (congeners 28, 52, 101, $138,153$, and 180$)$ in poultry meat $(n=395)$ had a median (P50) value of $9.74 \mathrm{ng} / \mathrm{g} U B$, a mean of $22.64 \mathrm{ng} / \mathrm{g} \mathrm{UB}$, and and a $95^{\text {th }}$ (P95) percentile of $83 \mathrm{ng} / \mathrm{g}$ UB. Lower levels were found in poultry fat $(n=150)$, with a median (P50) value of $0.83 \mathrm{ng} / \mathrm{g}$ fat $\mathrm{UB}$, a mean of $2.54 \mathrm{ng} / \mathrm{g}$ fat $U B$ and a $95^{\text {th }}$ (P95) percentile of $11.4 \mathrm{ng} / \mathrm{g}$ fat UB (European Food Safety Authority (EFSA), 2012).

For several years, concentrations of NDL-PCBs were analyzed in broilers in the course of the NMP . $^{3}$ From 2011 to 2016, concentrations of NDL-PCBs varied from $0.75 \mathrm{ng} / \mathrm{g}$ to $0.40 \mathrm{ng} / \mathrm{g}$ fat. A downward trend in concentration appeared to occur, but this was due to a lowering of the limits of quantification of the method, combined with upper bound reporting. The levels were well below the maximum limit of $40 \mathrm{ng} / \mathrm{g}$ fat (EC 1881/2006).

\subsection{Brominated flame retardants}

Brominated flame retardants can accumulate in food-producing animals and are less toxic than dioxins and DL-PCBs. Flame retardants of concern are polybrominated diphenyl ethers (PBDEs) and hexabromocyclododecanes (HBCDDs) (EFSA Panels on Biological Hazards (BIOHAZ) et al., 2012). Both groups of compounds have been applied to consumer products and industrial products.

\section{Polybrominated diphenyl ethers (PBDEs)}

PBDEs have been applied on a large scale in plastics, textiles, electronic castings, and circuitry. As a result, they are ubiquitously present in the environment and can subsequently accumulate in food and feed. Therefore, selected PBDEs are regulated under the Stockholm Convention as POPs, and the use of the tetra- and penta-PBDE mixtures has been prohibited in Europe since 2003 (EFSA Panel on Contaminants in the Food Chain (CONTAM), 2011b). Nevertheless, these compounds have been produced and used in large volumes in the past. Due to their persistence and bioaccumulation properties, they are still present in the environment (Bakker et al., 2008). PBDEs consist of various congeners. Occurrence data gathered by EFSA showed that highest concentrations in "meat and meat products (including edible offal)" were found for PBDE-209 (2.83 ng/g fat), whereas the concentrations of other congeners (BDE-28, BDE-47, BDE-99, BDE-100, BDE-153, BDE-154, and BDE183) ranged from $0.08 \mathrm{ng} / \mathrm{g}$ fat for $\mathrm{BDE}-183$ to $0.52 \mathrm{ng} / \mathrm{g}$ fat for $\mathrm{BDE}-47$ (all based on upper bound (UB)). Meat samples from goose and duck contained levels of BDE-28, -47, $-99,-100,-153$, and -154 ten times higher than the average of other meat products (EFSA Panel on Contaminants in the Food Chain (CONTAM), 2011b). No MLs have been set for these compounds. It depends on the dietary intake whether the concentrations found in the products can result in human health problems.

According to PBDE analyses of Dutch food products (2003/2004) and National Food Consumption Survey results (1997/1998), several food categories contributed to the intake of the sum of the five PBDEs (BDE-47, BDE-99, BDE-100, BDE-153+154), including dairy (39\% of the total intake), fish $(38 \%)$, and meat (7\%). The mean concentrations of BDE-47, BDE-99, BDE-100, BDE-153+154, and the sum of these PBDEs in poultry were $17,19,5,8$, and $49 \mathrm{pg} / \mathrm{g}$ fresh product, respectively (Bakker et al., 2008).

\section{Hexabromocyclododecanes (HBCDDs)}

HBCDDs have been used in expanded and extruded polystyrene applied as construction and packing materials and in textiles. Like PBDEs, they may leach into the environment (EFSA Panel on Contaminants in the Food Chain (CONTAM), 2011a). EFSA gathered data for HBCDDs in food products and found that the percentage of samples above the detection limit was $26 \%$ for eggs and egg products, $25 \%$ for fish and other seafood (25\%), and $19 \%$ for milk and dairy products (EFSA Panel on Contaminants in the Food Chain (CONTAM), 2011a). In May 2013, the Stockholm Convention on POPs decided to add HBCDDs to the list for elimination in order to be replaced by safer substitutes. Within the EU, the use of HBCDDs is prohibited under the EU REACH program (Regulation (EC) 1907/2006) after the $21^{\text {st }}$ of August 2015. It is estimated that $80 \%$ of the HBCDDs used in polystyrene foam are released into the environment. In the future, the contribution from polystyrene foam will increase as more and more of this material will become waste (EFSA Panel on Contaminants in the Food Chain

\footnotetext{
3 www.wageningenur.nl/en/Expertise-Services/Research-Institutes/rikilt/Research/Chemicalcontamination/Contaminants/Dioxin-analysis/Monitoring-dioxins-PCBs-and-flame-retardants.htm
} 
(CONTAM), 2011a). Due to its presence in the environment, HBCDDs may accumulate in food and feed. There are currently no MLs set for HBCDDs in food or feed within EU legislation, but HBCDDs have been detected in food products.

In the Netherlands, the highest contribution to total dietary intake of HBCDDs was from the food groups beef, poultry, and vegetable oils and fats (de Winter-Sorkina et al., 2003).

\subsection{Perfluoralkylated substances}

Perfluoralkylated substance (PFASs) include a group of industrial compounds, widely used in industrial and consumer products. Their extensive use in the past had led to a wide distribution of these compounds in the environment. The two most known PFASs include perfluoroctane sulfonate (PFOS) and perfluoroctanoic acid (PFOA). Both compounds are chemically stable, accumulate in the environment and are toxic to human health (Noorlander et al., 2011). They bind to proteins in blood and liver but do not accumulate in fat. An intake study for PFOS and PFOA via food consumption in the Netherlands showed that the intakes by the Dutch population were below the TDI of both compounds (PFOS 150ng/kg bw/day; PFOA $1500 \mathrm{ng} / \mathrm{kg}$ bw/day). Poultry meat was not an important contribution to human intake. Concentrations of PFOS and PFOA in poultry meat were lower than $10 \mathrm{pg} / \mathrm{g}$ product for PFOA and below LOD for PFOS.

\subsection{Heavy Metals and arsenic}

In general, heavy metals have shown to lead to a clear dose-related increase in the liver and kidney, in contrast to muscle (meat) (Kan \& Meijer, 2007). Cadmium is reported to accumulate mainly in the liver and kidneys, with carryover to meat as very low or even absent $(<0.05 \%)$. Lead can accumulate in the liver, kidneys, and bone, whereas the accumulation of arsenic and mercury depends on their chemical structure. "Alkylmercury compounds tend to accumulate in skeletal muscles and the brain, whereas aryl compounds and inorganic mercury salts accumulate in the liver and kidneys" (Kan \& Meijer, 2007). "In mammalian species (and poultry), inorganic arsenic is converted into methylated metabolites, which are rapidly excreted compared to other organic arsenic compounds. Hence, the carryover of arsenic compounds from feeds to edible tissues of mammalian species and poultry is very low" (EFSA Panel on Contaminants in the Food Chain (CONTAM), 2005a; Kan \& Meijer, 2007). In general, carryover of heavy metals to meat is low in comparison to other tissues such as the liver and kidneys. In Europe, the presence of the heavy metals cadmium, arsenic, and lead in feedstuffs has been regulated, and MLs for their presence in complete feed for poultry have been set (Directive 2002/32/EC). Regulation (EC) 1881/2006 defines the MLs for certain contaminants in foodstuffs. MLs for cadmium in poultry meat (excluding offal), liver, and kidney are $0.050,0.50$, and $1.0 \mathrm{mg} / \mathrm{kg}$ wet weight, respectively. For lead, MLs for poultry meat and poultry offal are set separately as 0.10 and $0.50 \mathrm{mg} / \mathrm{kg}$ wet weight, respectively (European Commission, 2006a). The MRLs for of mercury ( $\mathrm{Hg}$ ) and arsenic (As) in poultry products are set in Regulation (EC) 396/2005 (the Regulation on residues of plant protection products, PPPs), as As and Hg-containing PPPs were used in the past (their use was prohibited a long time ago). For sodium arsenite, the default MRL has been set $(0.01 * \mathrm{ppm})$; the MRL for $\mathrm{Hg}$ in poultry products is also $0.01 * \mathrm{ppm}$.

KAP data from 2009-2011 showed that twenty out of the 54 samples tested for heavy metals exceeded the legal MLs. Two samples contained concentrations above the ML for cadmium, of which one was from ostrich meat and the other from pigeon meat. Eighteen samples contained levels above the ML for lead, of which 13 were in duck meat and 5 in pigeon meat. Data from the National Plan showed that for the years 2011-2016 none of the samples of chicken liver exceeded the ML for cadmium and lead. Each year between 95 and 140 samples was analyzed. The highest cadmium level found was $0.41 \mathrm{mg} / \mathrm{kg}$ in 2014 and the highest lead level $0.21 \mathrm{mg} / \mathrm{kg}$ in 2013. Game samples (duck and pigeon) do show exceedances of the legal limits in most of the years. However, it must be noted that metal bullets are regularly found in these samples. Sometimes, they are removed prior to analysis, but in most cases, they are ground and will influence the outcome of the analysis. 


\section{Natural toxins}

\subsubsection{Mycotoxins}

Mycotoxins are toxic, secondary metabolites produced by fungi. Under favorable environmental and agronomic conditions, some fungi may infect the feed crop and produce mycotoxins. A wide variety of mycotoxins may occur in feed ingredients used in the poultry diet. The susceptibility of poultry to these mycotoxins also varies; in general, broilers appear to be less sensitive to mycotoxins than turkeys and ducks (Pettersson, 2012). For feed (used in chicken production), only the presence of aflatoxin $B_{1}$ is regulated in Directive 2002/32/EC. Guidance values are defined for some other mycotoxins, including deoxynivalenol, zearalenone, ochratoxin A, HT-2 and T-2 toxins, and fumonisins in products intended for animal feeding. In the EU, MLs for mycotoxins in food are laid down in Regulation (EC) 1881/2006. However, there are no MLs for poultry meat products.

Some mycotoxins that can impact the health and productivity of poultry include aflatoxins, zearalenone, ochratoxin A, fumonisins, and trichothecenes such as deoxynivalenol and T-2 toxin (Murugesan et al., 2015). Grenier and Applegate (2013) reviewed major mycotoxins in terms of their occurrence and toxicity in animals like poultry with a focus on aflatoxins, ochratoxin A, deoxynivalenol, T-2 toxin, zearalenone, and fumonisins. The extent of absorption of mycotoxins varies, this absorption ultimately influences systemic exposure and tissue distribution. According to their analyses in poultry, more than $80 \%$ of aflatoxins are absorbed in the proximal gastrointestinal track (Aliments, 2009), ochratoxin A is moderately absorbed (40\%) (Ringot, et al., 2006), while deoxynivalenol (5 to 20\%) (Cavret \& Lecoeur, 2006; Osselaere et al., 2013) and fumonisins (1\%) (Bouhet \& Oswald, 2007) are absorbed to a lesser extent (Grenier \& Applegate, 2013).

Mycotoxins that are considered most relevant, because of their presence and toxic effects, include aflatoxins produced by Aspergillus spp., ochratoxin A produced by Aspergillus spp. and Penicillium spp., followed to a lesser extent by toxins produced by Fusarium spp. (EFSA Panel on Contaminants in the Food Chain (CONTAM), 2004a, 2005b, 2006; Pettersson, 2012). For aflatoxins, aflatoxin $B_{1}$ is the most important in terms of toxicity and potency (EFSA Panel on Contaminants in the Food Chain (CONTAM), 2004a; Rawal, Kim, \& Coulombe Jr, 2010). Poultry (broilers), and especially turkeys, are susceptible to its toxic effects (Pettersson, 2012; Rawal et al., 2010). Aflatoxin $B_{1}$ is often found in ingredients of animal feed, such as products derived from maize kernels and peanuts, from the (sub) tropical regions. Since 2003, aflatoxin $B_{1}$ is also regularly found in maize grown in Europe (EFSA Panel on Contaminants in the Food Chain (CONTAM), 2004a). Via the feed, aflatoxin $B_{1}$ is transferred to poultry muscle (meat) and liver. For example, in a study by Hussain et al. (2010), in broiler chicks fed $6400 \mu \mathrm{g} / \mathrm{kg}$ aflatoxin $B_{1}$ levels of $6.97 \pm 0.08 \mathrm{ng} / \mathrm{g}$ were found in the liver and $3.27 \pm 0.05 \mathrm{ng} / \mathrm{g}$ in muscle. Furthermore, once diets shifted to non-aflatoxin $B_{1}$ contaminated feed, levels slowly dropped with aflatoxin $B_{1}$ detected for a longer duration in the liver and muscle of younger birds and those fed with highly contaminated aflatoxin $B_{1}$ diets (Hussain et al., 2010). The accumulation of ochratoxin A, as a result of transfer from animal feed, predominantly occurs in blood, liver, and kidney of farm animals (EFSA Panel on Contaminants in the Food Chain (CONTAM), 2006). Muscle, milk, and eggs contain much lower ochratoxin A levels when animals are exposed to this mycotoxin (EFSA Panel on Contaminants in the Food Chain (CONTAM), 2006). Mycotoxins produced most often by Fusarium spp. in feed crops include the trichothecenes deoxynivalenol, nivalenol, and T-2 and HT-2 toxins, as well as fumonisins and zearalenone (Pettersson, 2012). Of these, deoxynivalenol is the most well known and most regulated. EFSA has concluded that the carry-over of deoxynivalenol, zearalenone, and fumonisins to products of animal origin is "very low" (EFSA Panel on Contaminants in the Food Chain (CONTAM), 2004b, 2004c, 2005b).

\subsubsection{Plant toxins}

Plant toxins are secondary metabolites produced by plants that are harmful to animal and/or human health. There is a very wide variety of plant toxins, with different molecular structures. Plant toxins may contaminate animal feed. However, they are mainly found in grasslands and in weeds that grow in crop fields. For poultry meat products, plant toxins are considered of lesser relevance due to their (low) presence in poultry feed and low carry-over in poultry. However, little data is available. 


\section{Chemicals used in agriculture}

\subsection{Pesticides}

Pesticides are biological or chemical agents that can be used to prevent, destroy, or control harmful organisms (pests) or diseases as well as a protect plants or plant products during production, storage, and transport. Herbicides, insecticides, fungicides, acaricides, biocides, etc. are included under the term "pesticides." According to the Codex Alimentarius Procedural Manual, the term pesticide residue is defined as: "any specified substance in food, agricultural commodities, or animal feed resulting from the use of a pesticide. The term includes any derivatives of a pesticide, such as conversion products, metabolites, reaction products, and impurities considered to be of toxicological significance" (World Health Organization (WHO) \& Food Agriculture Organization of the United Nations (FAO), 2015). In the EU, MRLs for plant protection products in food are laid down in Regulation (EC) 396/2005.

Pesticide contamination in poultry meat can result from accidental exposure to contaminated feed (e.g., feed crops that have been treated with plant protection products during growth or storage) or use of biocides in the poultry housing environment, or the use of veterinary medicinal products (e.g., from insecticides and acaricides used to control poultry ectoparasites) (LeDoux, 2011; Waldron \& Naber, 1974). Organochlorine pesticides were banned for use a long time ago; however, residues of these persistent substances are still present in the environment. The presence of organochlorine pesticides in poultry and eggs, resulting from their presence in feedstuffs, has been reviewed by Kan (1978) and re-evaluated more recently by Kan and Meijer (2007). In brief, the rate that pesticides are depleted in broilers is dependent on the growth rate of the broiler, and thus, by dilution in the fat (Kan, 1978). Therefore, pesticides and residues thereof that can accumulate and persist in the broilers, e.g., dichlorodiphenyltrichloroethane (DDT) and it metabolites, dieldrin/aldrin, hexachlorobenzene, beta-Hexachlorocyclohexane $(\beta \mathrm{HCH})$, etc., are of a concern (EFSA Panels on Biological Hazards (BIOHAZ) et al., 2012; Kan \& Meijer, 2007).

As reported by EU member states in the results of targeted samples taken as part of their National Residue Control Plans (NRCPs) between 2005 and 2010, there were four non-compliant samples for organochlorine pesticides in poultry, all of which were sampled at the slaughterhouse (EFSA Panels on Biological Hazards (BIOHAZ) et al., 2012). Organochlorine pesticide residues were common in the 1970s, but since they were banned, a reduction in their presence has been achieved by controlling their entrance via the feed chain; however, the problems related to other organochlorine containing compounds (e.g., dioxins and PCBs) are more difficult to handle (Kan, 2002).

KAP data from 2009-2011 included 65 poultry samples tested for pesticides (59 for insecticides, acaricides, nematicides; 6 for bactericides and fungicides). None of the samples contained pesticide levels above the LOD.

\subsubsection{Veterinary Medicinal Products (VMPs) and Feed Additives}

Veterinary medicinal products (VMPs) or "veterinary drugs" comprise a wide variety of chemical compound classes like antibiotics and antiparasitic agents like anthelmintics or coccidiostats, among several others (Andrée et al., 2010; de Jong et al., 2015; EFSA Panels on Biological Hazards (BIOHAZ) et al., 2012). VMPs are administered to animals, including food-producing animals, to prevent or treat diseases, and consequently, their use may result in residues in animal tissues and products like milk, eggs, and meat. According to a recent scientific opinion by EFSA, prohibited antibiotics such as chloramphenicol, nitrofurans, and nitroimidazoles were ranked as a "high potential concern." This ranking was based on their distinct toxicological profile indicating a possible concern for human health and the residues found in poultry samples taken in the course of NRCPs in several member states despite the fact that their use for food-producing animals is prohibited in the EU (EFSA Panels on Biological Hazards (BIOHAZ) et al., 2012; European Commission, 2010a).

Within the EU, Regulation (EU) 37/2010 outlines pharmacologically active substances and their classification regarding maximum residue limits (MRLs). In the Annex of this Regulation, the pharmacologically active substances are listed that are allowed to be used in the EU (taking into account the restrictions mentioned) as well as a list of prohibited substances, such as, i.a, chloramphenicol, nitrofurans, and 5-nitroimidazoles like dimetridazole (DMZ), metronidazole (MNZ), 
and ronidazole (RNZ). For these prohibited substances, a MRL could not be established given the available data and since the residues of such substances, at whatever limit, constitute a hazard to human health (European Commission, 2010a). Similarly, the Codex Alimentarius Commission (CAC) reviewed MRLs and risk management recommendations (RMRs) for residues of veterinary drugs in foods and also found that no safe levels could be established for antibiotics like chloramphenicol, nitrofural (a nitrofuran, synonym: nitrofurazone), and several nitroimidazoles (mainly DMZ, ipronidazole, MNZ, and RNZ) as well as their metabolites (Codex Alimentarius Commission, 2013, 2014). Hence, authorities are instructed to prevent the occurrence of these antibiotic residues in food. In order to accomplish this objective, such antibiotics are banned for use in food-producing animals. Currently, the possible presence of prohibited substances in animal products is intensively monitored. Information on illegal use is not available. Reports from customs laboratories, monitoring results from other EU MS, and information on the internet can be used to select compounds included in the analyses.

\section{Chloramphenicol}

Chloramphenicol (CAP) is a broad-spectrum antibiotic that is effective against Gram-positive and Gram-negative bacteria, which has been used in the past in human and veterinary medicine (Kanarat, et al., 2008). Currently, "chloramphenicol is not authorized for use in food-producing animals in the EU but may be used in human medicine and in treatments for non-food-producing animals. Apart from its potential occurrence as a residue in food from the illicit treatment of food-producing animals, chloramphenicol has also been used in feed and food enzyme products and may occur naturally in plants from its production by the soil bacterium Streptomyces venezuelae" (EFSA Panel on Contaminants in the Food Chain (CONTAM), 2014).

Sources of CAP residues have generally been attributed to its intentional use and to a lesser extent because of environmental contamination. However, the detection of CAP in foods of animal origin, including poultry products, may also originate from CAP produced by microorganisms naturally present in the environment (Wongtavatchai, McLean, Ramos, \& Arnold, 2004). Kanarat et al. (2008) summarized several possible sources of CAP including i) the presence of CAP residues from unlicensed or counterfeit pharmaceutical products, as reported by Cannavan and Elliott (2004); ii) environmental contamination from past veterinary drug use, as reported by Wongtavatchai et al. (2004);

iii) contamination from CAP-containing topical medicinal preparations used by processing workers; and iv) ingestion of naturally occurring CAP from the environment. The WHO has recommended to investigate this last possibility, and then, in particular, the concentration of CAP in the soil in order to clarify any potential contamination of foods from environmental sources (Wongtavatchai et al., 2004). More recently, B. Berendsen et al. (2013) investigated the production, stability and fate of CAP, and transfer of CAP to wheat and maize in soils. The authors concluded that CAP residues could occur naturally in crops as a result of CAP production by soil bacteria, e.g., by Streptomyces venezuelae, in their natural environment and subsequent uptake by crops (Berendsen et al., 2013; Berendsen, Zuidema, \& de Jong, 2015). These results help to substantiate the background levels of CAP in animal feed, as well as other crops, like straw, which can be used for bedding, and hence, upon ingestion of potential residues by food-producing animals (Berendsen et al., 2013; Berendsen et al., 2015). EFSA has also recognized that CAP can be produced by soil bacteria and that it may occur in plants (EFSA Panel on Contaminants in the Food Chain (CONTAM), 2014).

In human medicine, treatment with CAP was limited to certain infections such as typhoid fever, bacterial meningitis, and conjunctivitis since it has been reported to cause aplastic anemia, a serious, sometimes fatal, disease where bone marrow is unable to generate blood cells (Ferguson et al., 2005; Wongtavatchai et al., 2004). In particular, aplastic anemia in humans is reported to be non-dose related and often irreversible; thus, an acceptable daily intake (ADI) value cannot be established (Trevisani, Diegoli, \& Fedrizzi, 2014; Wongtavatchai et al., 2004).

CAP is banned as result of genotoxic concerns, from CAP itself or its metabolites, as well as embryoand feto-toxicity, alongside potential carcinogenicity or aplastic anemia in humans (Berendsen et al., 2013; Kanarat et al., 2008; Trevisani et al., 2014). Unfortunately, the mechanisms of CAP-induced aplastic anemia are unknown; hence, the WHO committee was unable to identify animal or epidemiological studies to further evaluate the toxicity of CAP (Wongtavatchai et al., 2004). 
CAP can be used, in some instances, in human and in veterinary medicine, for example as a topical treatment in companion animals (Trevisani et al. 2014). However, the use of CAP in food-producing animals is prohibited in the EU (European Commission, 2010a). Several other countries including the United States, Canada, Australia, Japan, and China have also banned the use of CAP in food-producing animals (Berendsen et al., 2013). According to the National Residue Monitoring Plans for EU member states (2002-2012), "the animal species in which chloramphenicol was mostly reported were pigs, poultry and bovines with 91,74 and 68 non-compliant cases, respectively" (EFSA Panel on Contaminants in the Food Chain (CONTAM), 2014). In countries where CAP is allowed in foodproducing animals, treatments are for infections caused by anaerobic bacteria or those resistant to other antimicrobials. Such treatments are of concern since CAP is described as being well-absorbed orally and parenterally in animals such as poultry (Trevisani et al., 2014).

\section{Nitrofurans}

Nitrofurans are synthetic drugs with a five-membered heterocyclic furan ring containing a nitro group at the $5^{\text {th }}$ position and differing side-chains (Reeves, 2011). The five most important nitrofurans are furazolidone, furaltadone, nitrofurantoin, nitrofurazone, and nifursol (EFSA Panel on Contaminants in the Food Chain (CONTAM), 2015). Nitrofurans are antimicrobials that may be bacteriostatic, or at higher concentrations can be bactericidal; however, the antibacterial mode of action of furan derivatives is not known (Reeves, 2011).

Nitrofurans were commonly applied for the treatment of bacterial and protozoan infections in addition to being used as feed additives for growth promotion in livestock (i.e. poultry, swine, and cattle), (Vass et al. 2008). As of 1993, and for furazolidone 1995, nitrofuran use in livestock production has been prohibited in the EU. Nitrofurans are prohibited in food-producing species because of carcinogenicity concerns, the presence of protein-bound residues in edible tissues, and the resulting potential harmful effects on human health (Reeves, 2011; Trevisani et al., 2014; Vass, Hruska, \& Franek, 2008). A specific concern is the potential role of the side-chain, which can be released in the stomach, in the carcinogenic effects of nitrofurans (Hoogenboom et al., 2002). Nevertheless, nitrofurans are still available for veterinary use (in companion animals) and also for human therapy, in particular, nitrofurantoin (Vass et al., 2008). In some countries, e.g., India, nitrofurans are still used as growth promoters and prophylactic agents due to their affordability and effectiveness (Trevisani et al., 2014).

Nitrofurans are rapidly metabolized in vivo, but stable and persistent protein-bound metabolites are formed, which form the actual target for monitoring. The following residues are considered indicators for the administration of nitrofurans: 3-amino-2-oxazolidinone (AOZ) for furazolidone, 3-amino-5methylmorpholino-2-oxazolidinone (AMOZ) for furaltadone, 1-aminohydantoin (AHD) for nitrofurantoin, semicarbazide (SEM) for nitrofurazone, and 3,5-dinitrosalicylic acid hydrazide (DNSH) for nifursol. These metabolites can be measured after acid hydrolysis and derivatization with 2nitrobenzaldehyde (EFSA Panel on Contaminants in the Food Chain (CONTAM), 2015).

According to a recent risk ranking of chemical hazards in foods for several food products, including poultry, nitrofurans are amongst the most important antibiotics to monitor (van Asselt et al., 2013). According to the National Residue Monitoring Plans for EU member states (2002-2013), the occurrence of nitrofuran metabolites (AOZ, AMOZ, AHD, and SEM) in foods resulted in 105 non-compliant results in targeted samples in poultry. In total, 214 non-compliant samples were found out of 842,294 targeted samples in food products, a non-compliance rate of $0.01 \%$; it was not indicated how many of these non-compliant samples were related to the Netherlands (EFSA Panel on Contaminants in the Food Chain (CONTAM), 2015).

\section{Nitroimidazoles}

Nitroimidazoles are imidazoles that contain a nitro group at either the $2^{\text {nd }}, 4^{\text {th }}$, or $5^{\text {th }}$ position on the imidazole ring (Sebald et al., 1993). 5-nitroimidazoles are classified based on their nitro functional group location. Some examples include DMZ, MNZ, and RNZ (Granja et al., 2013; Trevisani et al., 2014; Wang, 2001; Xia et al., 2006). 5-nitroimidazoles have been used to treat and prevent some bacterial and protozoal diseases in poultry like histomoniasis and coccidiosis (Granja et al., 2013; Hurtaud-Pessel, Delepine, \& Laurentie, 2000; Wang, 2001; Xia et al., 2006). In particular, 5 -nitroimidazoles are reported to be rapidly metabolized with the main metabolites resulting from the 
oxidation of the side chains at the $\mathrm{C} 2$ position on the imidazole ring; the resulting metabolites may have a similar mutagenic potential as the parent compound (Hurtaud-Pessel et al., 2000).

Within the EU, several nitroimidazoles are included in Table 2 of Regulation (EU) 37/2010, including substances prohibited for use in food-producing animals; examples include RNZ (Regulation (EC) 3426/93), DMZ (Regulation (EC) 1798/95), and MNZ (Regulation (EC) 613/98), which were banned in 1993, 1995, and 1998, respectively (Granja et al., 2013; Hurtaud-Pessel et al., 2000; Trevisani et al., 2014; Wang, 2001; Xia et al., 2006). Australia, Brazil, Canada, China, and the United States also prohibit the use of nitroimidazoles. Nevertheless, nitroimidazoles are sometimes illegally used in animal husbandry including poultry production. "Illicit use of nitroimidazoles in poultry production, including MNZ which is readily available as a human medicine throughout the EU, cannot be excluded" (EFSA Panels on Biological Hazards (BIOHAZ) et al., 2012). Hence, monitoring remains imperative (Granja et al., 2013; Reeves, 2011) as nitroimidazoles have been reported as effective growth promoters in meat production and feed conversion (Granja et al., 2013). According to the NRCPs (2005-2010) for nitroimidazoles in poultry, 6 out of 94,602 targeted poultry samples were noncompliant for nitroimidazoles, a non-compliance rate of $0.006 \%$ (EFSA Panels on Biological Hazards (BIOHAZ) et al., 2012). It was not indicated if any of these 6 samples related to the Netherlands.

\section{KAP data 2009-2011}

Antimicrobial medicines: Twelve out of 1,201 samples tested for residues of antimicrobial substances were detected with concentrations exceeding the legal MRLs. Nitrofurans were detected in four samples taken between 2009 and 2011. Nitrofurazon was detected in one broiler meat sample, and furazolidone was detected in three hen meat samples. No MRL was established for nitrofurans as it is a prohibited substance. The minimum required performance limit (MRPL) for official laboratories for nitrofuran metabolites is $1 \mathrm{\mu g} / \mathrm{kg}$ (Decision 2002/657/EC). For tetracyclines, there were seven broiler meat samples which exceeded the MRL for doxycyclin (100 $\mu \mathrm{g} / \mathrm{kg}$ ) as set by Regulation (EU) 37/2010. One broiler meat sample was tested positive for quinolones, in which enrofloxacin and ciprofloxacin were detected as exceeding the MRL for enrofloxacin. This MRL is based on the sum of enrofloxacin and ciprofloxacin and is set at $100 \mu \mathrm{g} / \mathrm{kg}$ for poultry meat, by Regulation (EU) 37/2010 (European Commission, 2010a).

Antiprotozoans: In seven out of the 641 samples tested for antiprotozoals (456 anticoccidials and 185 nitroimidazoles), nicarbazin was found. These seven samples (36.4-216.8 $\mu \mathrm{g} / \mathrm{kg}$ ) were tested in 2009 and were from the meat of broiler/chickens. Within the EU, certain feed additives like nicarbazin or narasin are authorized. The European Food Safety Authority concluded that these additives do not have an adverse effect on animal health, consumer health, or the environment. Furthermore, the use of these additives effectively controls coccidiosis in chickens for fattening (European Commission, 2010b). According to Regulation (EU) 885/2010, there is an MRL for 4,4'-dinitrocarbanilide (DNC), a component of nicarbazin, in poultry meat, which is $4000 \mu \mathrm{g}$ of DNC/ kg fresh muscle and fresh skin/fat. None of these seven samples exceeded this MRL.

Growth regulators: Only 12 samples were analyzed for growth regulators (particularly the growth promoter metaproterenol). None of them were positive for these compounds. All samples were tested in 2011 and were from hen meat.

Non-steroidal anti-inflammatory drugs (NSAID): In two out of 192 samples, NSAIDs were detected; namely, salicylic acid at $15 \mu \mathrm{g} / \mathrm{kg}$ respectively $36 \mu \mathrm{g} / \mathrm{kg}$ in samples of meat of broilers/chickens. According to Regulation (EU) $37 / 2010$, there is no MRL for salicylic acid in poultry.

Sympathicomimetics: Only 12 samples were analyzed for the presence of sympathomimetic drugs (particularly the beta-agonist cimaterol). None of them were positive for these compounds. All samples were tested in 2011 and were from hen meat.

\subsubsection{Processing}

Poultry processing starts with truckloads of live birds arriving at the slaughterhouse. Animals are hung upside down on a line of shackles, and then stunned and killed. The next stages are: (1) scalding (transport through a warm water tank), (2) de-feathering (removal of the feathers), (3) evisceration 
(extraction of intestines), (4) washing (spraying with water), and (5) chilling (in air, at about $0{ }^{\circ} \mathrm{C}$ for 1 to 2 hours) (Nauta, van der Fels-Klerx, \& Havelaar, 2005). Chemical hazards that can occur during this first processing step (slaughtering) and further processing are generally less acknowledged in monitoring systems. Although good practices like good manufacturing practices (GMP) and good hygienic practices (GHP) as well as HACCP help to ensure food safety in the slaughterhouse and further processing parts of the chain, hazards from cleaning production lines migratory chemicals from packaging materials, or contaminants formed during processing (heat-generated food toxicants) may occur. Furthermore, in processed poultry products food additives may be used for certain purposes.

\subsection{Food additives and food enzymes}

Food additives are substances used during processing of foods to fulfill a technological purpose, as described in Regulation (EC) 1333/2008, and should be included in the ingredient list of products (European Commission, 2006b). Food additives may be used during poultry processing (e.g., as coatings or breading) to enhance the product's flavor, hold in the moisture during cooking, improve product appearance (e.g., coloring), or for preservation purposes. Incidents with food additives in poultry meat products are less common, and there is a lack of data with respect to monitoring these food additives in poultry (meat) products in the Netherlands. Although issues with the use of nonpermitted additives or excess amounts of permitted additives could occur, there are no recent indications to suspect such violations. For enzymes, Regulation (EC) 1332/2008 applies; for example, enzymes can be used for forming manufactured meat products. All food additives and food enzymes have to be approved at the EU level prior to use. As part of the approval process, a safety assessment is made by EFSA; only additives and enzymes that are safe to use are allowed on the market.

\subsection{Biocides/detergents}

Other agents used during poultry slaughtering and further processing are, for example, cleaning agents and disinfectants used on equipment (like chlorine in counter current chillers). Transport of poultry to the slaughterhouse occurs via crates in trucks, both of which are cleaned after use with cleaning agents and disinfectants. During transport, the birds are still alive and could be contaminated with residues from those agents. Contamination of derived products with residues from cleaning agents and disinfectants used during transport is considered negligible. Slaughtering lines and other processing equipment are also cleaned and disinfected regularly. In the Netherlands, only cleaning agents and disinfectants that are approved by the Board for the authorization of plant protection products and biocides (CTBG) ${ }^{4}$ may be used, following their prescribed use and by dedicated persons. Rinsing with clean water after using cleaning agents and disinfectants is required according to the Hygiene Code (Dutch Product Board for Poultry and Eggs (PPE) \& NEPLUVI, 2012). It would be too exhaustive to provide a complete list of chemical hazards associated with agents used during processing. In general, arranging an inspection of incoming goods and following procedures from suppliers, which is part of a HACCP-system, prevents the introduction of chemical hazards into poultry products during processing.

\subsection{Migration substances from packaging materials}

Packaging poultry (meat) products aids in the commercialization process, while also helping to control microbial and chemical hazards that could occur during transport, at retail, or during storage for the final consumer. Nevertheless, chemical residues from some contact materials can transfer into the poultry (meat) products causing the final product to be tainted. The EU regulates food contact materials (FCM) under Regulation (EC) 1935/2004, including active and intelligent materials, to ensure that: "they do not transfer their constitutes to food in quantities which could: (a) endanger human health; (b) bring about an unacceptable change in the composition of the food; or (c) bring about a deterioration in the organoleptic characteristics thereof" (European Commission, 2004). Also, plastic materials and articles intended to come into contact with foodstuffs are legislated under Directive 2002/72/EC in which a list of authorized monomers, starting substances, and additives are outlined (European Commission, 2002).

Dipheylbutadiene (DPBD) migration from low-density polyethylene (LDPE) was investigated in several meat products, including poultry meat. Results demonstrated that increased migration occurred with

\footnotetext{
4 http://www.ctgb.nl/
} 
increasing fat content and storage temperature (Sanches Silva et al., 2007). Other chemical substances like the residue $\varepsilon$-caprolactam, a precursor monomer of nylon 6 , can migrate into foodstuffs. Research has demonstrated that migration of $\varepsilon$-caprolactam (to $95 \%$ ethanol) has exceeded a total specific migration limit of $15 \mathrm{mg} / \mathrm{kg}$ (Regulation (EU) 10/2011) by 100\% and 33\% respectively for poultry breast and turkey blanquette packaging (Bhunia et al., 2013; Bomfim, Zamith, \& Abrantes, 2011; European Commission, 2011). Since processed poultry meat products are packed in multi-layer materials, researchers have suggested that the offset and transfer of migratory chemical hazards (e.g., isopropyl thioxanthone (ITX) from printing ink) through these layers should be considered (Bradley \& Castle, 2009). The EU has adopted legislation requiring that transfer of printing inks to the food contact surface (through "set-off" or migration) (Regulation (EC) 2023/2006). To date, limited monitoring data is available about the presence of migration contaminants from packaging materials and inks from packages of poultry meat (products).

\subsection{Processing contaminants}

Heterocyclic amines (HCAs)

Heterocyclic amines (HCAs) are a group of chemical compounds that can form in the surface layer of meat during cooking. The formation occurs when amino acids, sugars, and creatine react at high temperatures. HCAs have been found to be mutagenic, and according to the International Agency for Research on Cancer (IARC), eight of the known HCAs are classified as probably carcinogenic to humans (class 2a) and one as potentially (class 2b) carcinogenic to humans (IARC Working Group on the Evaluation of Carcinogenic Risks to Humans \& International Agency for Research on Cancer, 1993; IARC Working Group on the Evaluation of Carcinogenic Risks to Humans, International Agency for Research on Cancer, \& World Health Organization, 1987). Accordingly, the IARC recommends reducing exposure to these compounds.

HCA formation could occur at several stages during further processing such as at the processing plant (during food manufacturing), at retailers like restaurants, other food service providers, and at the supermarket, butcher, or market, as well as at the household by the consumer. Epidemiological studies suggest that the consumption of fried, broiled, or roasted meat, consequently the potential exposure to HCAs, is related to the development of several types of cancer although there is much debate on this topic (Knize \& Felton, 2005; Liao et al., 2010).

In general, the type and amount of HCAs that can occur in cooked poultry depend on the processing methods and conditions (Engel, Ratel, Bouhlel, Planche, \& Meurillon, 2015; Liao et al., 2010; Skog \& Solyakov, 2002). Liao et al. (2010) evaluated various cooking methods for chicken and duck breast and the formation of heterocyclic aromatic amines (HAAs). The highest total HAA formation occurred during charcoal grilling of chicken breast with levels up to $112 \mathrm{ng} / \mathrm{g}$, followed by "pan-frying of duck breast $(53.3 \mathrm{ng} / \mathrm{g})$, charcoal grilled duck breast (32 ng/g), pan-fried chicken breast (27.4 ng/g), deepfried chicken breast $(21.3 \mathrm{ng} / \mathrm{g})$, deep-fried duck breast $(14 \mathrm{ng} / \mathrm{g})$, roasted duck breast $(7 \mathrm{ng} / \mathrm{g})$, and roasted chicken breast (4 ng/g)" (Liao et al., 2010). In general, the HCA 2-amino-1-methyl-6phenylimidazo[4,5-b]pyridine (PhIP) has been found to occur in chicken more than other meats such as beef and pork (Aaslyng et al., 2013; Liao et al., 2010; Skog \& Solyakov, 2002).

\section{Polycyclic aromatic hydrocarbons (PAHs)}

Polycyclic aromatic hydrocarbons (PAHs) are a group of chemical compounds that can result due to the incomplete combustion or pyrolysis of organic matter. PAH formation can occur during industrial processing and domestic food preparation such as smoking, drying, barbecuing, grilling, baking, frying, and broiling. For example, PAH can form as a result of charcoal grilling or from lipids dripping on the hot charcoal (Aaslyng et al., 2013; Jägerstad \& Skog, 2005).

The carcinogenic and mutagenic properties of PAH benzo[a]pyrene (BPa) were widely studied, and the substantial contribution of BPa to the overall burden of cancer in humans is often generally accepted. According to the IARC, benzo[a]pyrene is carcinogenic to humans (group 1), based on "strong and extensive experimental evidence" in animal species alongside "consistent and coherent mechanistic evidence from experimental and human studies" (IARC Working Group on the Evaluation of Carcinogenic Risks to Humans, 2012). The EFSA CONTAM panel concluded that: "benzo[a]pyrene is 
not a suitable indicator for the occurrence of PAHs in food. Based on the currently available data relating to occurrence and toxicity, the CONTAM Panel concluded that PAH $4^{5}$ and PAH $8^{6}$ are the most suitable indicators of PAHs in food, with PAH8 not providing much added value compared to PAH4." Furthermore, the CONTAM noted some toxicological data gaps concerning individual PAHs in food and oral carcinogenicity data with mixtures, both of which are relevant for dietary exposure (EFSA Panel on Contaminants in the Food Chain (CONTAM), 2008). MLs for smoked meat and smoked meat products are $2.0 \mu \mathrm{g} / \mathrm{kg}$ for benzo(a)pyrene, and $12.0 \mu \mathrm{g} / \mathrm{kg}$ for the sum of benzo[a]pyrene, benz[a]anthracene, benzo(b)fluoranthene, and chrysene (i.e. the sum of PAH4) (Regulation (EC) $1881 / 2006)$

Similar to HCAs, PAHs are associated with certain health risks, but data on the intake of these components are limited. Domingo and Nadal (2015) recently reviewed scientific literature regarding human dietary exposure to PAHs, in which information from the Netherlands indicated that the diet was the main route of exposure in Dutch adults (Van Rooij, Veeger, Bodelier-Bade, Scheepers, \& Jongeneelen, 1994) and children aged 1-6 (van Wijnen, Slob, Jongmans-Liedekerken, van de Weerdt, $\&$ Woudenberg, 1996). Previous research indicated that total PAH contamination of smoke meat products in the Netherlands was below $20 \mu \mathrm{g} / \mathrm{kg}$ product (Vaessen, Jekel, \& Wilbers, 1988), while a market basket study carried out by de Vos, van Dokkum, Schouten, and de Jong-Berkhout (1990) noted that elevated PAHs, for example, from smoked meat products, were not reflected in their findings (Domingo \& Nadal, 2015). More recently, a study from Norway indicated that with a worst case scenario of 30 barbecues per year, $60 \%$ of the total intake of PAH by Norwegian adults was $60 \%$; however, estimations were based on limited data (Aaslyng et al., 2013; Knutsen et al., 2007). Aaslyng et al. (2013) reported PAH concentrations in home-barbecued meat to be higher for beef as compared to pork and chicken.

\subsubsection{Potential physical hazards}

Physical hazards associated with poultry (meat) products may originate from various extraneous materials or foreign particles and objects. A USDA hazard and control guide for meat and poultry products has indicated that physical hazards in finished products may rise from contaminated raw materials, poorly designed or maintained facilities and equipment, faulty processing procedures, or as a result of improper employee training and practices (United States Department of Agriculture (USDA), 1997). Physical hazards can, for example, include glass, metal, stones, plastics, rubber, wood, steel, bone, bullets, and shot or needles, as well as other non-animal foreign materials like lubricants for equipment (United States Department of Agriculture (USDA), 1997, 2003). Physical hazards are primarily introduced in poultry products during poultry processing, where pieces of equipment may enter the product; for example, metal pieces from the grinder (United States Department of Agriculture (USDA), 2005).

Most of the physical hazards associated with poultry products are also found in other processed foods. These include metal, glass, plastics, wood particles as a result of the equipment used and/or raw materials or packaging materials entered into the factory. Physical hazards specifically related to poultry (meat) products are the presence of feathers or bone pieces. Over the years, poultry processing has increasingly been automated leading to increased productivity. In large animals, such as beef and pork, deboning is primarily done manually. In poultry processing, this part is automated (Barbut, 2014). Bones are a consistent concern for the poultry industry and optimizing the deboning process is important in preventing such physical hazards in the final product, yet also for optimizing product yield (Daley \& Stewart, 2009). Ingestion of bones can cause human health problems via esophageal obstruction or perforation of the gastrointestinal tract. Among all the foreign bodies ingested by children, bones contribute up to $12 \%$ (Arana et al., 2001). For the Netherlands, the contribution of chicken bones to the total number of ingested foreign bodies is unknown.

\footnotetext{
5 benz[a]anthracene, benzo[a]pyrene, benzo[b]fluoranthene, and chrysene

6 benz[a]anthracene, benzo[a]pyrene, benzo[b]fluoranthene, benzo[ghi]perylene, benzo[k]fluoranthene, chrysene, dibenz $[\mathrm{a}, \mathrm{h}]$ anthracene, and indeno[1,2,3-cd]pyrene
} 


\subsubsection{Results alerting and monitoring data}

Data on chemical and physical hazards were collected from RASFF, KAP, and risk assessments from the Front Office. In addition, information on these hazards was collected from the NVWA MOS and NVIC.

\subsubsection{Rapid Alert System for Food and Feed (RASFF)}

Previously, chemical and physical hazards notified in feed material were analyzed in the associated dairy chain report of van Asselt et al. (2016). This analysis indicated that most notifications for feed were for aflatoxins, followed to a lesser extent by dioxins and dioxin-like compounds, heavy metals, and pesticides. The RASFF database does not identify the destination of the feed materials. Therefore, it is not possible to draw conclusions for poultry feed, and thus, broiler intake of these hazards.

In order to identify hazards within the product category "poultry meat and poultry meat products," RASFF notifications between 01/01/2009 and 01/01/2015 were collected. During the product category search, only food types were reported (i.e. feed and food contact materials were not found in the search). The RASFF database contained 758 notifications in poultry meat and poultry meat products during the identified period; however, six notifications were reported in more than one hazard category. Therefore, instead of using the 758 reported notifications, the total was adjusted to 764 to reflect these multiple hazards. Additionally, the product category "meat and meat products" was searched for the same time period. This resulted in an additional 16 notifications of food safety hazards in poultry meat. Thus, the total number of notifications of hazards in poultry meat was adjusted to 780 reports (Table 3 ).

Table 4 provides the summary of the results of the search in RASFF from 2009 until 2015 for notified hazards in poultry meat. The percentage of reports by notification type were: alerts (25\%), border rejections $(36 \%)$, information $(13 \%)$, information for attention $(18 \%)$, and information for follow-up $(8 \%)$. These data reflect the EU situation and are generally relevant for the Netherlands. Pathogenic micro-organisms (75\%) were the most reported hazard category, followed by veterinary drugs (10\%), and poor or insufficient controls (5\%). For the top reported hazard categories (Table 4), the notifications reported per poultry or avian related product are depicted per quarter from 2009 until 2015 (Fig. 3). Although the majority of reports are notified simply as "chicken" within the RASFF subject feature, the number of reports on turkey and poultry increased since 2013. This trend may be a result of a change in how a notification is reported over the years.

Tables A2.1, A2.2, and A2.3 (Annex 2) specify the RASFF notifications for industrial contaminants (including dioxins) and veterinary drugs (both feed additives and residues of VMPs) in the product category poultry and poultry meat products and aforementioned notifications from the product category meat and meat products from 2009 until 2015. Based on these RASFF data, there are only 2 notifications of dioxins in this period. For veterinary drugs, there were no reports of SEM and one notification of $A O Z$ above the minimum required performance level (MRPL) in chicken meat (Ref. 2009.1337) in poultry meat and poultry meat products product category. In 2012, feed additives were reported more frequently than in previous years. Before 2009, there was two dioxin-related notifications (Ref. 1999.45 and Ref. 2006.ADN) and one PCB alert (Ref. 2002.034). For veterinary drugs, the nitrofuran metabolite SEM had been detected in the food of animal origin including poultry meat and poultry meat products (Vass et al., 2008). Also, there were several notifications of the nitrofuran metabolite AMOZ in poultry meat and poultry meat products between 2002 and 2003.

Figure 4 shows that $63 \%$ of all RASFF notifications for chemical and physical hazards $(n=127)$ were related to VMPs, of which the majority were prohibited substances nitrofuran and chloramphenicol as well as the unauthorized substance clopidol. In particular, clopidol was regularly found in broiler meat between 2012-2014; especially in products imported from Brazil. No producer of clopidol has requested approval in Europe, and so there is no MRL. However, safety issues related to clopidol are expected to be low since the USA and Canada have relatively high MRLs (and thus presumably for clopidol are relatively high Acceptable Daily Intake (ADI) was established by these countries). The chemical and physical hazards reported in RASFF were primarily detected in chicken (broiler) meat. A few notifications were related to poultry products, such as pâté, but these notifications were related to adulterations/fraud or allergens. 
Table 4 RASFF reports within the poultry meat and poultry meat products product category, and the relevant notifications from the meat and meat products product category, between 01/01/2009 and 01/01/2015.

\begin{tabular}{lll} 
Category & Number of reports & Percentage \\
\cline { 2 - 3 } Total & Frequency & 100 \\
\hline & & 780 \\
\hline Notification type & & 25 \\
\hline Alert & 193 & 36 \\
\hline Border rejection & 284 & 13 \\
\hline Information & 102 & 18 \\
\hline Information for attention & 140 & 18 \\
\hline Information for follow-up & 61 & 8 \\
\hline
\end{tabular}

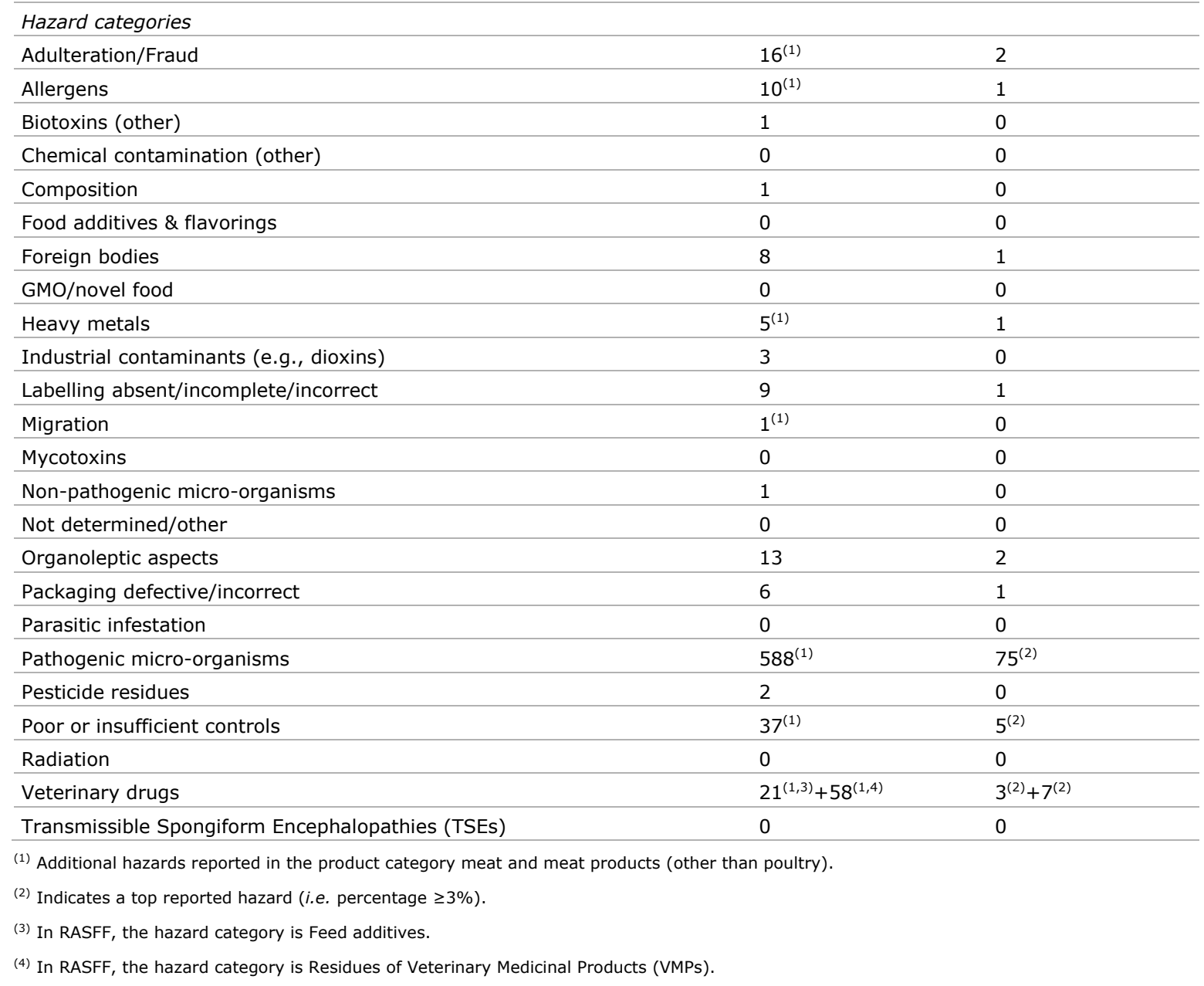




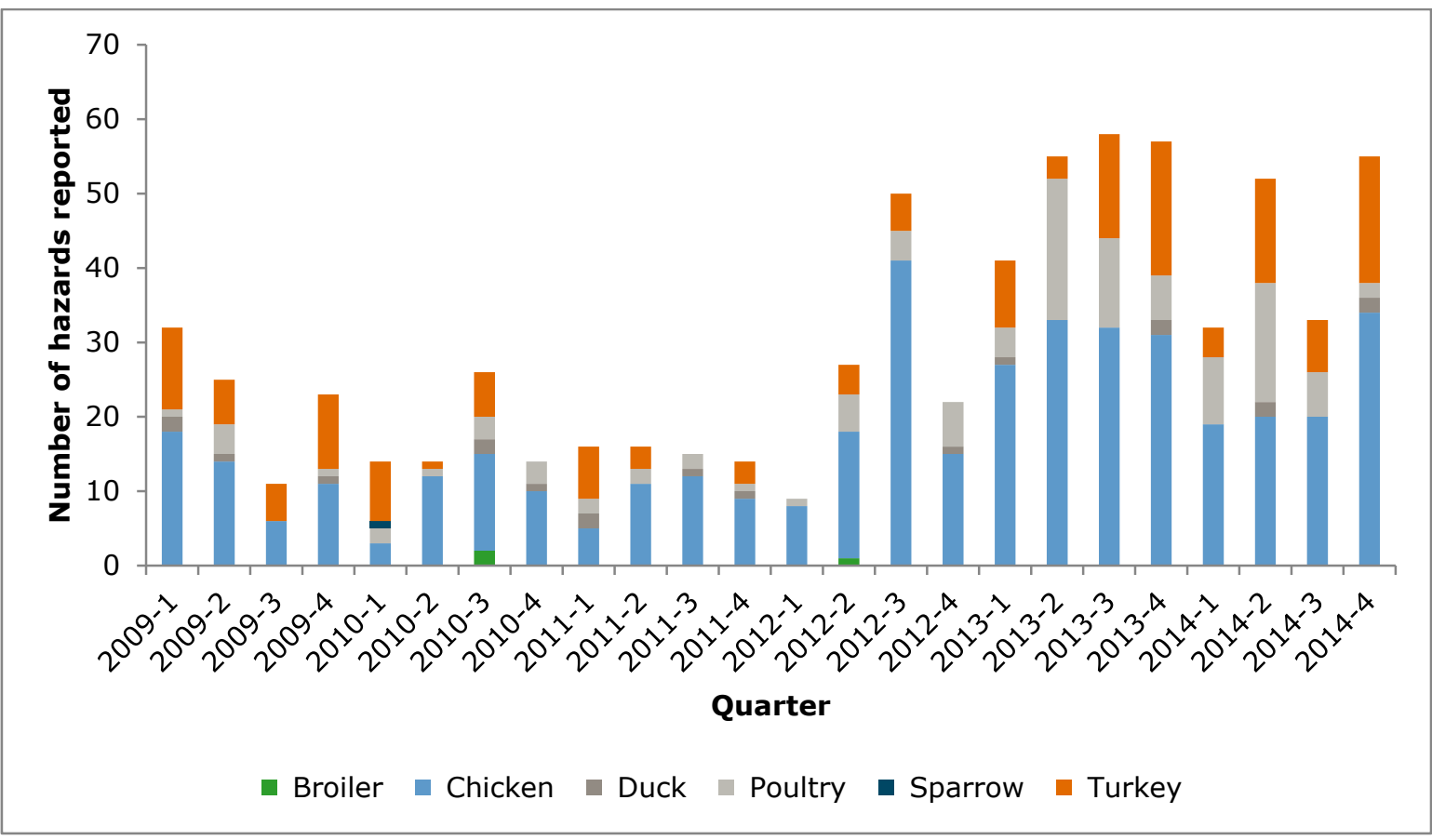

Figure 3 RASFF products reported for the top reported hazards in product categories poultry meat and poultry meat products and aforementioned notifications from the meat and meat products (other than poultry) from 2009 until 2015.

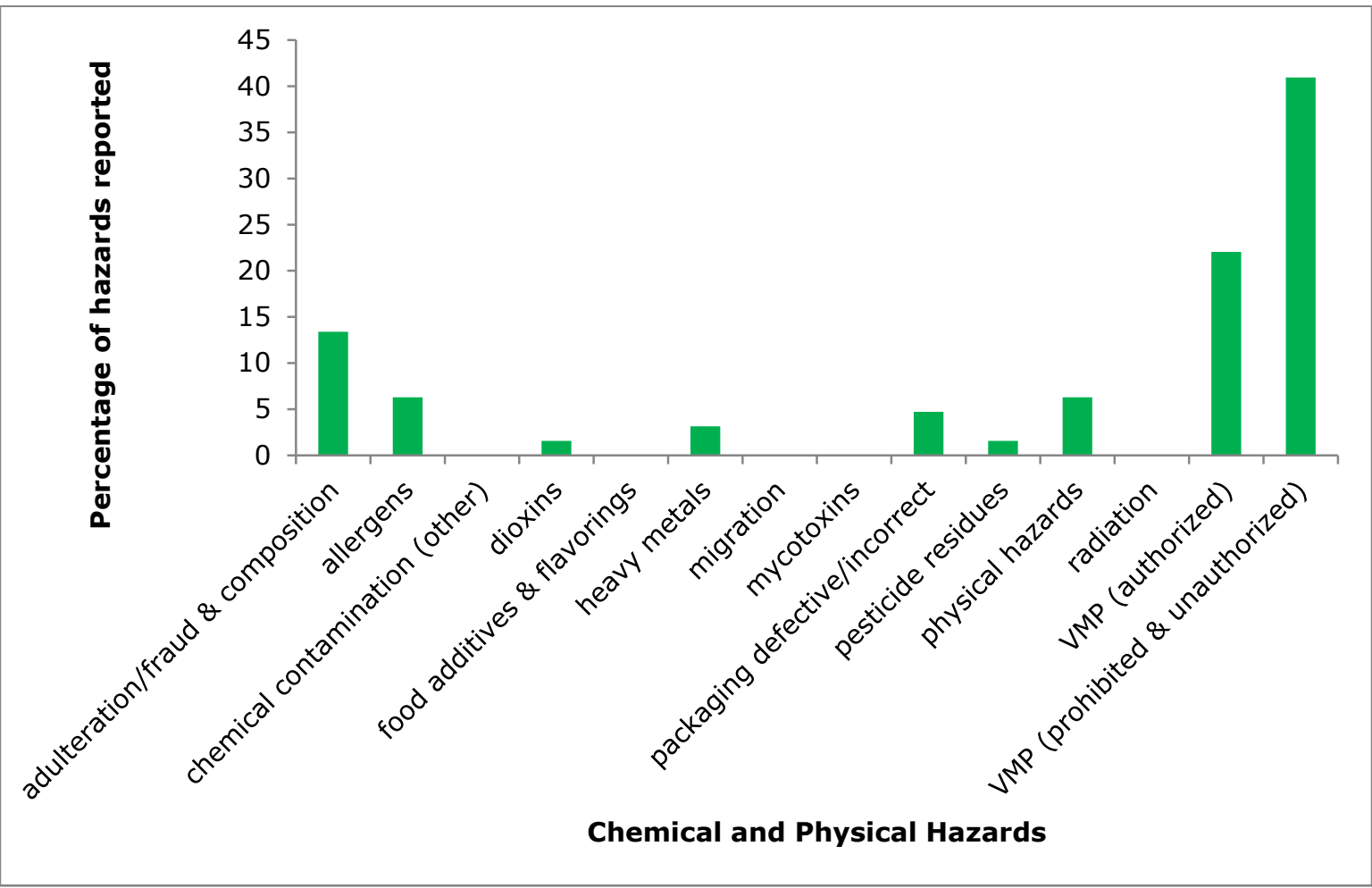

Figure 4 Percentage of chemical and physical hazards reported in the product categories poultry meat and poultry meat products and aforementioned notifications from the meat and meat products (other than poultry) from 2009 until 2015. VMP = veterinary medicinal product. 


\subsubsection{NVWA Meldingenondersteuningssysteem (MOS), National Poisons Information Centre (NVIC), and Front Office Risk Assessments}

From 2010-2012, there were no notifications to the NVWA or the NVIC related to chemical hazards occurring in poultry meat or poultry meat products. Similarly, from 2010-2014, there were no risk assessments performed by the Front Office related to chemical hazards occurring in poultry meat or poultry meat products.

\subsubsection{Main chemical hazards}

Based on the literature review (section 3.1.1 and 3.1.2) and data analyses (section 3.1.3) on the chemical and physical hazards in poultry meat products, the main hazards of concern are:

- Dioxins and dioxin-like polychlorinated biphenyls (DL-PCBs);

- Non-dioxin-like polychlorinated biphenyls (NDL-PCBs);

- Prohibited antimicrobial substances, and;

- Brominated flame retardants.

These hazards were selected based on their occurrence and/or potential to carry over to poultry meat.

The chemical categories (Table 2) considered of lesser relevance for the Dutch poultry meat chain include mycotoxins, toxic (heavy) metals, residues of veterinary drugs other than residues of prohibited antimicrobial substances, feed additives, and pesticide residues. The presence of residues of prohibited, unauthorized, and authorized antimicrobial substances are frequently reported in RASFF and in Dutch monitoring (section 3.1.3). Residues of prohibited antimicrobial substances are considered to be of a higher concern - based on their toxicological effect on human health - than authorized antibiotics. However, residues of all VMPs are considered relevant for poultry products imported from outside the EU. The presence of plant toxins and PFASs in poultry meat products seem to be of lesser importance, but available data is limited, and thus, more data should be collected to draw firm conclusions.

Chemical hazards introduced due to or during further processing (processing contaminants, chemical substances migrating from packaging materials) or intentionally added (food additives) are considered of lesser relevance. Physical hazards are also considered less relevant in comparison to the aforementioned main hazards. Although they can occur, e.g., pieces of bones and feather in meat products, they can be controlled during poultry slaughtering and processing.

This list of main hazards of concern corresponds with results from a recent opinion from the European Food Safety Authority (EFSA) in which EFSA evaluated and ranked the risks for public health associated with chemical substances in poultry meat in Europe. In this study, variations in European farming and processing methods for poultry were recognized.

Criteria utilized for identification and ranking of chemical hazards in the EFSA study included:

- Substances that accumulate in food-producing animals;

- Substances with a specific toxicological profile, and;

- The likelihood that a substance under consideration will occur in poultry.

Taking these criteria into account, EFSA ranked the individual contaminants into four categories denoted as either having a high, medium, low, or negligible potential concern (EFSA Panels on Biological Hazards (BIOHAZ) et al., 2012). EFSA concluded that all examined chemical substances were "unlikely to pose an immediate or acute health risk for consumers" (European Food Safety Authority (EFSA), 2012a).

Chemical substances that were indicated as having a "high potential concern" in poultry meat were: dioxins, DL-PCBs, as well as prohibited antibiotics like chloramphenicol, nitrofurans, and nitroimidazoles. In particular, dioxins and DL-PCBS were regarded as "new" chemical hazards ranked with a "high potential concern" since these substances were not yet comprehensively covered by NRCPs for meat inspection (European Food Safety Authority (EFSA), 2012a). In addition, for dioxins and DL-PCBs, a high ranking was given based on their known accumulation in food-producing animals, 
high risk for exceeding MLs, and toxicological profile. For prohibited antibiotics, their toxicological profile and residue presence in poultry during NRCPs in various member states have raised concern (EFSA Panels on Biological Hazards (BIOHAZ) et al., 2012).

For NDL-PCBs and brominated flame retardants, a medium ranking was given due to their possible accumulation in food-producing animals and limited data regarding residues in poultry. Furthermore, in comparison to dioxins and DL-PCBs, both types of hazards are also less toxic. EFSA indicated that the potential occurrence of such substances should be monitored to improve exposure assessments (EFSA Panels on Biological Hazards (BIOHAZ) et al., 2012).

The toxicological effects and disease burden of the above-mentioned main hazards are provided in the following sections.

\subsection{Human health effects of the main chemical hazards}

The main chemical hazards, identified in section 3.1.4, were investigated for their toxicological effects and disease burden as it relates to human health effects.

\subsubsection{Dioxins and polychlorinated biphenyls (PCBs)}

Dioxins and DL-PCBs exhibit a planar structure with varying chlorine atoms (Fig. 5). However, the 2,3,7,8-substituted congeners are, to a certain extent, metabolically resistant, and therefore, accumulate in biological systems (Hoogenboom, 2012). The 17 dioxin congeners with this 2,3,7, and 8-position pose a risk to human health and the environment (Food Standards Australia New Zealand (FSANZ), 2005). The most toxic congener, 2,3,7,8-tetrachlorodibenzo-p-dioxin (TCDD), is widely studied and used as a reference compound with a toxic equivalency factor (TEF) set at 1.0. TEFs for other congeners, based on the result of available studies, vary between 1 and 0.00003 . These TEFs are used to translate the absolute levels of the various dioxin and DL-PCB congeners into a level expressed in toxic equivalent (TEQ) (Food Standards Australia New Zealand (FSANZ), 2005).

Dioxins and DL-PCBs are classified as human carcinogens by IARC and also have been shown to cause adverse effects in reproductive and immune systems, teratogenesis, and neurobehavioral effects (de Jong et al., 2015; Food Standards Australia New Zealand (FSANZ), 2005; Reyes-Herrera \& Donoghue, 2012; World Health Organization (WHO), 2014a). Dioxins and DL-PCBs can occur in animal-derived food products (milk, eggs, meat, organs, and fish) and, to a lesser extent, in food products of plant origin. Depending on the diet, consumers are, in principle, exposed on a daily basis, resulting in a gradual increase of the body burden. In the subsection on exposure, the contribution of poultry meat (fat) is described.

\subsubsection{Toxicity}

\subsection{Acute toxicity}

Several $\mathrm{LD}_{50}{ }^{7}$ values have been reported: in mice: $180-2600 \mu \mathrm{g} / \mathrm{kg}$ bw; rat: $25-3000 \mu \mathrm{g} / \mathrm{kg} \mathrm{bw}$; rhesus monkey: $50-70 \mu \mathrm{g} / \mathrm{kg}$ bw; guinea pigs: 0.6-2.1 $\mu \mathrm{g} / \mathrm{kg}$ bw (Joint FAO/WHO Expert Committee on Food Additives (JECFA), 2002).

\subsection{Subchronic and chronic exposure}

In laboratory animals, a number of effects have been observed, like reduced sperm count and delayed onset of puberty, effects on the immune system, and decreased learning. Some of these effects were observed in offspring of mothers treated with TCDD. At higher doses and chronic exposure, some dioxin and DL-PCB congeners were shown to cause liver tumors.

Follow-up studies of incidents with dioxins and PCBs, like the incident in Seveso, showed decreased sperm production in men either exposed as young boys but also those breastfed by mothers exposed

\footnotetext{
$7 \mathrm{LD}_{50}$ (Lethal Dose, 50\%): represents the dose of a substance required to kill 50 percent of a population of test animals
} (e.g., fish, mice, rats) after a specified test duration. 
during the incident. Three-day-old children born to exposed mothers, showed an increase in TSH levels, suggesting an effect on the thyroid. Higher doses lead to a typical skin disease, called chloracne. There are also indications for effects on teeth development and diabetes, as well as a slight increase in the incidence of certain tumors.

\subsection{Health-based Guidance Values}

In 2001, EFSA's predecessor, the Scientific Committee on Food (SCF) determined a Tolerable Weekly Intake (TWI) of 14 pg TEQ/kg bw per week (Scientific Committee on Food, 2001) for dioxins and DLPCBs. This TWI was derived based on reproductive toxicity observed in the male rat offspring when exposed in utero, i.e. developmental effects on the male reproductive system, in particular, on sperm formation. In the derivation of the TWI, a body burden approach was used. In deriving the TWI, the estimated body burden leading to these effects in the rats was extrapolated to an estimated daily human intake by taking into account the half-life of TCDD in humans. Intake below this TWI ensures that the chronic daily exposure to dioxins and DL-PCBs from food does not lead to an "internal" (body burden) during pregnancy that may induce the above-mentioned reproductive toxicity. An overall factor of 10 was applied to translate the LOAEL in rats to a NOAEL and to account for differences in sensitivity between humans. Finally, the TWI is deliberately defined on a weekly basis. Within this period, the TWI thus corresponds to an average daily exposure of $2 \mathrm{pg} T E Q / \mathrm{kg}$ bw per day. Based on similar effects, the Joint FAO/WHO Expert Committee on Food Additives (JECFA) (2002) derived a health-based guidance value but extended it to a Provisional Tolerable Monthly Intake (PTMI) of 70 pg TEQ/kg bw.

Recently, the United States Environmental Protection Agency (EPA) derived a "Reference Dose" (RfD) of $0.7 \mathrm{pg} T E Q / \mathrm{kg}$ bw per day (United States Environmental Protection Agency (EPA), 2012). This health based guidance value was based on two epidemiological studies on persons exposed to TCDD during the Seveso incident. In concordance with SCF's derivation of the TWI, the epidemiological studies indicated reproductive toxicity but also effects on the thyroid, as the most sensitive noncarcinogenic effects in humans. An overall uncertainty factor of 30 was used to extrapolate the lowest dose causing reduced sperm production to a no-effect level and to account for differences between humans.

\subsubsection{Exposure}

In 2014, the chronic dietary exposure to dioxins and DL-PCBs was estimated for two Dutch populations: young children 2 to 6 years of age and persons 7 to 69 years of age (P. E. Boon, te Biesebeek, de Wit-Bos, \& van Donkersgoed, 2014). These two populations were addressed because two separate food consumption databases were available for these population groups. Consumption data were linked to concentrations analyzed within the Dutch monitoring program on dioxins, DLPCBs, indicator PCBs, and flame retardants in primary agricultural products, ${ }^{8}$ as well as one on contaminants in Dutch fish and fishery products in order to assess the chronic dietary exposure. ${ }^{9}$

The contribution of poultry meat (fat), including chicken and turkey, ${ }^{10}$ to the chronic exposure to dioxins and DL-PCBs, is not reported by Boon et al. (2014). After examining the underlying exposure results (not published), data showed that the contribution of poultry meat to the chronic exposure was very low: around $1 \%$ in both age groups. This was due to a relatively low-fat consumption via this type of meat (due to low-fat content) and low dioxin concentrations compared to the major sources of exposure to dioxins (milk, fish, beef, and vegetable oils and fats) due to either higher consumption and/or higher dioxin concentrations. This $1 \%$ can be used to assess the exposure to dioxins due to the consumption of poultry meat (fat) based on the reported exposure estimates for the whole diet. The median exposure to dioxins via the consumption of poultry meat (fat) ranged from $0.005 \mathrm{pg}$ $\mathrm{TEQ}_{w H 02005} / \mathrm{kg}$ bw per day in persons 7 to 69 years of age to $0.01 \mathrm{pg} \mathrm{TEQ}_{w H 02005} / \mathrm{kg}$ bw per day in young children 2 to 6 years of age. Corresponding dioxin exposure estimates via the consumption of poultry meat (fat) for the P99 level of exposure were $0.01 \mathrm{pg}$ TEQwH02005 $/ \mathrm{kg} \mathrm{bw}$ per day in persons 7 to 69 years of age and $0.02 \mathrm{pg} \mathrm{TEQ}{ }_{W H 02005} / \mathrm{kg}$ bw per day in young children 2 to 6 years of age. Dioxin

\footnotetext{
8 www.wageningenur.nl/en/Expertise-Services/Research-Institutes/rikilt/Research/Chemicalcontamination/Contaminants/Dioxin-analysis/Monitoring-dioxins-PCBs-and-flame-retardants.htm 9 www.wageningenur.nl/en/project/Monitoring-contaminants-in-Dutch-fish-and-fishery-products.htm 10 Consumption of other poultry species is not recorded in both food consumption databases.
} 
concentrations in chicken liver were not available. The exposure via the consumption of this product, which is known to accumulate dioxins and DL-PCBs (Ghimpeteanu et al., 2014) was therefore not included in the assessment (Boon et al., 2014). If these concentrations become available, the contribution of chicken liver to the exposure to dioxins can be estimated. However, the contribution is expected to be very low: consumption of chicken liver was recorded on only $0.1 \%$ of the consumption days (7 out of 7630) in the consumption database of persons aged 7 to 69 years. The database of young children does not contain any information on the consumption of chicken liver.

It should be noted that the estimated contribution of poultry meat (fat) to the dioxin exposure via the whole diet was based on the total exposure distribution. At the upper tail of the exposure distribution, the contribution of food products to the exposure may be different. Based on a contribution of $2.5 \%$ at the upper tail of the dioxin exposure distribution, obtained from an examination of the underlying exposure results, the exposure at the P99 due to poultry meat (fat) is very likely only slightly higher than the figures mentioned above.

\subsubsection{Burden of disease}

With respect to the carcinogenicity of dioxins, Hänninen et al. (2014) mention an Environmental Burden of Disease (EBD) of 10,794 Disability-Adjusted Life Years (DALYs) per 1 million people. Given a current population size of about 16.9 million in the Netherlands, this results in $16.9 \times 10,794=$ 182,419 DALYs. Hänninen et al. (2014) estimated that approximately $2.1 \%$ of the EBD results from dioxin exposure, i.e. 227 DALYs per million, or 3,831 DALYs.

This calculation is based on the dietary dioxin exposure in the Netherlands in 2004. This could be adjusted for the Dutch dietary exposure in 2014, but it cannot be deduced from this publication if this means that the 3,831 DALYs can be interpreted as 3,831 DALYs per year.

In 2004, RIVM performed a preliminary burden of disease assessment on dioxins. At that time, no burden of disease was attributed to non-cancer effects of dioxins (van Kreijl \& Knaap, 2004). Within WHO's Foodborne Disease Burden Epidemiology Reference Group (FERG), a DALY approach has recently been developed for the non-cancer effects of dioxins (Zeilmaker, Bokkers, \& Mengelers, in preparation).

\subsubsection{NDL-PCBs}

Due to the concern that many, if not all, effects of PCB mixtures can be attributed to dioxins and DLPCBs (TEQ-driven), health-based guidance values for NDL-PCBs could not be established (EFSA Panel on Contaminants in the Food Chain (CONTAM), 2005c). In short, since mixtures, and often pure standards, contain trace amounts of PCDFs and DL-PCBs, it remains difficult to differentiate between dioxins and PCBs during toxicological and epidemiological studies.

\subsubsection{Chloramphenicol}

\subsubsection{Toxicity}

\subsection{Acute toxicity}

"In mice, the oral median lethal dose ( $\left(D_{50}\right)$ was estimated to be $2,640 \mathrm{mg} / \mathrm{kg}$ bw and neurotoxic effects were observed after acute oral dosing at $1,250 \mathrm{mg} / \mathrm{kg}$ bw and higher. In dogs, neurotoxic effects were observed at $300 \mathrm{mg} / \mathrm{kg}$ bw given orally" (EFSA Panel on Contaminants in the Food Chain (CONTAM), 2014).

\subsection{Subchronic and chronic toxicity}

"Chloramphenicol causes toxicity in liver, small intestine, spleen and thymus of laboratory animals. Chloramphenicol also caused a concentration-dependent inhibition of the activity of some cytochrome P450 (CYP)-enzymes in rat liver microsomal fractions. It also induced signs of haemolytic anaemia as well as an inhibitory action on the bone marrow. The most sensitive endpoint was liver toxicity, with effects found at the lowest tested dose of $25 \mathrm{mg} / \mathrm{kg}$ bw per day in rats. Consequently, a NOAEL for repeated-dose toxicity could not be identified from these studies" (EFSA Panel on Contaminants in the Food Chain (CONTAM), 2014). 
"Chloramphenicol also caused embryotoxicity and teratogenicity in laboratory animals orally administered chloramphenicol in doses ranging from $500-2000 \mathrm{mg} / \mathrm{kg}$ bw per day. In addition, degeneration of the testes and effects on sperm quality were observed in three studies in rats applying only one oral dose level in the range from 25 to $112 \mathrm{mg}$ chloramphenicol/kg bw per day administered over periods spanning from 8 to 25 days" (EFSA Panel on Contaminants in the Food Chain (CONTAM), 2014).

"Chloramphenicol is genotoxic in vivo, inducing chromosomal aberrations, sister chromatid exchange (SCE) and/or DNA damage in mice and rats following oral or parenteral administration. The CONTAM Panel noted that no conclusion could be drawn regarding the potential carcinogenicity of chloramphenicol because of the lack of appropriate and well-documented long-term studies" (EFSA Panel on Contaminants in the Food Chain (CONTAM), 2014).

\subsection{Acceptable daily intake (ADI)}

Both the European Medicines Agency (EMA) and the JECFA concluded that it was not possible to derive an ADI for chloramphenicol (European Medicines Agency, 1996a; Wongtavatchai et al., 2004). For that reason, zero tolerance was established. A Minimum Required Performance Level (MRPL) of $0.3 \mu \mathrm{g} / \mathrm{kg}$ was set for meat and urine. This MRPL was selected as the Reference Point of Action (RPA). In 2014, the EFSA CONTAM Panel concluded that the RPA of $0.3 \mu \mathrm{g} / \mathrm{kg}$ was low enough to protect human health. This was based on a hypothetical human dietary exposure based on a "scenario in which specific food groups (foods of animal origin; foods in which enzyme preparations reported to be contaminated with chloramphenicol, may be used during food production; and grains and grain-based products in which chloramphenicol could occur naturally) are considered to contain chloramphenicol at the concentration level of $0.3 \mu \mathrm{g} / \mathrm{kg}$." The mean chronic dietary exposure across the different European countries and dietary surveys for this scenario would range from 11 to $17 \mathrm{ng} / \mathrm{kg}$ bw per day for toddlers and from 2.2 to $4.0 \mathrm{ng} / \mathrm{kg}$ bw per day for adults (EFSA Panel on Contaminants in the Food Chain (CONTAM), 2014).

"When comparing the median chronic dietary exposure across European countries and dietary surveys for the average consumer, with the reference point for aplastic anaemia ( $4 \mathrm{mg} / \mathrm{kg}$ bw per day), the Margin of Exposure (MOE) is about $2.7 \times 10^{5}$ for toddlers and $1.3 \times 10^{6}$ for adults" (EFSA Panel on Contaminants in the Food Chain (CONTAM), 2014). "When comparing the median chronic dietary exposure across European countries and dietary surveys for the average consumer, with the reference point for reproductive/hepatotoxic effects ( $25 \mathrm{mg} / \mathrm{kg}$ bw per day), the MOE is about $1.7 \times 10^{6}$ for toddlers and $8.1 \times 10^{6}$ for adults."

Considering these large MOEs and the relatively low frequency of occurrence of aplastic anaemia following systemic treatment of patients with chloramphenicol, EFSA considered it "unlikely that exposure to food contaminated with chloramphenicol at or below $0.3 \mu \mathrm{g} / \mathrm{kg}$ is a health concern with respect to aplastic anaemia or reproductive/hepatotoxic effects" (EFSA Panel on Contaminants in the Food Chain (CONTAM), 2014). However, given the lack of data, carcinogenicity could not be fully assessed (EFSA Panel on Contaminants in the Food Chain (CONTAM), 2014). Furthermore, the current reference point of action (RPA) was also concluded as appropriate to apply to food of non-animal origin and feed (EFSA Panel on Contaminants in the Food Chain (CONTAM), 2014), which is of relevance regarding the presence of CAP in certain enzymes used in food and feed production.

\subsubsection{Exposure}

\subsubsection{Nitrofurans}

Nitrofurans are synthetic broad-spectrum antimicrobial agents, including furazolidone, furaltadone, nitrofurantoin, nitrofurazone, and nifursol. "Nitrofurans share a nitrofuran ring, which is coupled to a side-chain via an azomethine bond." As aforementioned, the side-chains differ for the various drugs, being AOZ for furazolidone, AMOZ for furaltadone, AHD for nitrofurantoin, SEM for nitrofurazone, and DNSH for nifursol (EFSA Panel on Contaminants in the Food Chain (CONTAM), 2015). "Nitrofurans are not authorized for use in food-producing animals in the EU, but some nitrofurans such as furazolidone, nitrofurantoin, and nitrofurazone may be used in human medicine" (EFSA Panel on Contaminants in the Food Chain (CONTAM), 2015). 


\subsubsection{Toxicity}

\subsection{Acute toxicity}

The $\mathrm{LD}_{50}$ for furazolidone, $\mathrm{AOZ}, \mathrm{AMOZ}$, nitrofurantoin, AHD, nitrofurazone, and SEM are summarized in Table 5. No information regarding the acute toxicity of furaltadone, nifursol, or DNSH was identified. "Acute toxicity studies in laboratory animals showed that for furazolidone, nitrofurantoin, and nitrofurazone, the lung is an important target for toxicity, leading to decreased respiratory function and death. Signs of neurotoxicity such as hyperirritability, tremors, and convulsions were also found" (EFSA Panel on Contaminants in the Food Chain (CONTAM), 2015).

Table 5 Oral $L D_{50}$ of nitrofurans and their metabolites by species.

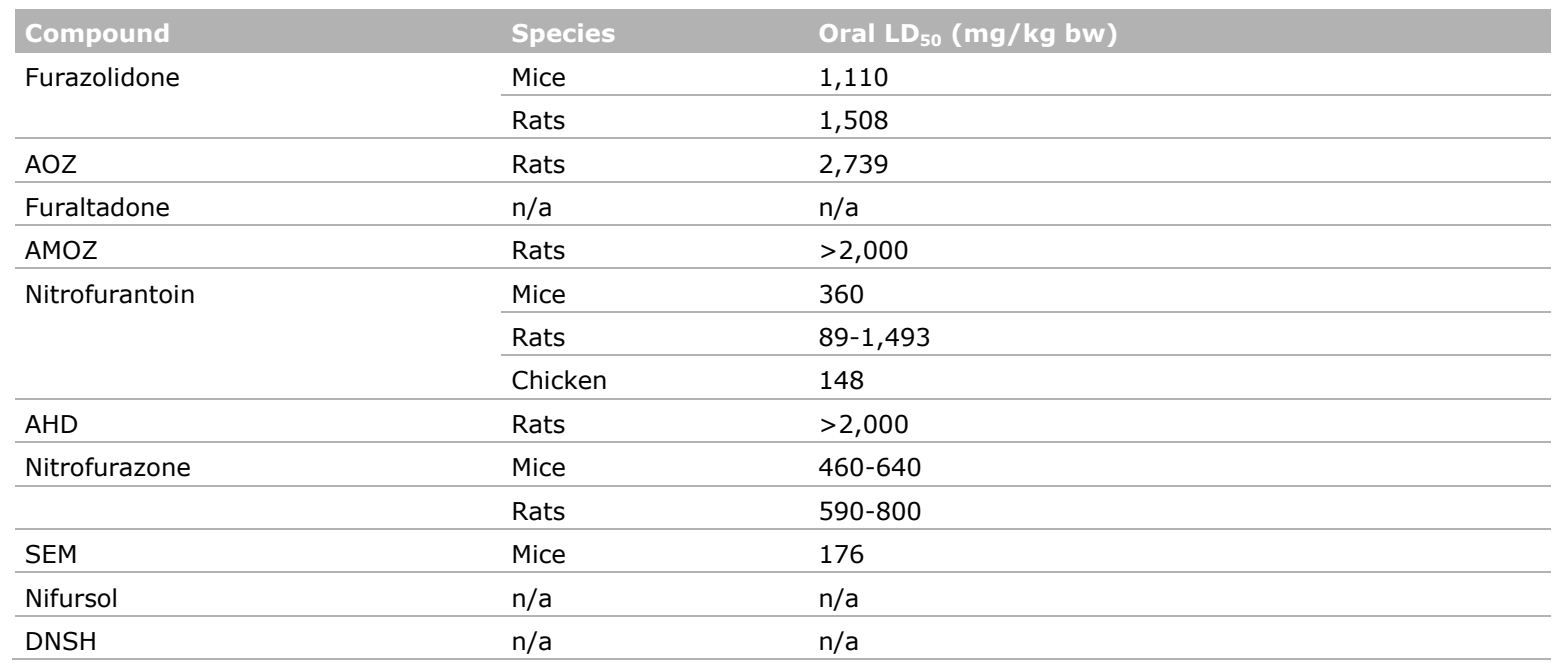

\subsection{Subchronic and chronic toxicity}

No repeated-dose toxicity studies were identified for furazolidone, furaltadone, AMOZ, AHD, and DNSH (EFSA Panel on Contaminants in the Food Chain (CONTAM), 2015).

"AOZ was tested in a 90-day study with rats and in a 90-day study with dogs. Hepatotoxicity, decreased body weight gain, and anemia were observed at the lowest tested dose of $1.2 \mathrm{mg} / \mathrm{kg} \mathrm{bw}$ per day in rats and at $1 \mathrm{mg} / \mathrm{kg}$ bw per day in dogs" (EFSA Panel on Contaminants in the Food Chain (CONTAM), 2015).

"In studies on repeated-dose toxicity of nitrofurantoin in rats, mice, and rabbits, the main toxic effects of nitrofurantoin were on liver, kidney, testes (resulting in aspermatogenesis), and necrosis of the ovarian follicles. In a 13-week rat study, a no observed adverse effect level (NOAEL) of $117 \mathrm{mg} / \mathrm{kg}$ bw per day was identified, based on effects on the testes and on ovarian follicles. In a 13-week mice study, a NOAEL of $120 \mathrm{mg} / \mathrm{kg}$ bw per day was identified based on effects on the testes" (EFSA Panel on Contaminants in the Food Chain (CONTAM), 2015).

"Nitrofurazone was tested in rats, mice, monkeys, and dogs. Nitrofurazone caused the same effects as nitrofurantoin, with the exception of necrosis of the ovarian follicles in rats and mice. The lungs were investigated in some studies (e.g., 13-week studies with nitrofurantoin and nitrofurazone in mice and rats), but no effects were reported. The lowest doses of nitrofurazone that did not cause effects in mice and rats were 62 and $13.5 \mathrm{mg} / \mathrm{kg}$ bw per day, respectively. Therefore, a NOAEL of $13.5 \mathrm{mg} / \mathrm{kg}$ bw per day was established for effects on the testes in rats" (EFSA Panel on Contaminants in the Food Chain (CONTAM), 2015).

"In a 28-days study, SEM caused absence of mineralisation in the epiphyseal cartilage of juvenile rats at the lowest tested dose of $40 \mathrm{mg} / \mathrm{kg}$ bw per day. Therefore, no NOAEL could be identified. In a 90day study in rats, severe deformation of limbs, osteochondral lesions, altered form of the interlaminar spaces in the thoracic aorta and decreased body weight gain were observed. Toxic effects were found 
in all dose groups, including the lowest dose tested of $23 \mathrm{mg} / \mathrm{kg}$ bw per day," so no NOAEL could be identified. Upon BMD analysis, "a lowest $\mathrm{BMDL}_{10}{ }^{11}$ for effects on bones was derived of $1.0 \mathrm{mg} / \mathrm{kg} \mathrm{bw}$ per day" (EFSA Panel on Contaminants in the Food Chain (CONTAM), 2015).

"In rats, nifursol caused slight changes in red blood cell parameters. From this 13-week study, a NOAEL of $14 \mathrm{mg} / \mathrm{kg}$ bw per day was identified" (EFSA Panel on Contaminants in the Food Chain (CONTAM), 2015).

"Nitrofurans and their marker metabolites, generally, are genotoxic and carcinogenic and, also, have non-neoplastic effects in animals" (EFSA Panel on Contaminants in the Food Chain (CONTAM), 2015). The Joint FAO/WHO Expert Committee on Food Additives (JECFA) concluded that nitrofurazone is carcinogenic, yet not genotoxic, while furazolidone was classified as a genotoxic carcinogen.

"In studies on spermatogenesis, furazolidone, furaltadone, nitrofurantoin, and nitrofurazone caused toxic effects on the testes in rats and mice." In addition, some nitrofurans and nitrofuran metabolites were found to be embryotoxic or teratogenic (EFSA Panel on Contaminants in the Food Chain (CONTAM), 2015).

\subsection{Acceptable Daily Intake (ADI)}

"Because most of the nitrofurans and their marker metabolites are genotoxic and/or carcinogenic, derivation of health-based guidance values (HBGVs)" including ADI or tolerable daily intake (TDI) is not appropriate (EFSA Contam, 2015). Also, JECFA has not established ADIs, and Codex Alimentarius Commission could not establish MRLs for any nitrofurans (Reeves, 2011). However, the EU established an MRPL of $1.0 \mu \mathrm{g} / \mathrm{kg}$ for the side-chains, which was subsequently selected as the RPA.

In order to evaluate whether the RPA would protect human health, EFSA calculated human dietary exposure "for a scenario in which a single nitrofuran marker metabolite is present at the RPA of $1.0 \mu \mathrm{g} / \mathrm{kg}$ in all foods of animal origin, excluding milk and dairy products. The mean chronic dietary exposure for this worst-case scenario would range from 3.3 to 8.0 and 1.9 to $4.3 \mathrm{ng} / \mathrm{kg}$ bw per day for toddlers and adults, respectively. MOEs were calculated at $2.0 \times 10^{5}$ or greater for carcinogenicity and at $2.5 \times 10^{3}$ or greater for non-neoplastic effects. The CONTAM Panel, therefore, concluded that it is unlikely that exposure to food contaminated with nitrofuran marker metabolites at or below $1.0 \mu \mathrm{g} / \mathrm{kg}$ is a health concern" (EFSA Panel on Contaminants in the Food Chain (CONTAM), 2015).

AOZ, AMOZ, AHD, and DNSH have not been reported to occur in foods of non-animal origin. "Only SEM is reported to occur in food of non-animal origin due to its potential presence in the food additive carrageenan, which is used in a large variety of foods. The food additive carrageenan may also be used in foods of animal origin." "SEM is carcinogenic in mice, but not in rats. However, the available information is too limited to conclude on a reference point for carcinogenicity in mice and the cancer risk cannot be assessed. For non-neoplastic effects, the CONTAM Panel identified a BMDL 10 of $1.0 \mathrm{mg} / \mathrm{kg}$ bw per day for the effect on bones caused by SEM." For the estimation of chronic dietary intake, EFSA considered a scenario (no. 2C), in which foods of animal origin and foods of non-animal origin "are contaminated with SEM at a concentration equal to the RPA level of $1 \mu \mathrm{g} / \mathrm{kg}$ ". When comparing the $\mathrm{BMDL}_{10}$ of $1.0 \mathrm{mg} / \mathrm{kg}$ bw per day with the median chronic dietary exposure to SEM, based on scenario $2 \mathrm{C}$, across dietary surveys for the average consumer, the MOE would be $3.4 \times 10^{4}$ for toddlers and $1.0 \times 10^{5}$ for adults. "The CONTAM Panel considered that for SEM these MOEs for non-neoplastic effects are sufficiently large and do not indicate a health concern" (EFSA Panel on Contaminants in the Food Chain (CONTAM), 2015).

\subsubsection{Exposure}

\subsubsection{Nitroimidazoles}

"Nitroimidazoles have historically been legally available and used as VMPs for poultry in the EU, but are currently prohibited in the EU for use in food-producing animals, because no ADI could be established." "Nitroimidazoles have been used primarily to prevent and treat the diseases

\footnotetext{
${ }^{11} \mathrm{BMDL}_{10}$ is the lower limit of the confidence interval of the BMD (BMDL) that is associated with a $10 \%$ response adjusted for background.
} 
histomoniasis, and trichomoniasis in turkeys, pigeons and game birds as no other approved VMPs are available to treat this condition" (EFSA Panels on Biological Hazards (BIOHAZ) et al., 2012).

This report focuses on DMZ, MNZ, and RNZ, which are the most widely studied and discussed nitroimidazoles. They have shown to exhibit antibacterial, antiprotozoal, and anticoccidial activity (EFSA Panels on Biological Hazards (BIOHAZ) et al., 2012).

\subsubsection{Toxicity}

\subsection{Acute toxicity}

The acute toxicity for most of the nitroimidazoles is low (Table 6). For MNZ, oral $L_{50}$ values vary between 4,350-5,000 mg/kg bw for mice, greater than 5,000 mg/kg bw for rats, and greater than 750 $\mathrm{mg} / \mathrm{kg}$ bw for dogs (EMA, 1997). For RNZ, oral $L_{50}$ values vary between $2,330-2,440 \mathrm{mg} / \mathrm{kg}$ bw for mice, 2,850-3,140 mg/kg bw for rats, and 1,250 mg/kg bw for rabbits (Joint FAO/WHO Expert Committee on Food Additives (JECFA), 1990).

Table 6 Oral $L D_{50}$ of metronidazole $(M N Z)$ and ronidazole $(R N Z)$ by species.

\begin{tabular}{lll} 
Compound & Species & Oral LD ${ }_{50}(\mathrm{mg} / \mathrm{kg}$ bw $)$ \\
Metronidazole (MNZ) & Mice & $4,350-5,000$ \\
\cline { 2 - 3 } & Rats & $>5,000$ \\
\cline { 2 - 3 } & Dogs & $>750$ \\
\hline Ronidazole (RNZ) & Mice & $2,330-2,440$ \\
\cline { 2 - 3 } & Rats & $2,850-3,140$ \\
\cline { 2 - 3 } & Rabbits & 1,250 \\
\hline
\end{tabular}

\subsection{Subchronic and chronic toxicity}

"No toxicological no observed effect level (NOEL) could be identified for metronidazole in repeated dose toxicity studies, as effects were also seen at the lowest doses tested" (European Medicines Agency, 1997). "The influence of metronidazole on fertility has not been specifically tested, although impairment of male fertility was noted." Metronidazole has been shown to have a teratogenic potential, although teratogenicity was not adequately tested (European Medicines Agency, 1997). MNZ is considered genotoxic and mutagenic and shows carcinogenicity in mice and rats. IARC classified MNZ as "possibly carcinogenic to humans" belonging to group 2B substances (European Medicines Agency, 1997).

For RNZ, a NOEL of $5 \mathrm{mg} / \mathrm{kg}$ bw/day or higher was observed in several long-term and reproductive studies. Testicular atrophy was observed in rats receiving RNZ (Joint FAO/WHO Expert Committee on Food Additives (JECFA), 1990). Results with RNZ in mutagenesis tests are ambiguous. RNZ has been found to increase the incidence of various types of tumors in laboratory animals, including mammary fibroadenoma, mammary adenocarcinoma, and lung tumors (European Medicines Agency, 1996c; Joint FAO/WHO Expert Committee on Food Additives (JECFA), 1990).

DMZ has shown mutagenic activity in several bacterial tests. However, this activity was linked to the enzyme activity of the nitroreductases of the bacteria used in the tests. Results from other in vitro and in vivo tests suggested that DMZ was not a genotoxic compound. However, recent data from other nitroimidazoles suggest that nitroimidazoles may be genotoxic as they induced chromosomal aberrations in human lymphocytes in vitro and in vivo at high therapeutic dose levels. The possibility that DMZ might be genotoxic could not be excluded (European Medicines Agency, 1996b).

\subsection{Acceptable daily intake (ADI)}

Due to the genotoxic mechanisms of the carcinogenicity of MNZ, it is not possible to establish a threshold level, and thus, an ADI (European Medicines Agency, 1997). 
In 1990, JECFA established a temporary ADI of 0-0.025 mg/kg bw per day for RNZ based on a NOEL of $5 \mathrm{mg} / \mathrm{kg}$ bw per day and a safety factor of 200 . The safety factor was selected based on results of genotoxicity studies on RNZ in mammalian systems and of two carcinogenicity studies. It was also influenced by the lack of mutagenicity of several metabolites of RNZ (Joint FAO/WHO Expert Committee on Food Additives (JECFA), 1990).

For DMZ, no ADI could be established as a NOEL could not be identified (European Medicines Agency, 1996b).

\subsubsection{Exposure}

Exposure data for nitroimidazoles are not available. Together with chloramphenicol and nitrofurans, EFSA ranked nitroimidazoles as being of high potential concern, as they have a distinct toxicological profile comprising a potential concern for human health. Furthermore, residues in poultry have been found in the course of the NRCPs in various member states, although these substances are prohibited for use in food-producing animals in the EU (EFSA Panels on Biological Hazards (BIOHAZ) et al., 2012). According to a joint report from FAO/WHO, the Codex Committee on Residues of Veterinary Drugs in Foods (CCRVDF) recalls that the working group had not yet reached a conclusion on Risk Management Recommendations (RMRs) for the various nitroimidazoles. However, the group recognized the human health concern for such compounds and noted a significant data gap and missing JECFA assessment for MNZ (Food and Agriculture Organization of the United Nations (FAO) \& World Health Organization (WHO), 2014, 2015).

\subsubsection{Polybrominated diphenyl ethers (PBDEs)}

PBDEs are a class of brominated hydrocarbons with a basic structure consisting of two phenyl rings linked by an oxygen atom. PBDEs are a widely used group of flame retardants used in technical mixtures of different PBDE congeners, e.g., penta-, octa-, or deca-BDE. There are 209 possible compounds, commonly referred to as PBDE congeners, which differ in the number and position of the bromine atoms in the two phenyl rings. Based on the composition of the technical PBDE mixtures, occurrence in the environment and in food, the EFSA CONTAM Panel considered the following eight PBDE congeners to be of primary interest: BDE-28, -47, -99, -100, -153,-154, -183, and -209 (EFSA Panel on Contaminants in the Food Chain (CONTAM), 2011b).

\subsubsection{Toxicity}

\subsection{Acute toxicity}

No information is available on the acute toxicity of any specific BDE congener. $\mathrm{LD}_{50}$ values are available for technical mixtures: penta-BDE (oral $L_{50}$ values in rats between 2,640 and 6,200 mg/kg bw), octa-BDE (oral $L_{50}$ value in rats $>5,000 \mathrm{mg} / \mathrm{kg} \mathrm{bw}$ ) and deca-BDA (oral $\mathrm{LD}_{50}$ value in rats > $5,000 \mathrm{mg} / \mathrm{kg} \mathrm{bw}$ ) have low acute toxicity (EFSA Panel on Contaminants in the Food Chain (CONTAM), 2011b).

\subsection{Subchronic and chronic toxicity}

The available genotoxicity studies indicate that PBDEs do not induce gene mutations, but that they can cause DNA damage through the induction of reactive oxygen species (ROS) (EFSA Panel on Contaminants in the Food Chain (CONTAM), 2011b).

"The available data on the effects of PBDEs provide convincing evidence that they have the potential to disrupt endocrine systems at multiple target sites. While the thyroid hormone system appears to be the main target of these compounds, recent studies demonstrated in vivo effects on both the estrogen- and androgen-mediated processes as well" (EFSA Panel on Contaminants in the Food Chain (CONTAM), 2011b).

"The animal studies showed that exposure to PBDEs during gestation and/or postnatally can cause developmental and reproductive effects, including impaired spermatogenesis and changes in female reproductive organs, and perturbation of thyroid hormone regulation." "No teratogenic effects have 
been observed. Fetotoxic effects of PBDEs seem to occur at lower doses than those causing maternal toxicity" (EFSA Panel on Contaminants in the Food Chain (CONTAM), 2011b).

"Exposure to PBDE congeners during development can cause neurobehavioral effects. Alterations in the thyroid hormone regulation may play a critical role in the onset of these effects" (EFSA Panel on Contaminants in the Food Chain (CONTAM), 2011b).

\subsection{Benchmark dose (BMD)}

Based on the information from animal experiments on neurodevelopmental behavioral changes the EFSA CONTAM Panel derived $\mathrm{BMDL}_{10}$ values for individual PBDE congeners: BDE-47 as $309 \mu \mathrm{g} / \mathrm{kg} \mathrm{bw}$, BDE-99 as $12 \mu \mathrm{g} / \mathrm{kg}$ bw, BDE-153 as $83 \mu \mathrm{g} / \mathrm{kg}$ bw, and BDE-209 as 1,700 $\mu \mathrm{g} / \mathrm{kg}$ bw (EFSA Panel on Contaminants in the Food Chain (CONTAM), 2011b). In addition, Bakker et al. (2008) derived an expected human "no adverse effect level" (NAEL) for impaired spermatogenesis. This calculation resulted in a range of 0.23-0.30 ng BDE 99/kg bw/day (Bakker et al., 2008).

\subsubsection{Exposure}

In 2011, the EFSA reported on the exposure of PBDEs in Europe. The results showed that the highest dietary exposure was due to BDE-47 and -209. The estimated mean chronic dietary exposure for average consumers across the dietary surveys in European countries ranged from 0.29 to $1.91 \mathrm{ng} / \mathrm{kg}$ bw per day for BDE-47, and from 0.35 to $2.82 \mathrm{ng} / \mathrm{kg}$ bw per day for BDE-209. In the case of BDE-153 and -154 , the estimates ranged from 0.03 to $0.42 \mathrm{ng} / \mathrm{kg}$ bw per day and from 0.03 to $0.51 \mathrm{ng} / \mathrm{kg} \mathrm{bw}$ per day, respectively (EFSA Panel on Contaminants in the Food Chain (CONTAM), 2011b).

Based on these exposure estimates and the derived $\mathrm{BMDL}_{10}$ values, the EFSA CONTAM panel calculated MOEs for BDE-47, -99, -153, and -209. The Panel concluded that for BDE-47, -153 , and 209 the MOE was unlikely to raise a health concern. Further, the EFSA CONTAM panel concluded that the MOEs for BDE-99 for young children (1-3 years) with average and high exposure were 1.4 and 0.7 , respectively. These MOEs indicate a potential health concern for dietary exposure to BDE-99 in this age group (1-3 years) (EFSA Panel on Contaminants in the Food Chain (CONTAM), 2011b), which may be due to an overestimation of the exposure due to a single high result in food for infants and young children.

A Dutch study on the intake of PBDE-47, -99, -100, and -209 confirmed these findings. The dietary exposure to PDBE-47 and -209 did not pose a human health concern, whereas exposure to PBDE-99 resulted in a MOE for reproductive toxicity (based on the human NAEL of 0.23 reported by Bakker et al. (2008)) below 0.5 for the total population, which differs from the EFSA opinion where a Small MOE was only determined for young children (see above). The main food categories contributing to the intake of the investigated PBDEs were dairy products (31-37\%), pork meat (11-17\%) and oils (615\%) (M. J. Zeilmaker, Bokkers, te Biesebeek, Mengelers, \& Noorlander, 2014).

Currently, there is a reasonable amount of data on the occurrence of PBDEs in poultry products available from the KAP database. Approximately 100 broiler samples have been analyzed between 2009-2014. The levels for BDE -47, -99, -100 , and -153 ranged from $<10-130,<10-142,<10-40$, and $<10-44 \mathrm{pg} / \mathrm{g}$ fat, respectively. For BDE-209 no monitoring data is available yet, due to limitations in the method of analysis. These limitations were solved in 2015. Monitoring of BDE-209 may be increased (because it is regarded an important congener) to obtain more information on the potential risks from this compound related to poultry products. However, a recent assessment of the intake of PBDEs in the Netherlands (P.E. Boon et al., in preparation) showed that that poultry meat contributed to $<5 \%$ of the exposure to the Dutch population. The intake assessment was based on $59 \mathrm{KAP}$ sample results from the period 2011-2013.

\subsubsection{Hexabromocyclododecanes (HBCDDs)}

HBCDDs are stereoisomers of 1,2,5,6,9,10-hexabromocyclododecane. "HBCDDs constitute an important and widely used group of additive flame retardants primarily used in polystyrene applied as construction and packing materials, and also used in textiles." HBCDDs used to be mixed with the polymers, and may thus leach from the product applications into the environment. However, since the 
$21^{\text {st }}$ of August 2015, HBCDDs are included in Annex XIV of REACH ("Authorization List") in Regulation (EC) $1107 / 2009$. This means that HBCDDs can no longer be placed on the market or used by any manufacturer, importer or downstream user unless an authorization has been granted. Granted exemptions concern the use of HBCDD in polystyrene materials in buildings, which may still be a significant application. There are no known natural sources of HBCDDs (EFSA Panel on Contaminants in the Food Chain (CONTAM), 2011a).

\subsubsection{Toxicity}

\subsection{Acute toxicity}

"Acute toxicity from exposure to technical HBCDD is very low, and an $\mathrm{LD}_{50}$ value has not been determined. The oral lethal dose is more than $20 \mathrm{~g} / \mathrm{kg}$ bw in rats and more than $40 \mathrm{~g} / \mathrm{kg}$ bw in mice" (EFSA Panel on Contaminants in the Food Chain (CONTAM), 2011a).

\subsection{Subchronic and chronic toxicity}

"Toxicological studies have been carried out using different experimental designs with single or repeated administration during gestation, postnatally, or in adulthood using HBCDD. Main targets for toxicity were the liver, thyroid hormone homeostasis, and the reproductive, the nervous, and the immune system" (EFSA Panel on Contaminants in the Food Chain (CONTAM), 2011a).

"Available studies indicate that HBCDDs are not genotoxic." "Given the negative results of an 18month study of carcinogenicity in mice, and the fact that HBCDDs are not genotoxic, it was concluded that carcinogenicity is not a critical effect" (EFSA Panel on Contaminants in the Food Chain (CONTAM), 2011a).

"Developmental studies did not demonstrate teratogenicity or fetotoxicity of technical HBCDD in rats. However, in a two-generation reproduction study in rats, an increased pup mortality during lactation was observed" (EFSA Panel on Contaminants in the Food Chain (CONTAM), 2011a).

"Exposure to technical HBCDD during development in rodents affects the nervous system with subsequent behavioral changes. Alterations in the thyroid hormone regulation may play a critical role in the onset of the observed effects. Effects on the immune system (increased immunoglobulin $G$ response) were also observed" (EFSA Panel on Contaminants in the Food Chain (CONTAM), 2011a).

\subsection{Benchmark Dose (BMD)}

"Based on neurodevelopmental effects on behavior in mice, the EFSA CONTAM Panel derived a BMDL 10 value for HBCDDs of $0.93 \mathrm{mg} / \mathrm{kg}$ bw. Because the elimination kinetics for HBCDDs between experimental animals and humans differ, the EFSA CONTAM Panel converted the BMDL ${ }_{10}$ into an estimated chronic human dietary intake associated with the body burden at the $\mathrm{BMDL}_{10}$, as a basis for the risk assessment." The estimated chronic human dietary intake associated with the body burden at the $\mathrm{BMDL}_{10}$ is $0.003 \mathrm{mg} / \mathrm{kg}$ bw per day (EFSA Panel on Contaminants in the Food Chain (CONTAM), 2011a).

\subsubsection{Exposure}

The mean dietary exposure to HBCDDs across dietary surveys in European countries was estimated for children from three to ten years old to range from 0.15 to $1.85 \mathrm{ng} / \mathrm{kg}$ bw per day (EFSA Panel on Contaminants in the Food Chain (CONTAM), 2011a). Total dietary exposure for adults was about half the exposure in children, ranging from 0.09 to $0.99 \mathrm{ng} / \mathrm{kg}$ bw per day. Dietary exposure to HBCDDs decreased with increasing age down to $0.06-0.54 \mathrm{ng} / \mathrm{kg}$ bw per day for elderly from 75 years of age and older (EFSA Panel on Contaminants in the Food Chain (CONTAM), 2011a). Similar exposure patterns across age classes were found for the dietary intake of high consumers (95th percentile). The intake of HBCDDs across dietary surveys in European countries were $0.80-4.46 \mathrm{ng} / \mathrm{kg}$ bw per day for children (3-10 years old), $0.39-2.07 \mathrm{ng} / \mathrm{kg}$ bw per day for adults, and down to $0.27-1.26 \mathrm{ng} / \mathrm{kg}$ bw for the elderly 75 years and older (EFSA Panel on Contaminants in the Food Chain (CONTAM), 2011a).

The EFSA CONTAM Panel used the MOE approach for the risk characterization of HBCDDs. For this, the dietary intake of HBCDDs was compared to the estimated human intake associated with the body 
burden at the $\mathrm{BMDL}_{10}$. A calculated MOE to cover interspecies differences (factor 2.5) and uncertainty in elimination half-life in humans (factor 3.2) were considered; " this implies that an MOE larger than $8(2.5 \times 3.2)$ might indicate that there is no health concern." The maximum dietary intake for average and high adult consumers resulted in an MOE of about 3,000 and 1,450, respectively. For children 3-10 years of age with an average and high consumption, the maximum dietary intake resulted in an MOE of 1,600 and 700, respectively. Overall, then the EFSA CONTAM Panel concluded that current dietary exposure to HBCDD does not raise a health concern (EFSA Panel on Contaminants in the Food Chain (CONTAM), 2011a).

No Dutch national exposure assessments to HBCDDs are available although fish consumption related exposure was estimated to be $8.3 \mathrm{ng} /$ day (van Leeuwen \& de Boer, 2008). Limited data are available from the KAP database, where results of 14 samples were recorded (2009-2014). This shows that only in two samples a detectable level of a-HBCDD was found (0.07-0.09 $\mathrm{ng} / \mathrm{g}$ fat). More generally, if $\mathrm{HBCDD}$ is found in products of animal origin, it concerns mostly a-HBCDD, whereas $\beta-H B C D D$ $\mathrm{Y}$-HBCDD are mostly below detection limits.

\subsection{Possible intervention measures}

This section presents the results for identified intervention measures that can help to prevent or reduce the presence of the most relevant chemical and physical hazards in the poultry meat production chain. First, intervention measures for primary production are presented, and then, processing intervention measures are evaluated.

\subsubsection{Intervention measures at primary production}

The main route for the introduction of chemical hazards during primary production originates from environmental contaminations or the use of agricultural chemicals. Chemical hazards can be introduced into the chain via environmental sources such as soil, air, and water, as well as via feed. Furthermore, the administration of veterinary drugs may result in residues of pharmacologically active substances. (Table 2). Some chemical hazards, like dioxins, DL-PCBs, and NDL-PCBs, deposit in the lipid component of animal-derived foods (e.g., poultry, fish, eggs, meat, and milk). Thus, if these chemicals are present in the feed, they will end up in food derived from animals consuming this feed. In a report from the Food and Agriculture Organization of the United Nations (FAO) and World Health Organization (WHO) (2012), control measures within the food chain for air, soil, and water as well as feed, among others, are recommended at the farm level. These practices are based on GAP, good manufacturing practices (GMP), good storage practices (GSP), and good animal feeding practices (GAFP). GAP is a good practice code developed for the primary producer (farm level). An example of the measures includes the identification and control of contaminated soil in order to prevent possible animal exposure via ingestion of this soil or the plants growing in the soil. In brief, primary production practices in contaminated environments should be restricted (Food and Agriculture Organization of the United Nations (FAO) \& World Health Organization (WHO), 2012). The animal housing system (indoor, free-range, etc.) also influences the type of exposure encountered. Some housing conditions result in higher infection pressures than other; this has an effect on the use of veterinary drugs.

At the global level, GLOBALG.A.P., also known as the Integrated Farm Assurance Standard (IFA), can be used. GLOBALG.A.P consists of requirements on GAPs demanded by European retailers (obligated and recommended). These requirements are mainly focused on food safety and traceability, but also on animal welfare, environment, workers' health, safety, and welfare. GLOBALG.A.P. certification can include Integrated Crop Management (ICM), Integrated Pest Control (IPC), Quality Management System (QMS), and HACCP. ${ }^{12}$

The current quality assurance system for poultry in the Netherlands, entitled "IKB Kip," is used for guaranteeing to consumers that requirements concerning the production, quality, and origin of poultry

12 http://www.globalgap.org/ 
meat are upheld. Since the abolishment of the Dutch Product Boards for Livestock, Meat and Eggs (PVE), which includes the Dutch Product Board for Poultry and Eggs (PPE), on the $1^{\text {st }}$ of January 2015, the IKB Kip program is currently covered by PLUIMNED. ${ }^{13}$ Additionally, the Dutch poultry sector provides extra guarantees for the consistent quality and reliability of its end products. The poultry supply chain also uses obligatory, "food chain information" forms, also known as VKI

(Voedselketeninformatie) forms, to provide information on the health of the animals to be slaughtered (e.g., which veterinary drugs have been used) and about the company from which they originate.

Also, the IKB certification scheme (Annex 12 A.2. Animal Health Situation) outlines some measures, for example, poultry farms must provide detailed information regarding the use of VMP, operational hygiene, feed, and drinking water (Dutch Product Boards for Livestock, Meat and Eggs (PVE) \& Dutch Product Board for Poultry and Eggs (PPE), 2014b). These forms, which are mandatory throughout the EU, need to be filled in by the farmers and handed over to the slaughterhouse. As part of the HACCP system or hygiene codes for the slaughterhouses, these forms are checked (Dutch Product Boards for Livestock, Meat and Eggs (PVE) \& Dutch Product Board for Poultry and Eggs (PPE), 2014e). Within the IKB Kip program, establishments are obliged to comply with statutory regulations concerning prohibited animal proteins and antimicrobial growth promoters in animal feed as noted in the general terms and conditions under Article 12 (Dutch Product Boards for Livestock, Meat and Eggs (PVE) \& Dutch Product Board for Poultry and Eggs (PPE), 2014d).

\subsubsection{Intervention measures for further processing}

Food safety and quality during processing can be secured by implementing basic requirements and a HACCP plan or hygiene codes. Basic requirements are described in good practices, like GMP and GHP. GMP consists of fundamental principles, procedures, and means needed to design the basic environmental and operating conditions for food production (van der Spiegel, 2004). Guidelines for GMP are prescribed on aspects like buildings and facilities, personnel, equipment, production, and process control (United States Food and Drug Administration (FDA), 2014). GHP is a good practice code focused on hygiene with guidelines describing hygienic aspects, like cleaning and disinfection, health and hygiene of personnel, pest control, and training.

The Netherlands IKB Kip program outlines rules at hatcheries, abattoirs (i.e. slaughterhouses), and further processing including general aspects, building and layout, pest control, company hygiene and food safety, records (e.g., received, personal, delivered), quality and traceability, supply, transport, business operations, as well as animal performance and health (Dutch Product Boards for Livestock, Meat and Eggs (PVE) \& Dutch Product Board for Poultry and Eggs (PPE), 2014a). Also, specific hygiene codes for processing at poultry slaughterhouses and cutting plants have been established in close consultation with the Dutch Association of Poultry Processing Industry (NEPLUVI) and the NVWA. These codes can help companies to meet their HACCP requirements (Dutch Product Boards for Livestock, Meat and Eggs (PVE) \& Dutch Product Board for Poultry and Eggs (PPE), 2014c).

In general, chemical hazards can be prevented by a good quality control of raw materials entering the production process, following procedures from suppliers and properly performing processing to prevent process contaminants, which is all part of HACCP. Physical hazards can be prevented by good maintenance of the equipment and by applying visual inspections. For example, foreign particles and objects in raw materials and packaging materials, cleaning compounds, etc. should be included in a supplier's HACCP plan as a preventative measure (United States Department of Agriculture (USDA), 1997). Since bones are a recurring physical hazard, newer monitoring techniques to improve the deboning process including specialized illuminated cone and target software algorithms can help to prevent bone pieces from occurring in the final product.

13 https://pluimned.avined.nl/ 


\subsection{Trends in the poultry meat chain}

This section evaluates the trends in developments within the poultry meat chain up to 2025 that may influence the presence of food and feed safety hazards especially those related to the main chemical and physical hazards identified in this research.

\subsubsection{Broiler farms}

Figure 5 depicts the development in the number of broiler farms, the number of broilers, and the average number of broilers per farm from 2000-2014. The figure illustrates that the number of broiler farms has clearly decreased in the last 10 years, while simultaneously the average farm size has increased. In 2004, there were 771 broiler farms with an average size of 57,409 broilers. As of 2014, there were 576 broiler farms with an average size of 81,632 broilers (Landbouw-Economisch Institut (LEI), 2015). The total number of broilers has slightly increased between 2004 and 2014 from 44 to 47 million. This Figure clearly indicates the shift towards fewer farms with larger flocks. The trend for larger farms is expected to continue in the coming years (van der Meulen et al., 2010). With manual labor becoming continuously more mechanized and automated, management tasks are expected to take up a larger part of the working time, and thus, are a driving force for increased farm size. On the other hand, farmers can outsource part of the work and further specialize in broiler production (Backus et al., 2009). By 2020, the family farm will become less dominant and be partly replaced by the family plus farm, in which the entrepreneurs of the family farm work with one or two employees.

Number of farms, animals and animals per farm Broilers

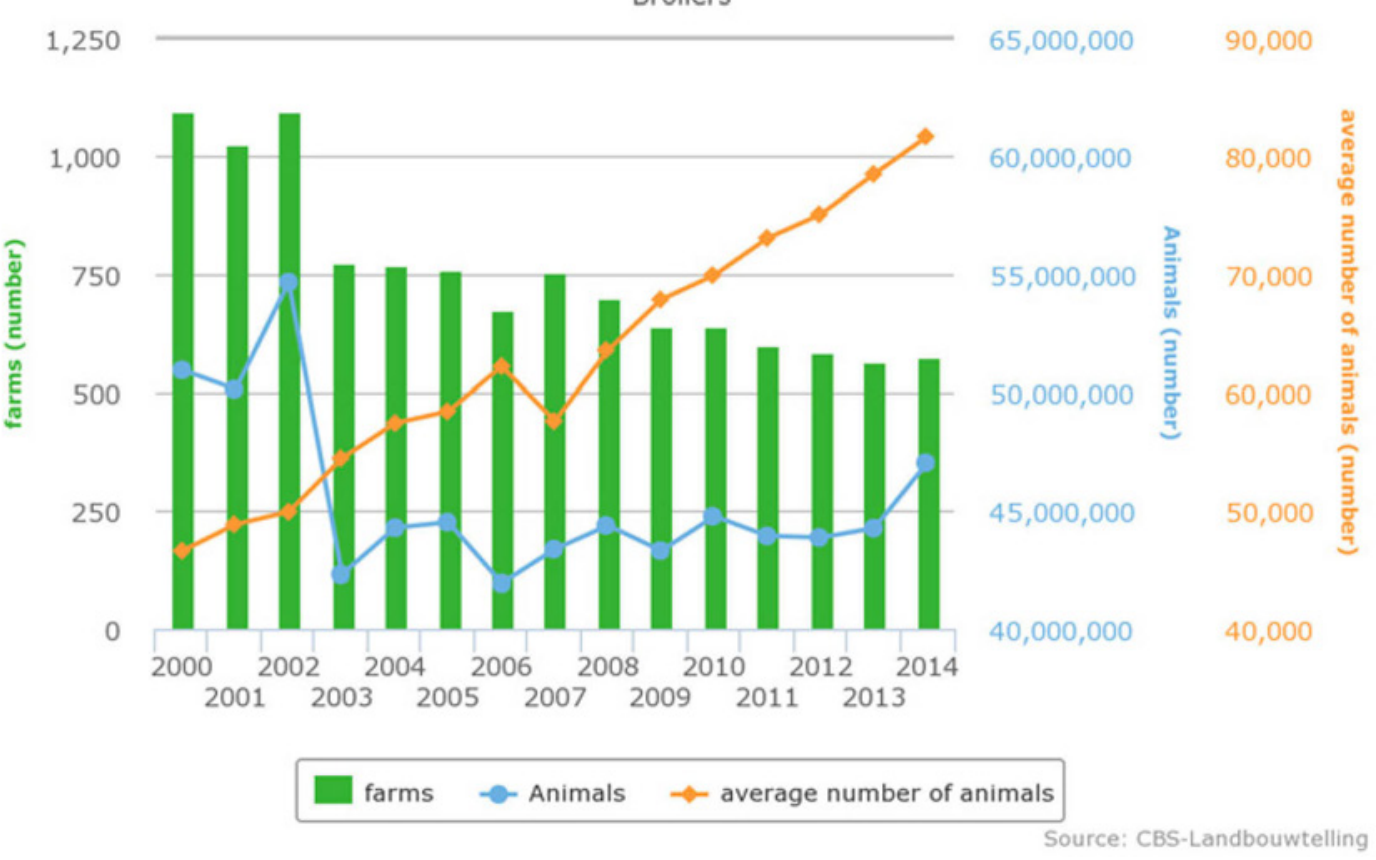

Figure 5 Relationship between the number of broiler farms, the number of broilers, and the average number of broilers per farm from 2000-2014.

\subsubsection{Production, Trade, and Consumption}

In 2013, the total production of broiler meat in Dutch slaughterhouses was 867,000 tons (slaughtered weight) (Dutch Product Board for Poultry and Eggs (PPE), 2014). Figure 6 depicts the development of production since 1995. From this figure, it is clear that Dutch production increases continuously. As a result of the bird flu outbreak in 2003, the production in the following years was lower, but since 2008 the production has increased annually (van Horne, 2013). Although the Netherlands has a system of 
quota on poultry production, the number of broilers slaughtered in Dutch slaughterhouses has increased due to the increase in imports of live broilers. In the coming years, production will further increase, mainly with respect to imported live broilers from Germany.

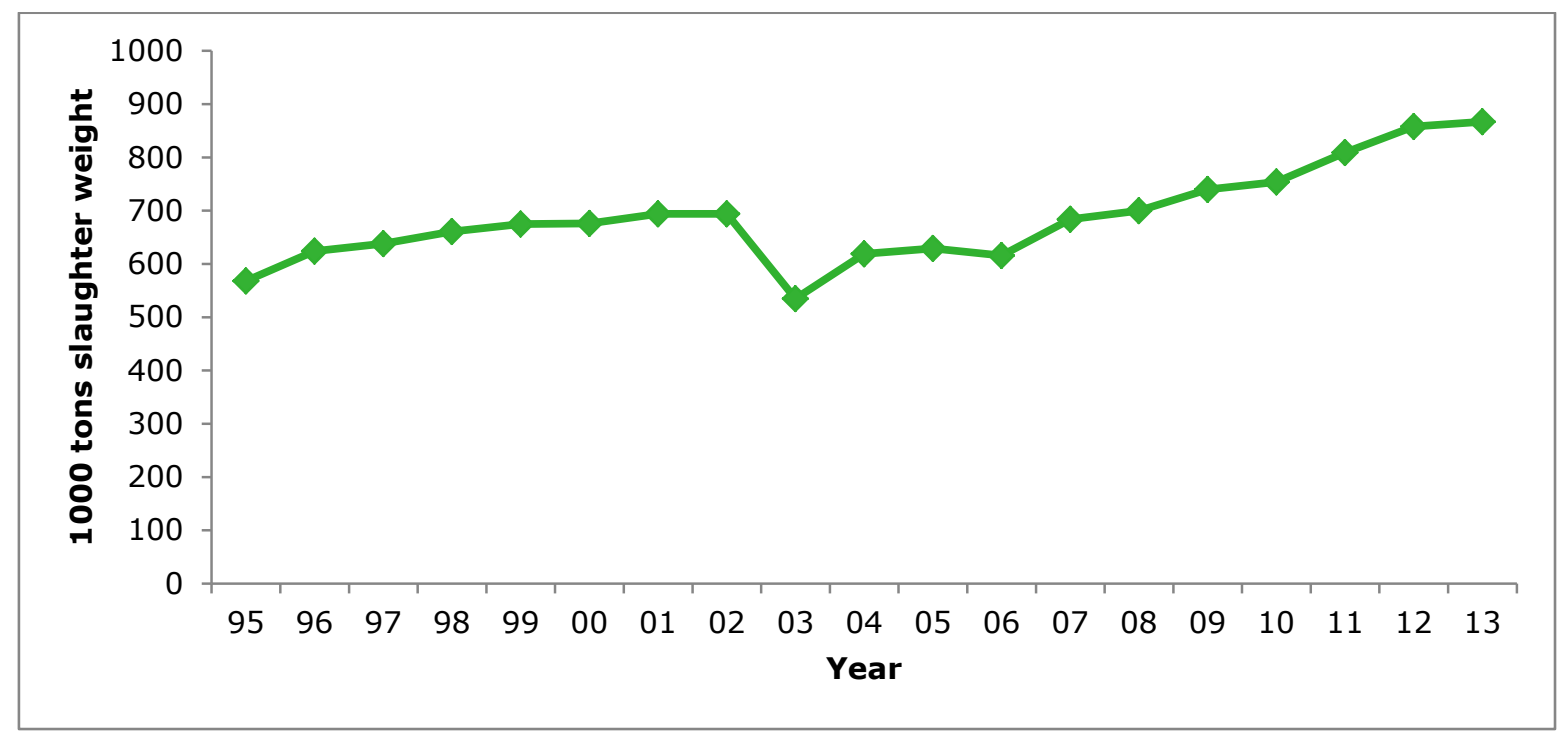

Figure 6 Production of broiler meat slaughtered in the Netherlands from 1995-2013.

After 2000, there was a significant increase in the import of (frozen) poultry meat from third countries outside the EU. In 2004, the total import of chicken breast for the EU was 300,000 tons. In 2007, the amount had increased to almost 600,000 tons. The import concerned salted, cooked, and frozen chicken breast. In 2007, the EU took measures to prevent a further increase. A system of quotas and import duties were enforced. Since then, imports from third countries stabilized at 550,000 tons (van Horne \& Bondt, 2014). The EU is negotiating with other third countries about liberalizing trade in agricultural products. These agreements are meant to create free trade, with or without reduced import duties. In a scenario with low import duties, third countries would have a lower price for chicken breast. In this situation, the import of poultry meat from third countries like Ukraine, Brazil, and Thailand could increase, while the position of the EU poultry meat sector would further weaken (van Horne \& Bondt, 2014). Ultimately, the poultry meat chain is expected to increase globally, which will result in a more complex production chain. This may hamper the transparency and control within the poultry production chain.

In November 2014, Germany, the Netherlands, and the United Kingdom had identified outbreaks of highly pathogenic avian influenza (H5N8) at several poultry farms (World Health Organization (WHO), 2014b). Although the potential risk for the general public was considered extremely low, as no cases of H5N8 infection in humans are known, national authorities had taken precautionary measures as other avian influenza viruses can infect humans and H5 viruses (e.g., H5N1) have previously affected humans (World Health Organization (WHO), 2014b). Due to these outbreaks and the unfulfilled declarations on health certificates, exports were restricted to most member states and third countries, while only a few banned Dutch poultry including Hong Kong, South Korea, Ukraine, and South Africa. As a result, the Dutch poultry sector was estimated to lose between \$100-200 million in meat exports (Flach, 2014). Provided favorable feed prices and availability, which can be influenced by external factors like climate change, and given that avian influenza outbreaks are kept under control, EU production is forecasted to reach 13.5 million tons by 2016 (Table 7) (European Union (EU), 2015). Thus, shifts in the global economy affect the Dutch production of poultry meat, international trade, and subsequently consumer consumption. 
Table 7 EU-28 poultry meat market balance ('000 tons slaughter (carcass) weight equivalent), as reported by the European Commission (European Union (EU), 2015). ${ }^{14}$

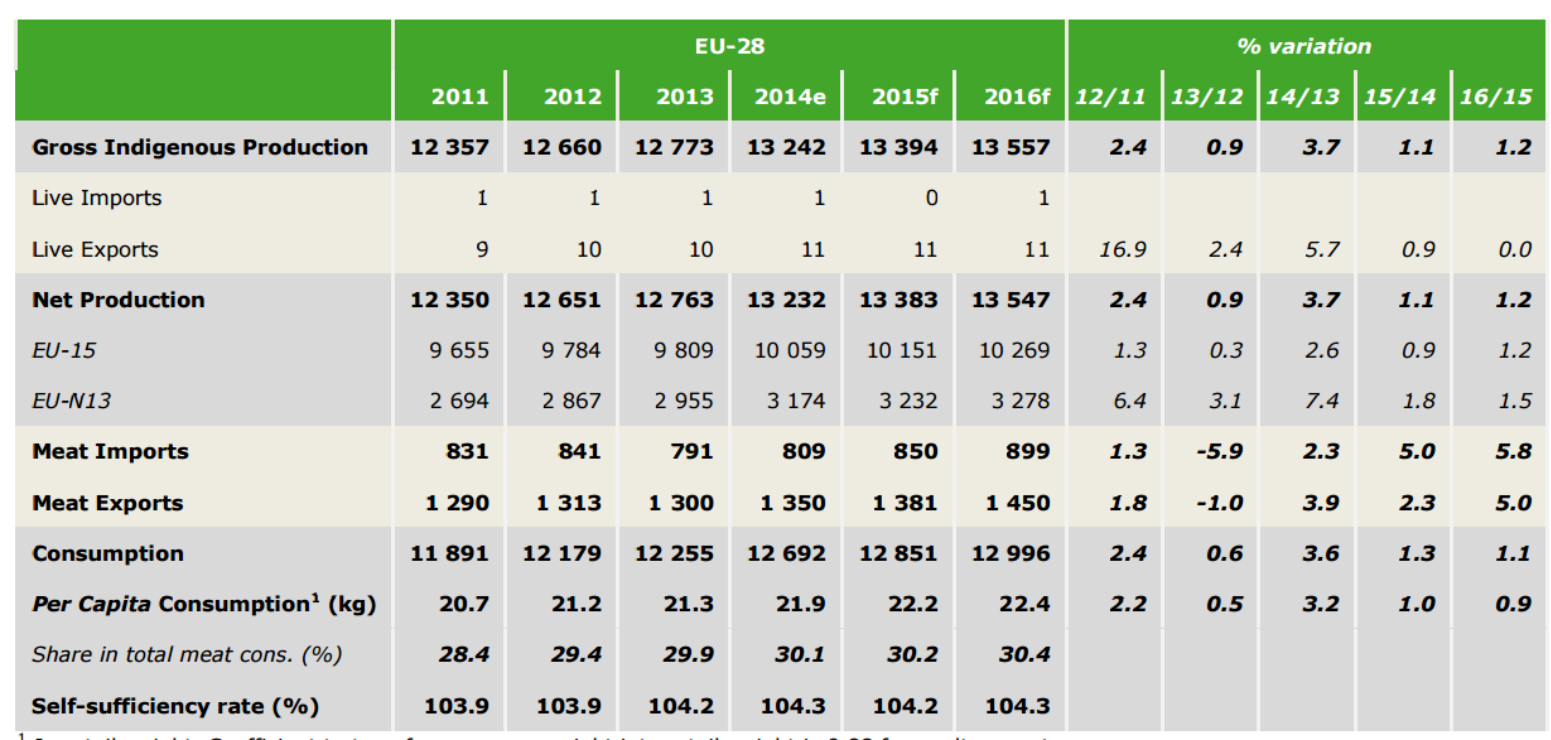

${ }^{1}$ In retail weight. Coefficient to transform carcass weight into retail weight is 0.88 for poultry meat.

In 2013, the consumption of broiler meat in the Netherlands was $18.5 \mathrm{~kg}$ per capita. The total consumption of poultry meat (including other sources like turkey and duck) was $22.5 \mathrm{~kg}$ per capita (Dutch Product Board for Poultry and Eggs (PPE), 2014). Figure 7 depicts the development of broiler meat consumption since 1995. In 1995, consumption was around $15 \mathrm{~kg}$ per capita and in 2013 consumption was more than $18 \mathrm{~kg}$ per capita. From 2009, there was a decrease in the consumption. This trend leveled off in the past few years but is expected to increase in the coming years slightly. Dutch consumption is equal to the EU-28 average, but in comparison with, for example, the United Kingdom (22.5 kg per capita in 2013) the consumption is low (MEG Marktinfo Eier \& Geflügel, 2014). However, chicken, in comparison to other types of meat, is relatively cheap and has a healthy image. Furthermore, changes in food processing technologies (e.g., ready-to-eat meals, packaging with sensors) and consumer demands for healthier products (e.g., with less salt, sugar, and fat) alongside increased demands for animal-friendly products will affect consumption.

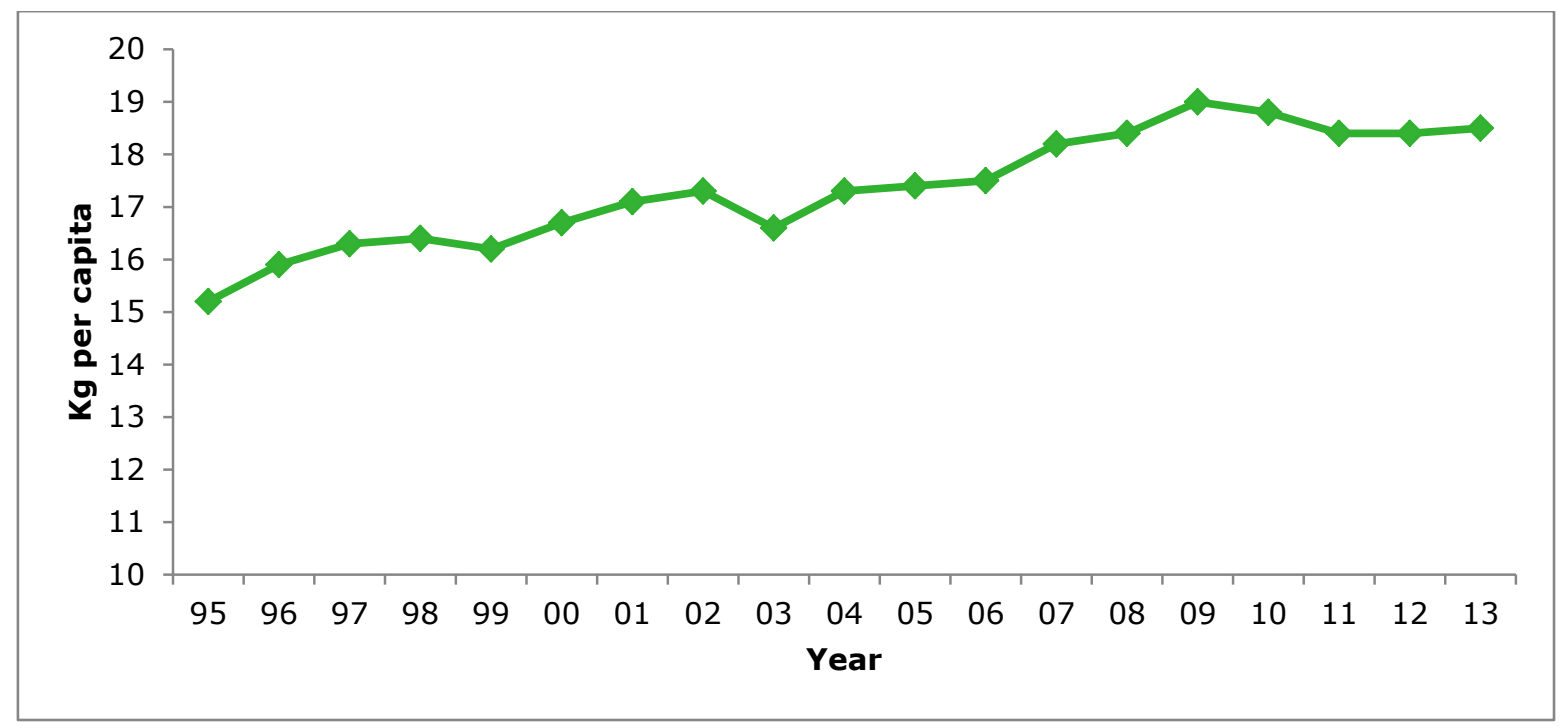

Figure 7 Development in the consumption of broiler meat in the Netherlands from 1995-2013.

\footnotetext{
${ }^{14}$ EU-28 includes EU-15 plus EU-N13, i.e. the European Union since 2013. EU-15 includes EU member states in 2003: Belgium, Denmark, Germany, Ireland, Greece, Spain, France, Italy, Luxembourg, the Netherlands, Austria, Portugal, Finland, Sweden and the United Kingdom, while EU-N13 includes EU-N12 plus Croatia, which joined the EU on the $1^{\text {st }}$ of July 2013.
} 
An important, recent development in the poultry sector is the rise of production systems in between conventional and organic production. Besides conventional or regular ("gangbaar") and organic ("biologisch") broiler meat, a specific type of animal-friendly broiler meat, which has had a better standard of living, is available in the majority of Dutch supermarkets. A group of broiler farmers produces broiler meat according to the rules of the Better Life standards ( 1 star) with a lower growth level (slow growing breed), more space, daylight, and access to covered outdoor areas. In the last few years, production has increased rapidly from 4 million in 2010 to 14 million slaughters in 2013. This development can also be seen in sales. In 2013, the share of animal-friendly broiler meat was $9 \%$ of the total revenue from poultry in supermarkets, butchers, and at the wholesale (Ministerie van Economische Zaken (EZ), 2014). Figure 8 shows the development of spending in organic and animalfriendly broiler meat from 2007 until 2013.

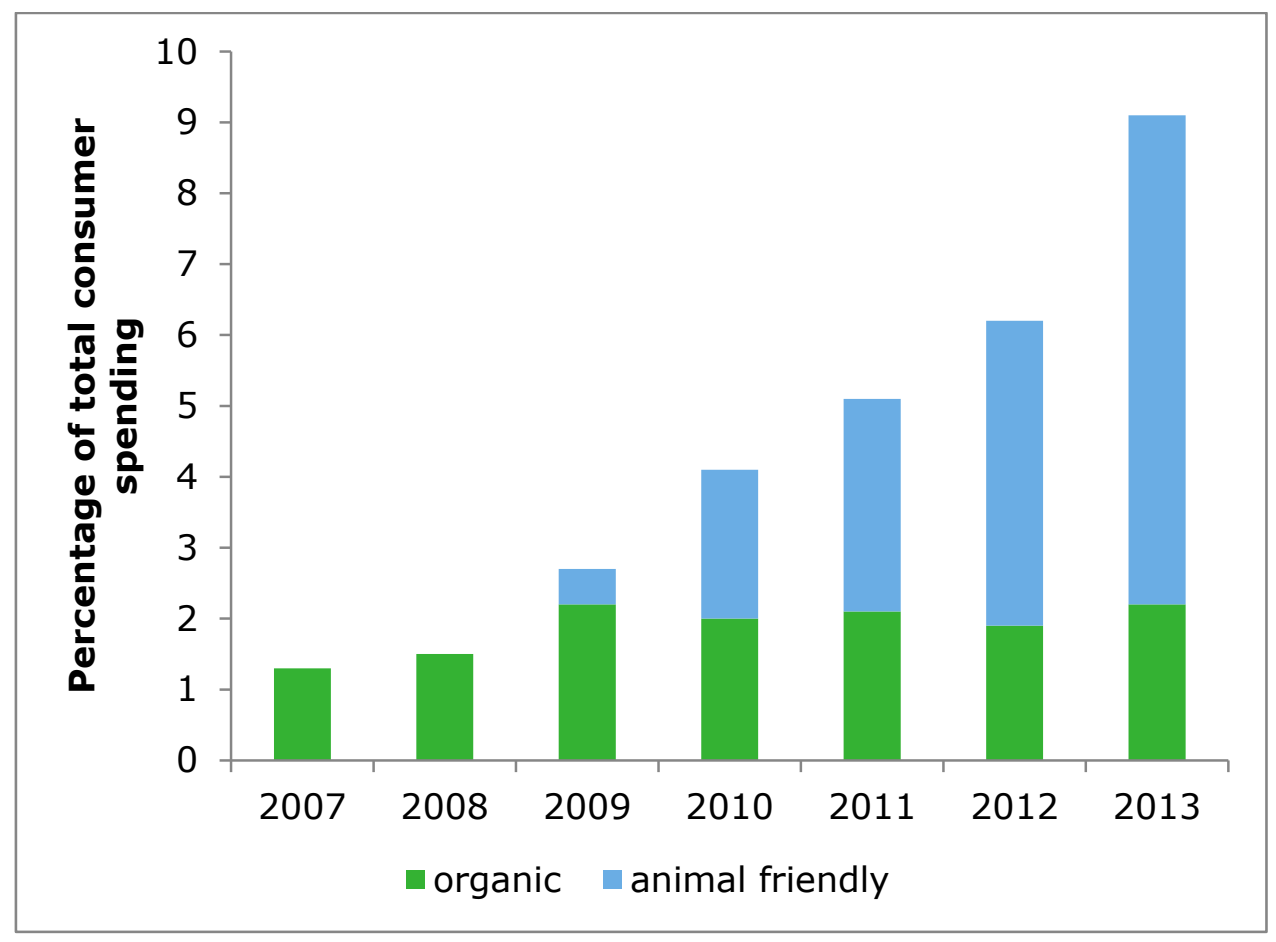

Figure 8 Development of spending on organic and animal-friendly broiler meat in the Netherlands from 2007-2013.

Besides the production according to the Better Life standards, increasingly more retailers sell broiler meat produced accordingly to the specification Chicken of Tomorrow (COT), which is based on slow growing breeds, or comparable concepts. Some well-known examples are "de Hollandse kip" (the Dutch chicken) from Albert Heijn and the "Nieuwe Standaard Kip" (New Standard Chicken) from Jumbo. These supermarkets are taking the lead in replacing standard broiler meat with CoT or comparable alternatives. In short, slow-growing breeds will replace $30-40 \%$ of the Dutch broiler production, while the remaining production will be based on fast growing breeds whose meat will go to food industry or be exported. A shift towards slow-growing broilers for the Dutch consumer will have some consequences for the farms, such as decreased revenue due to diminished annual production, and on animal health, such as increased exposure to some hazards.

\subsubsection{Consequences for hazards}

The most important developments and trends in the poultry meat chain concern a reduction in the number of broiler farms, an increase in production, and an increased demand for "animal-friendly" broiler meat.

With a reduced number of broiler farms, and consequently a larger farm flock size, GAP among other good practices is critical in maintaining the safety and quality standards at the farm. However, the expenses accrued from raising more livestock, most likely over longer periods to coincide with the 
animal-friendly practices, may become financially burdensome. For example, in order to cope with the rising flock numbers, farmers may turn to alternative feeding practices such as using their own feed sources, purchasing larger quantities (which need to be stored properly), as well as mixing these, or utilizing alternative proteins sources like insects or algae. However, the use of alternative sources of protein, like insects, remains unclear in terms of the effects on food and feed safety including the potential transfer of chemical contaminants.

An increase in broiler production will also affect the slaughterhouses meaning increased automatization of the processing line will become critical in order to maintain or even increase profits. The potential for physical hazards such as bones or feathers may increase, while the quality of inspection may consequently decrease due to the influx of production. Other hazards that can occur during processing (Table 2) are also potentially affected. Thus, HACCP and hygiene codes are important to uphold. Additionally, trade can affect production size. Pending EU trade negotiations, the import and export rate of broilers in the Netherlands may be hampered. Globalization of food and feed supply chains, like the poultry meat chain, is inevitable; nevertheless, transparency and control cannot be questioned, and thus, monitoring the entire chain is crucial.

The increase in animal-friendly poultry may have an effect on the chemical hazards encountered. Although there are differences in the nutritional composition of conventional, free-range and organic chicken, the fat content of raw chicken breast and chicken thighs is not significantly different (Husak, Sebranek, \& Bregendahl, 2008). However, outdoor access and a longer life span may influence the presence of chemical hazards in more animal-friendly poultry. Consumer demands for animal-friendly practices are a trend that has resulted in several alternative housing strategies for poultry. Although animal welfare practices are important to respect, the effects of slower growing breeds and outdoor or free-range broilers on human health is also important to consider. When broilers can roam outdoors, they may encounter environmental contaminants, such as heavy metals and dioxins. For example, free-range eggs have generally shown higher levels of dioxins than conventional eggs (Kan, 2005), in recent years however poultry farmers have taken measures to prevent exposure (Adamse et al. 2015). In a report from the Livestock Research - Wageningen UR (Ellen et al., 2012), different broiler farming systems were compared. This report indicated that a longer stay at the farm, in general, would lead to a higher prevalence of Campylobacter in broilers. Similarly, this trend can be expected for chemical hazards especially those hazards that are known to accumulate. For example, slower growing breeds that have longer life expectancies will have a longer exposure to potential hazards. Accumulation of hazards, especially those like dioxins, DL-PCBs, and NLD-PCBs, is a relevant aspect when determining the potential exposure to a hazard. Current practices appear to shown no indications of concern since access to the outdoor environment is limited, yet if broilers are kept on contaminated soil, e.g., with dioxins, or if the outdoor exposure is increased, then problems cannot be excluded. Similarly, this might be true when using contaminated coverage for the floor (e.g., wood), which might result in an option during alternative housing strategies, but is also related to farm management practices. On an optimistic note, Ellen et al. (2012) found that there is a difference in the antibiotic use between the different broiler housing systems with alternative systems (organic and animal-friendly) reported as using fewer antibiotics. 


\section{$4 \quad$ Conclusions and recommendations}

\subsection{Conclusions}

Due to the complex structure of the Dutch poultry meat chain, there are various points at which chemical and physical hazards may be introduced, at primary production and further processing, including processing, manufacturing, retail, and the consumer (Fig. 9). This section describes the conclusions regarding the chemical and physical hazards that may be encountered from "farm to fork" in the poultry meat chain.

Based on literature review, alerting and monitoring data, and expert input, the following chemical hazards may be introduced during poultry production and result in contamination with hazardous chemicals of poultry products in the Netherlands: dioxins and DL-PCBs and prohibited antibiotics (chloramphenicol (CAP), nitrofurans and nitroimidazoles). To a lesser extent, NDL-PCBs and emerging contaminants like brominated flame retardants (BFRs) were considered relevant, but more data on the latter group of compounds should be collected. For products imported from outside the EU, the possible presence of residues of authorized and prohibited VMPs is also considered relevant. In brief, an overview of these most relevant chemicals is described below. The most relevant physical hazards that may occur during processing are the presence of feathers and bone pieces. Poultry processors control this hazard with the use of HACCP plans or hygiene codes, equipment maintenance, and visual inspections.

Dioxins and DL-PCBs are reported to accumulate in food-producing animals upon consumption of contaminated feed. Dutch monitoring data from 2001-2011 showed that dioxins and DL-PCBs were below the EC action and maximum levels. Dioxins, DL-PCBs, and NDL-PCBs are known to occur in food products containing animal fat (milk, eggs, meat, and fish), and consumers are exposed to these products almost daily. Although exposure in the Netherlands appears to be well below the current TWI, the margin of exposure for these compounds is relatively small. In addition, the EU aims at lower maximum levels for food and feed. For NDL-PCBs, EFSA was unable to derive a health-based guidance value, but the EU set MLs for these compounds as well. Therefore, accurate and reliable monitoring of these dioxins, DL-PCBs, as well as NDL-PCBs in relevant feed and food, like poultry meat, fat, and liver, remains critical.

The use of chloramphenicol, nitrofurans, and nitroimidazoles in food-producing animals is not allowed, and reference points of actions were derived from these compounds, as well as their metabolites. A number of these compounds were shown to cause aplastic anemia or should be considered as genotoxic carcinogens. Hence, the Codex Alimentarius Commission instructs authorities to prevent their occurrence in food by banning their use in food producing animals. However, CAP can originate from other (environmental) sources, e.g., microorganisms naturally present in the soil, and via these routes, CAP residues may transfer to animal feed that is later used for food-producing animals. Nitrofurans have been widely used and are amongst the most important antibiotics to monitor, both in poultry products produced in the Netherlands as well as from outside the EU. Nitroimidazoles are sometimes still illegally used in animal husbandry, as they are effective growth promoters in meat production and feed conversion, and hence, monitoring is critical. Even more, since 5-nitroimidazoles can metabolize rapidly with resulting metabolites exhibiting similar mutagenic potential as the parent compound; sensitive monitoring for the detection and control of nitroimidazoles and their metabolites is warranted. Veterinary drugs were frequently reported in poultry meat in the RASFF database between 2009 - 2014. Of all RASFF notifications for chemical and physical hazards in the category poultry and poultry meat products $(n=127), 63 \%$ were related to VMPs, of which the majority were prohibited or unauthorized.

Brominated flame retardants, such as polybrominated diphenyl ethers (PBDEs) and hexabromocyclododecanes (HBCDDs), can also accumulate in food-producing animals. PBDEs are 
ubiquitously present in the environment and can subsequently accumulate in food and feed. The EFSA calculated the Margin of Exposure (MOE) of several PBDEs and found that only the dietary intake of PBDE-99 in young children (1-3 years) may be a human health concern. However, poultry meat was not one of the main contributing food products.

HBCDDs may also leach into the environment from sources like construction, packing materials, and textiles. There are currently no maximum levels (MLs) set for HBCDDs in food or feed within EU legislation, but HBCDDs have been detected in food products, with the highest reported values in eggs and egg products, followed by fish and other seafood, and milk and dairy products (EFSA Panel on Contaminants in the Food Chain (CONTAM), 2011a). Based on the MOE, the EFSA CONTAM Panel concluded that current dietary exposure to HBCDD does not raise a health concern (EFSA Panel on Contaminants in the Food Chain (CONTAM), 2011a). Currently, there are limited data on the occurrence of brominated flame retardants in poultry products. Monitoring of these compounds should be increased, and analytical methods should be refined to obtain more information on the potential presence of these compounds in poultry products. The same is true for perfluoralkylated substances and plant toxins.

Chemical hazards can be introduced at the farm either via the feed, or other environmental sources (soil, building materials, litter) or administered to poultry in the form of veterinary drugs or as feed additives. Good farm management is therefore important. For this purpose, quality assurance schemes have been developed, such as GLOBALG.A.P., describing Good Agricultural Practices (GAPs). In the Netherlands, farmers can be certified to IKB Kip covered by PLUIMNED. This system describes various criteria in order to produce safe poultry meat of good quality. Furthermore, the Dutch poultry sector provides extra guarantees for the consistent quality and reliability of its end products and makes use of VKIs (food chain information) forms. Such quality assurance systems also have to meet future developments and trends as described below.

The most relevant trends in the poultry (meat) chain for the coming decade are a reduction in the number of broiler farms, an increase in production, and an increased demand for animal-friendly broiler meat. With these developments, management tasks at the farm will increase for farmers, and hence, the adherence to quality assurance schemes remains crucial in preventing further agricultural contaminations. The increase in sustainable or animal-friendly poultry may have an effect on the chemical hazards encountered. When chickens roam outdoors, they may come in contact with environmental contaminants, such as heavy metals, dioxins, and DL-PCBs. Currently, almost all broilers are kept indoors or have access to a covered outdoor area with a fixed floor, thereby limiting access to the outdoor environment. Additionally, retail standards (Better Life, CoT, etc.) will affect Dutch production with a shift towards slow-growing breeds, which also has consequences for farms and animal health. Climate change is another trend that may affect food safety as higher levels of, for instance, mycotoxins are expected in feed materials. Climate change may also have an impact on plant and animal diseases, and subsequently, on the use of pesticides, antibiotics, and even alternative medicines or herbal uses ( a potential hazard for plant toxins) as treatments. Furthermore, globalization may hamper transparency (e.g., of transport conditions) in the already complex poultry chain. EU negotiations with third countries on liberalizing trade in agriculture products could create unforeseen safety and quality issues as a result of the variation in potential hazards between domestic and imported poultry chains as well as an economically weaker EU poultry meat sector. 


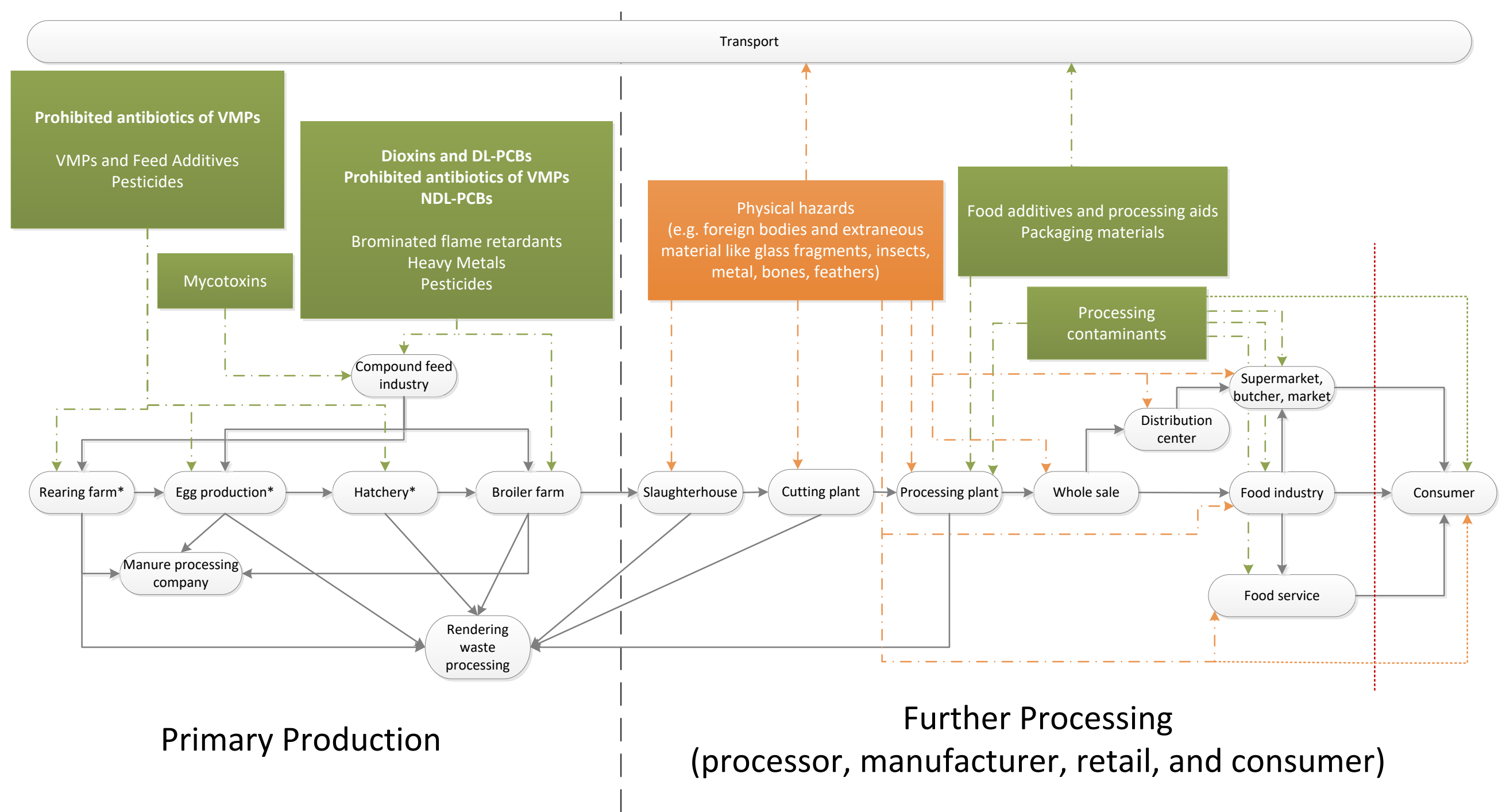

Figure 9 Overview of the chemical (green) and physical (orange) hazards that may be introduced into the poultry chain. The main hazards are bolded. * The first three steps are representative for great-grandparent, grandparent, and parent farms. 


\subsection{Recommendations}

In this research, potential chemical and physical hazards in the poultry meat chain were investigated. The main focus concerned chicken, as most information was available for broilers, although turkey, duck, quail, guinea fowl, pheasant, among other game birds, were considered when literature or data were available. It is recommended to allocate budget to perform a survey on chemical hazards associated with other poultry types (although volumes for these meat sources are only a fraction of the total volumes of broiler meat produced in the Netherlands). Also, research should be performed on the indicated data gaps, such as on the possible presence of processing contaminants and packaging migration contaminants in poultry (meat) products.

Based on the current analysis of the poultry meat production chain in the Netherlands, the main hazards were considered to be:

- Dioxins and DL-PCBs, and to lesser extent NDL-PCBs, in feed and/or poultry products (meat, fat, and liver) and through imported feed and meat products;

- Residues of prohibited and unauthorized veterinary drugs in poultry from primary production;

- (Residues of) prohibited and authorized veterinary drugs in imported feed and meat products from outside the EU.

The major chemical hazards in the poultry meat chain are introduced during primary production - on the farm or via the feed. Currently, there is a lack of data on the potential presence of several contaminants that seem to be important for poultry meat, including brominated flame retardants, and more of such data should be collected. Although considered of lesser importance for poultry meat products, more data should also be collected for plant toxins and perfluoralkylated substances (PFASs) to validate this. Current trade initiatives may impact import supplies of feed and poultry products (live and slaughtered meat). Hence, in addition to the domestic poultry meat production (farm and feed plants), monitoring should also be specified for imports of feed and poultry products. Products from countries outside the EU may need to be increased monitoring, especially for VMPs and feed additives, as these have been reported above the legal or authorized limit in the RASFF database. Additionally, the other steps in the chain should be taken into account, and some level of inspection should be arranged at these later stages in the chain. In order to maintain current food safety in the poultry meat sector, development towards future trends that may affect food safety (mainly globalization of agriculture supply chains, effects of climate change, alternative methods for animal husbandry, and production) should continuously be investigated. 


\section{Acknowledgements}

The authors acknowledge Gerrit Wolterink (RIVM) and Marco Zeilmaker (RIVM) for their suggestions to section 3.2 as well as Paulien Adamse (RIKILT Wageningen Research) and Gerda van Donkersgoed (RIVM) for providing KAP data. The contributions from Ferry Leenstra (Wageningen Livestock Research), Ron Hoogenboom (RIKILT Wageningen Research), Mariël Pikkemaat (RIKILT Wageningen Research), and Marca Schrap (NVWA) to the report are acknowledged. The financial contribution of the NVWA was highly appreciated. 


\section{$6 \quad$ References}

Aaslyng, M. D., Duedahl-Olesen, L., Jensen, K., \& Meinert, L. (2013). Content of heterocyclic amines and polycyclic aromatic hydrocarbons in pork, beef and chicken barbecued at home by Danish consumers. Meat Science, 93(1), 85-91. http://dx.doi.org/10.1016/j.meatsci.2012.08.004.

Adamse P, Van der Fels-Klerx HJ, Schoss S, De Jong J, Hoogenboom LAP. 2015. Concentrations of dioxins and dioxin-like PCBs in feed materials in the Netherlands in the period 2001-2011. Food Additives and Contaminants $A$ 32: 1301-1311.

Aliments, A. F. d. S. S. d. (2009). Évaluation des risques liés à la présence de mycotoxines dans les chaînes alimentaires humaine et animale: rapport final: Agence française de sécurité sanitaire des aliments.

Andrée, S., Jira, W., Schwind, K. H., Wagner, H., \& Schwägele, F. (2010). Chemical safety of meat and meat products. Meat Science, 86(1), 38-48. http://dx.doi.org/10.1016/j.meatsci. 2010.04.020.

Arana, A., Hauser, B., Hachimi-Idrissi, S., \& Vandenplas, Y. (2001). Management of ingested foreign bodies in childhood and review of the literature. European Journal of Pediatrics, 160(8), 468-472. http://dx.doi.org/10.1007/s004310100788.

Backus, G. B. C., Baltussen, W. H. M., van Galen, M. A., van der Meulen, H. A. B., \& Poppe, K. J. (2009). Voorbij het gezinsbedrijf? Organisatie van het agrarisch bedrijf, nu en in de toekomst. Den Haag: LEI Wageningen UR.

Bakker, M. I., de Winter-Sorkina, R., de Mul, A., Boon, P. E., van Donkersgoed, G., van Klaveren, J. D., Baumann, B. A., Hijman, W. C., van Leeuwen, S. P. J., de Boer, J., \& Zeilmaker, M. J. (2008). Dietary intake and risk evaluation of polybrominated diphenyl ethers in the Netherlands. Molecular Nutrition \& Food Research, 52(2), 204-216. http://dx.doi.org/10.1002/mnfr.200700112.

Barbut, S. (2014). Review: Automation and meat quality-global challenges. Meat Science, 96(1), 335345. http://dx.doi.org/10.1016/j.meatsci.2013.07.002.

Berendsen, B., Pikkemaat, M., Romkens, P., Wegh, R., van Sisseren, M., Stolker, L., \& Nielen, M. (2013). Occurrence of chloramphenicol in crops through natural production by bacteria in soil. Journal of Agricultural and Food Chemistry, 61(17), 4004-4010. http://dx.doi.org/10.1021/Jf400570c.

Berendsen, B. J. A., Zuidema, T., \& de Jong, J. (2015). The natural occurrence of chloramphenicol in crops. Wageningen: RIKILT Wageningen UR.

Bhunia, K., Sablani, S. S., Tang, J., \& Rasco, B. (2013). Migration of Chemical Compounds from Packaging Polymers during Microwave, Conventional Heat Treatment, and Storage. Comprehensive Reviews in Food Science and Food Safety, 12(5), 523-545. http://dx.doi.org/10.1111/1541-4337.12028.

Bomfim, M. V. J., Zamith, H. P. S., \& Abrantes, S. M. P. (2011). Migration of $\varepsilon$-caprolactam residues in packaging intended for contact with fatty foods. Food Control, 22(5), 681-684. http://dx.doi.org/10.1016/j.foodcont.2010.09.017.

Boon, P. E., te Biesebeek, J. D., de Wit-Bos, L., \& van Donkersgoed, G. (2014). Dietary exposure to dioxins in the Netherlands. Bilthoven, the Netherlands: National Institute of Public Health and the Environment (RIVM).

Boon, P. E., te Biesebeek, J. D., van Donkersgoed, G., van Leeuwen, S., Hoogenboom, L. A. P., \& Zeilmaker, M. J. (in preparation). Dietary exposure to polybrominated diphenyl ethers in the Netherlands. In. Bilthoven, the Netherlands: National Institute of Public Health and the Environment (RIVM).

Bouhet, S., \& Oswald, I. P. (2007). The intestine as a possible target for fumonisin toxicity. Mol Nutr Food Res, 51(8), 925-931. http://dx.doi.org/10.1002/mnfr.200600266.

Bradley, E. L., \& Castle, L. (2009). Residues of Food Contract Materials. In L. M. Nollet \& F. Toldrá (Eds.), Handbook of processed meats and poultry analysis (pp. 619-634): CRC Press.

Cannavan, A., \& Elliott, C. (2004). The implementation of veterinary drug residues monitoring programmes in developing countries. In Conference on Residues of Veterinary Drugs in Food. Proceedings of the Euroresidue V Conference (pp. 151-158). 
Cavret, S., \& Lecoeur, S. (2006). Fusariotoxin transfer in animal. Food Chem Toxicol, 44(3), 444-453. http://dx.doi.org/10.1016/j.fct.2005.08.021.

Codex Alimentarius Commission. (2013). Report of the twenty-first session of the Codex Committee on residues of veterinary drugs in foods.

Codex Alimentarius Commission. (2014). Maximum residue limits (MRLs) and risk management recommendations (RMRs) for residues of a veterinary drugs in foods. Available from:

Daley, W. D. R., \& Stewart, J. (2009). Proactive detection of bones in poultry processing. In Sensing for Agriculture and Food Quality and Safety (Vol. 7315). Orlando, FL.

de Jong, J., Kleter, G., van Raamsdonk, L., Hoogenboom, R., van der Fels-Klerx, H. J., Banach, J., de Nijs, M., Kok, E., Slot, M., Bouwmeester, H., \& Noordam, M. (2015). Hazards associated with animal feed - a review: RIKILT Wageningen UR.

de Vos, R. H., van Dokkum, W., Schouten, A., \& de Jong-Berkhout, P. (1990). Polycyclic aromatic hydrocarbons in Dutch total diet samples (1984-1986). Food Chem Toxicol, 28(4), 263-268.

de Winter-Sorkina, R., Bakker, M., Van Donkersgoed, G., \& Van Klaveren, J. (2003). Dietary intake of brominated flame retardants by the Dutch population. In RIVM rapport 310305001.

Domingo, J. L., \& Nadal, M. (2015). Human dietary exposure to polycyclic aromatic hydrocarbons: A review of the scientific literature. Food Chem Toxicol, 86, 144-153. http://dx.doi.org/10.1016/j.fct.2015.10.002.

Dutch Product Board for Poultry and Eggs (PPE). (2013). PPE statistisch jaarrapport pluimveevlees en eieren 2012 voorlopig. Zoetermeer.

Dutch Product Board for Poultry and Eggs (PPE). (2014). Voorlopige jaarcijfers 2013 pluimveevleessector.

http://www.pve.nl/wdocs/dbedrijfsnet/up1/ZicydiaJO_vjc_2013_versie_pluimveevlees_en_eieren. pdf Accessed November 11, 2015.

Dutch Product Board for Poultry and Eggs (PPE), \& NEPLUVI. (2012). Hygiënecode pluimveeslachterijen en -uitsnijderijen. Zoetermeer.

Dutch Product Boards for Livestock, Meat and Eggs (PVE), \& Dutch Product Board for Poultry and Eggs (PPE). (2014a). Annex 1.1: IKB Kip regulations for hatcheries, abattoirs and cutting plants.

Dutch Product Boards for Livestock, Meat and Eggs (PVE), \& Dutch Product Board for Poultry and Eggs (PPE). (2014b). Annex 12: Template of animal health plan and animal treatment plan for IKB Kip poultry farms.

Dutch Product Boards for Livestock, Meat and Eggs (PVE), \& Dutch Product Board for Poultry and Eggs (PPE). (2014c). Hygiënecode pluimveeslachterijen en -uitsnijderijen. http://www.pve.nl/pve?waxtrapp=alc]sHsuOnbPTEcBZKN\&context=nfMsHsuOnbPTEC Accessed November 10, 2015.

Dutch Product Boards for Livestock, Meat and Eggs (PVE), \& Dutch Product Board for Poultry and Eggs (PPE). (2014d). IKB KIP general terms and conditions. http://www.pve.nl/wdocs/dbedrijfsnet/up1/ZsudeecJO_0-414General_terms_and_conditions_IKB_Kip_version_10.pdf Accessed November 10, 2015.

Dutch Product Boards for Livestock, Meat and Eggs (PVE), \& Dutch Product Board for Poultry and Eggs (PPE). (2014e). Voedselketeninformatie (VKI).

http://www.pve.nl/pve?waxtrapp=xbbHsHsuOnbPTEcBZE\&context=nfMsHsuOnbPTEC Accessed November 10, 2015.

Dutch Product Boards for Livestock, Meat and Eggs (PVE). (2013). Livestock, meat and eggs in the Netherlands. Zoetermeer.

EFSA Panel on Contaminants in the Food Chain (CONTAM). (2004a). Opinion of the Scientific Panel on contaminants in the food chain [CONTAM] related to aflatoxin B1 as undesirable substance in animal feed. EFSA Journal 2004, 2004(39), 27. http://dx.doi.org/10.2903/j.efsa.2004.39.

EFSA Panel on Contaminants in the Food Chain (CONTAM). (2004b). Opinion of the Scientific Panel on contaminants in the food chain [CONTAM] related to deoxynivalenol (DON) as undesirable substance in animal feed. EFSA Journal 2004, 2004(73), 42. http://dx.doi.org/10.2903/j.efsa.2004.73.

EFSA Panel on Contaminants in the Food Chain (CONTAM). (2004c). Opinion of the Scientific Panel on contaminants in the food chain [CONTAM] related to zearalenone as undesirable substance in animal feed. EFSA Journal 2004, 2004(89), 35. http://dx.doi.org/10.2903/j.efsa.2004.89. 
EFSA Panel on Contaminants in the Food Chain (CONTAM). (2005a). Opinion of the Scientific Panel on contaminants in the food chain [CONTAM] related to arsenic as undesirable substance in animal feed. EFSA Journal 2005, 2005(3), 35. http://dx.doi.org/10.2903/j.efsa.2005.180.

EFSA Panel on Contaminants in the Food Chain (CONTAM). (2005b). Opinion of the Scientific Panel on contaminants in the food chain [CONTAM] related to fumonisins as undesirable substances in animal feed. EFSA Journal 2005, 2005(235), 32. http://dx.doi.org/10.2903/j.efsa.2005.235.

EFSA Panel on Contaminants in the Food Chain (CONTAM). (2005c). Opinion of the Scientific Panel on contaminants in the food chain [CONTAM] related to the presence of non dioxin-like polychlorinated biphenyls (PCB) in feed and food. EFSA Journal 2005, 284, 137. http://dx.doi.org/10.2903/j.efsa.2005.284.

EFSA Panel on Contaminants in the Food Chain (CONTAM). (2006). Opinion of the Scientific Panel on contaminants in the food chain [CONTAM] related to ochratoxin A in food. EFSA Journal 2006, 2006(365), 56. http://dx.doi.org/10.2903/j.efsa.2006.365.

EFSA Panel on Contaminants in the Food Chain (CONTAM). (2008). Scientific Opinion of the Panel on Contaminants in the Food Chain on a request from the European Commission on Polycyclic Aromatic Hydrocarbons in Food. EFSA Journal 2008, 2008(724), 114. http://dx.doi.org/10.2903/j.efsa.2008.724.

EFSA Panel on Contaminants in the Food Chain (CONTAM). (2011a). Scientific opinion on hexabromocyclododecanes (HBCDDs) in food. EFSA Journal 2011, 9(7), 118. http://dx.doi.org/10.2903/j.efsa.2011.2296.

EFSA Panel on Contaminants in the Food Chain (CONTAM). (2011b). Scientific Opinion on polybrominated diphenyl ethers (PBDEs) in food. EFSA Journal 2011, 9(5), 274. http://dx.doi.org/10.2903/j.efsa.2011.2156.

EFSA Panel on Contaminants in the Food Chain (CONTAM). (2014). Scientific opinion on chloramphenicol in food and feed. EFSA Journal 2014, 12(11), 145. http://dx.doi.org/10.2903/j.efsa.2014.3907.

EFSA Panel on Contaminants in the Food Chain (CONTAM). (2015). Scientific opinion on nitrofurans and their metabolites in food. EFSA Journal 2015, 13(6), 217.

http://dx.doi.org/10.2903/j.efsa.2015.4140.

EFSA Panels on Biological Hazards (BIOHAZ), on Contaminants in the Food Chain (CONTAM), \& on Animal Health and Welfare (AHAW). (2012). Scientific opinion on the public health hazards to be covered by inspection of meat (poultry). EFSA Journal, 10(6), 2741. http://dx.doi.org/10.2903/j.efsa.2012.2741.

Ellen, H. H., Leenstra, F. R., van Emous, R. A., Groenestein, C. M., van Harn, J., van Horne, P. L. M., de Jong, I. C., Kense, M., Mevius, D. J., \& Wagenaar, J. A. (2012). Vleeskuikenproductiesystemen in Nederland. Lelystad: Wageningen UR Livestock Research.

Engel, E., Ratel, J., Bouhlel, J., Planche, C., \& Meurillon, M. (2015). Novel approaches to improving the chemical safety of the meat chain towards toxicants. Meat Sci, 109, 75-85. http://dx.doi.org/10.1016/j.meatsci.2015.05.016.

European Commission. (2002). Commission Directive 2002/72/EC of 6 August 2002 relating to plastic materials and articles intended to come into contact with foodstuffs Official Journal of the European Communities, 45(L 220), 18-58.

European Commission. (2004). Regulation (EC) No 1935/2004 of the European Parliament and of the Council of 27 October 2004 on materials and articles intended to come into contact with food and repealing Directives 80/590/EEC and 89/109/EEC Official Journal of the European Union, 47(L 338), 4-17.

European Commission. (2006a). Commission Regulation (EC) No 1881/2006 of 19 December 2006 setting maximum levels for certain contaminants in foodstuffs. Official Journal of the European Union, 49(L 364), 5-24.

European Commission. (2006b). Regulation (EC) No 1333/2008 of the European Parliament and of the Council of 16 December 2008 on food additives. Official Journal of the European Union, 51(L 354), 67-84.

European Commission. (2010a). Commission Regulation (EU) No 37/2010 of 22 December 2009 on pharmacologically active substances and their classification regarding maximum residue limits in foodstuffs of animal origin Official Journal of the European Union, 53(L 15), 1-72.

European Commission. (2010b). Commission Regulation (EU) No 885/2010 of 7 October 2010 concerning the authorisation of the preparation of narasin and nicarbazin as a feed additive for 
chickens for fattening (holder of authorisation Eli Lilly and Company Ltd) and amending Regulation (EC) No 2430/1999. Official Journal of the European Union, 53(L 265), 5-8.

European Commission. (2011). Commission Regulation (EU) No 10/2011 of 14 January 2011 on plastic materials and articles intended to come into contact with food. Official Journal of the European Union, 54(L 12), 1-89.

European Commission Health \& Consumer Protection Directorate-General Scientific Committee on Food. (2001). Opinion of the Scientific Committee on Food in the risk assessment of dioxins and dioxin-like PCBs in food Brussels, BE: European Commission.

European Food Safety Authority (EFSA). (2010). Results of the monitoring of non dioxin-like PCBs in food and feed. EFSA Journal 2010, 8(7), 35. http://dx.doi.org/10.2903/j.efsa.2010.1701.

European Food Safety Authority (EFSA). (2012a). Poultry meat inspection: EFSA reviews risks for public health. http://www.efsa.europa.eu/en/press/news/120629.htm Accessed November 10, 2015.

European Food Safety Authority (EFSA). (2012b). Update of the monitoring of levels of dioxins and PCBs in food and feed. EFSA Journal, 10(7), 2832. http://dx.doi.org/10.2903/j.efsa.2012.2832.

European Medicines Agency. (1996a). Chloramphenicol: Summary report - Committee for veterinary medicinal products. London, UK.

European Medicines Agency. (1996b). Dimetridazole: Summary report (3). London, UK.

European Medicines Agency. (1996c). Ronidazole: Summary report (1) London, UK.

European Medicines Agency. (1997). Metronidazole Summary Report. London, UK.

European Union (EU). (2015). Short term outlook for EU arable crops, dairy and meat markets in 2015 and 2016.

Ferguson, J., Baxter, A., Young, P., Kennedy, G., Elliott, C., Weigel, S., Gatermann, R., Ashwin, H., Stead, S., \& Sharman, M. (2005). Detection of chloramphenicol and chloramphenicol glucuronide residues in poultry muscle, honey, prawn and milk using a surface plasmon resonance biosensor and Qflex $®$ kit chloramphenicol. Analytica Chimica Acta, 529(1-2), 109-113.

http://dx.doi.org/10.1016/j.aca.2004.11.042.

Flach, B. (2014). Bird flu outbreak in the Netherlands.

Food and Agriculture Organization of the United Nations (FAO), \& World Health Organization (WHO). (2012). Prevention and reduction of food and feed contamination (1st ed.). Rome: World Health Organization : Food and Agriculture Organization of the United Nations.

Food and Agriculture Organization of the United Nations (FAO), \& World Health Organization (WHO). (2014). Report of the twenty-first session of the Codex Committee on residues of veterinary drugs in foods.

Food and Agriculture Organization of the United Nations (FAO), \& World Health Organization (WHO). (2015). Report of the twenty-second session of the Codex Committee on resiudes of veterinary drugs in foods.

Food Standards Australia New Zealand (FSANZ). (2005). Scientific assessment of the public health and safety of poultry meat in Australia. Available from:

http://www.foodstandards.gov.au/code/primaryproduction/poultry/documents/P282_Poultry\%20_ \%20DAR\%20Attach3.pdf.

Front Office. (2010-2014). Annual reviews of risk assessments carried out by RIVM for 2010, 2011, 2012, 2013 and 2014. Bilthoven, the Netherlands: National Institute of Public Health and the Environment (RIVM).

Ghimpeţeanu, O.-M., Militaru, M., \& Scippo, M. L. (2014). Dioxins and polychlorinated biphenyls contamination in poultry liver related to food safety - A review. Food Control, 38(0), 47-53. http://dx.doi.org/10.1016/j.foodcont.2013.09.054.

Granja, R. H., Nino, A. M., Reche, K. V., Giannotti, F. M., de Lima, A. C., Wanschel, A. C., \& Salerno, A. G. (2013). Determination and confirmation of metronidazole, dimetridazole, ronidazole and their metabolites in bovine muscle by LC-MS/MS. Food Addit Contam Part A Chem Anal Control Expo Risk Assess, 30(6), 970-976. http://dx.doi.org/10.1080/19440049.2013.787653.

Grenier, B., \& Applegate, T. J. (2013). Modulation of intestinal functions following mycotoxin ingestion: Meta-analysis of published experiments in animals. Toxins (Basel), 5(2), 396-430. http://dx.doi.org/10.3390/toxins5020396.

Hänninen, O., Knol, A. B., Jantunen, M., Lim, T. A., Conrad, A., Rappolder, M., Carrer, P., Fanetti, A. C., Kim, R., Buekers, J., Torfs, R., Iavarone, I., Classen, T., Hornberg, C., Mekel, O. C. L., \& Group, E. W. (2014). Environmental burden of disease in Europe: Assessing nine risk factors in six 
countries. Environmental Health Perspectives, 122(5), 439-446.

http://dx.doi.org/10.1289/Ehp.1206154.

Hoogenboom, L. A., Kan, C. A., Bovee, T. F., van der Weg, G., Onstenk, C., \& Traag, W. A. (2004).

Residues of dioxins and PCBs in fat of growing pigs and broilers fed contaminated feed.

Chemosphere, 57(1), 35-42. http://dx.doi.org/10.1016/j.chemosphere.2004.04.057.

Hoogenboom, L. A. P., van Bruchem, G. D., Sonne, K., Enninga, I. C., van Rhijn, J. A., Heskamp, H., Huveneers-Oorsprong, M. B. M., van der Hoeven, J. C. M., \& Kuiper, H. A. (2002). Absorption of a mutagenic metabolite released from protein-bound residues of furazolidone. Environmental Toxicology and Pharmacology, 11(3-4), 273-287. http://dx.doi.org/10.1016/S13826689(02)00013-3.

Hoogenboom, R. (2012). Animal feed contamination by dioxins, polychlorinated biphenyls (PCBs) and brominated flame retardants. In J. Fink-Gremmels (Ed.), Animal Feed Contamination (pp. 131182): Woodhead Publishing.

Hoogenboom, R., Traag, W., Fernandes, A., \& Rose, M. (2015). European developments following incidents with dioxins and PCBs in the food and feed chain. Food Control, 50, 670-683. http://dx.doi.org/10.1016/j.foodcont.2014.10.010.

Hoste, R. (2014). Palmolieverbruik in de Nederlandse diervoederindustrie 2011-2013. Wageningen: LEI Wageningen UR and NEVEDI.

Hurtaud-Pessel, D., Delepine, B., \& Laurentie, M. (2000). Determination of four nitroimidazole residues in poultry meat by liquid chromatography-mass spectrometry. J Chromatogr A, 882(1-2), 89-98. http://dx.doi.org/10.1016/S0021-9673(00)00336-8.

Husak, R. L., Sebranek, J. G., \& Bregendahl, K. (2008). A Survey of Commercially Available Broilers Marketed as Organic, Free-Range, and Conventional Broilers for Cooked Meat Yields, Meat Composition, and Relative Value. Poultry Science, 87(11), 2367-2376. http://dx.doi.org/10.3382/ps.2007-00294.

Hussain, Z., Khan, M. Z., Khan, A., Javed, I., Saleemi, M. K., Mahmood, S., \& Asi, M. R. (2010). Residues of aflatoxin B1 in broiler meat: effect of age and dietary aflatoxin B1 levels. Food Chem Toxicol, 48(12), 3304-3307. http://dx.doi.org/10.1016/j.fct.2010.08.016.

IARC Working Group on the Evaluation of Carcinogenic Risks to Humans. (2012). Chemical agents and related occupations. IARC monographs on the evaluation of carcinogenic risks to humans/World Health Organization, International Agency for Research on Cancer, 100(Pt F), 9.

IARC Working Group on the Evaluation of Carcinogenic Risks to Humans, \& International Agency for Research on Cancer. (1993). Some naturally occurring substances: food items and constituents, heterocyclic aromatic amines and mycotoxins. Available from:

IARC Working Group on the Evaluation of Carcinogenic Risks to Humans, International Agency for Research on Cancer, \& World Health Organization. (1987). Overall evaluations of carcinogenicity: an updating of IARC monographs volumes 1 to 42 (Vol. 7). Lyon, France: World Health Organization.

Jägerstad, M., \& Skog, K. (2005). Genotoxicity of heat-processed foods. Mutat Res, 574(1-2), 156172. http://dx.doi.org/10.1016/j.mrfmmm.2005.01.030.

Joint FAO/WHO Expert Committee on Food Additives (JECFA). (1990). WHO Food Additives series 25: Ronidazole

Joint FAO/WHO Expert Committee on Food Additives (JECFA). (2002). Fifty-seventh meeting of the Joint FAO/WHO Expert Committee on food additives. Geneva, Switzerland: World Health Organization (WHO).

Kan, C. A. (1978). Accumulation of organochlorine pesticides in poultry: a review. J Agric Food Chem, 26(5), 1051-1055.

Kan, C. A. (2002). Prevention and control of contaminants of industrial processes and pesticides in the poultry production chain. Worlds Poultry Science Journal, 58(2), 159-167. http://dx.doi.org/10.1079/Wps20020015.

Kan, C. A., \& Meijer, G. A. L. (2007). The risk of contamination of food with toxic substances present in animal feed. Animal Feed Science and Technology, 133(1-2), 84-108. http://dx.doi.org/10.1016/j.anifeedsci.2006.08.005.

Kan, K. (2005). Chemical residues in poultry and eggs produced in free-range or organic systems Wageningen UR.

Kanarat, S., Tangsirisup, N., Nijthavorn, N., Elliott, C., \& Cannavan, A. (2008). An investigation into the possible natural occurrence of chloramphenicol in poultry litter. In L. van Ginkel \& A. Bergwerff 
(Eds.), EuroResidue IV Conference on residues of veterinary drugs in food (Vol. 1). Egmond aan Zee, the Netherlands.

Knize, M. G., \& Felton, J. S. (2005). Formation and human risk of carcinogenic heterocyclic amines formed from natural precursors in meat. Nutr Rev, 63(5), 158-165.

Knutsen, H., Binderup, M., Vikse, R., \& Øvrebø, S. (2007). Vurdering af helserisiko ved konsum av grillet mat. Norges Vitenskapskomiteen for mattrygghet (VKM). Norwegian, English summary. < http://www. vkm. no.

Landbouw-Economisch Institut (LEI). (2015). Agrimatie - informatie over de agrosector. http://www.agrimatie.nl/ Accessed March 31, 2015.

Le Blansch, K., \& Heesen, T.-J. (2016). Verkenning van de toepassing van biociden met formaldehyde (-releasers) - Alternatieven beschikbaar in betrokken sectoren? the Hague, the Netherlands: Bureau KLB.

LeDoux, M. (2011). Analytical methods applied to the determination of pesticide residues in foods of animal origin. A review of the past two decades. Journal of Chromatography $A, 1218(8), 1021$ 1036. http://dx.doi.org/10.1016/j.chroma.2010.12.097.

Liao, G. Z., Wang, G. Y., Xu, X. L., \& Zhou, G. H. (2010). Effect of cooking methods on the formation of heterocyclic aromatic amines in chicken and duck breast. Meat Sci, 85(1), 149-154. http://dx.doi.org/10.1016/j.meatsci.2009.12.018.

Malisch, R., \& Kotz, A. (2014). Dioxins and PCBs in feed and food--review from European perspective. Sci Total Environ, 491-492, 2-10. http://dx.doi.org/10.1016/j.scitotenv.2014.03.022.

MEG Marktinfo Eier \& Geflügel. (2014). MEG-Marktbilanz eier und geflügel 2014. Stuttgart, DE: Eugen Ulmer.

Ministerie van Economische Zaken (EZ). (2014). Monitor duurzaam voedsel 2013. Consumentenbestedingen aan duurzaam gelabelde producten. Den Haag, NL.

Mitchell, M. A., \& Kettlewel, P. A. (2009). Welfare of poultry during transport - a review. In Poultry Welfare Symposium (pp. 90-100). Cervia, Italy.

Murugesan, G. R., Ledoux, D. R., Naehrer, K., Berthiller, F., Applegate, T. J., Grenier, B., Phillips, T. D., \& Schatzmayr, G. (2015). Prevalence and effects of mycotoxins on poultry health and performance, and recent development in mycotoxin counteracting strategies. Poult Sci, 94(6), 1298-1315. http://dx.doi.org/10.3382/ps/pev075.

National Institute of Public Health and the Environment (RIVM). (2010-2012). Annual reviews of reports on trend analysis of chemical risks in food carried out by RIVM in 2010, 2011 and 2012. Bilthoven, the Netherlands: National Institute of Public Health and the Environment (RIVM).

Nauta, M., van der Fels-Klerx, I., \& Havelaar, A. (2005). A poultry-processing model for quantitative microbiological risk assessment. Risk Analysis, 25(1), 85-98. http://dx.doi.org/10.1111/j.02724332.2005.00569.x.

Nicholson, F. A., Chambers, B. J., Williams, J. R., \& Unwin, R. J. (1999). Heavy metal contents of livestock feeds and animal manures in England and Wales. Bioresource Technology, 70(1), 23-31. http://dx.doi.org/10.1016/S0960-8524(99)00017-6.

Noorlander CW. vLS, te Biesebeek JD., Mengelers MJB., Zeilmaker MJ., 2011. Levels of Perfluorinated Compounds in Food and Dietary Intake of PFOS and PFOA in The Netherlands. Journal of Agricultural and Food Chemistry, 59, 7496-7505.

Osselaere, A., Devreese, M., Goossens, J., Vandenbroucke, V., De Baere, S., De Backer, P., \& Croubels, S. (2013). Toxicokinetic study and absolute oral bioavailability of deoxynivalenol, T-2 toxin and zearalenone in broiler chickens. Food Chem Toxicol, 51, 350-355. http://dx.doi.org/10.1016/j.fct.2012.10.006.

Pettersson, H. (2012). Mycotoxin contamination of animal feed. In J. Fink-Gremmels (Ed.), Animal Feed Contamination (pp. 233-285): Woodhead Publishing.

Rawal, S., Kim, J. E., \& Coulombe Jr, R. (2010). Aflatoxin B1 in poultry: Toxicology, metabolism and prevention. Research in Veterinary Science, 89(3), 325-331. http://dx.doi.org/10.1016/j.rvsc.2010.04.011.

Reeves, P. T. (2011). Antibiotics: Groups and properties. In Chemical Analysis of Antibiotic Residues in Food (pp. 1-60): John Wiley \& Sons, Inc.

Reyes-Herrera, I., \& Donoghue, D. J. (2012). Chemical contamination of poultry meat and eggs. In D. Schrenk (Ed.), Chemical Contaminants and Residues in Food (pp. 469-497): Woodhead Publishing. 
Ringot, D., Chango, A., Schneider, Y. J., \& Larondelle, Y. (2006). Toxicokinetics and toxicodynamics of ochratoxin A, an update. Chem Biol Interact, 159(1), 18-46.

http://dx.doi.org/10.1016/j.cbi.2005.10.106.

Sanches Silva, A., Cruz, J. M., Sendón Garcı 'a, R., Franz, R., \& Paseiro Losada, P. (2007). Kinetic migration studies from packaging films into meat products. Meat Science, $77(2), 238-245$. http://dx.doi.org/10.1016/j.meatsci.2007.03.009.

Sebald, M., Reysset, G., Su, W.-J., \& Sebald, M. (1993). Genetics of 5-nitroimidazole resistance in bacteroides. In Genetics and Molecular Biology of Anaerobic Bacteria (pp. 494-504): Springer New York.

Skog, K., \& Solyakov, A. (2002). Heterocyclic amines in poultry products: a literature review. Food Chem Toxicol, 40(8), 1213-1221.

Tähkäpää, S., Maijala, R., Korkeala, H., \& Nevas, M. (2015). Patterns of food frauds and adulterations reported in the EU rapid alert system for food and feed and in Finland. Food Control, 47, 175-184. http://dx.doi.org/10.1016/j.foodcont.2014.07.007.

Trevisani, M., Diegoli, G., \& Fedrizzi, G. (2014). Public health hazards: C. Chemical hazards and their control. In T. Ninios, J. Lunden, H. Korkeala \& M. Fredriksson-Ahomaa (Eds.), Meat Inspection and Control in the Slaughterhouse (pp. 354-384): John Wiley \& Sons, Ltd.

United States Department of Agriculture (USDA). (1997). Meat and poultry products hazards and control guide. Available from: http://www.haccpalliance.org/sub/haccpmodels/hzrdcontrolguid.pdf.

United States Department of Agriculture (USDA). (2003). FSIS Directive 7310.5 presence of foreign material in meat or poultry products. Available from: http://www.meathaccp.wisc.edu/validation/assets/Directive\%207310.pdf.

United States Department of Agriculture (USDA). (2005). Meat and Poultry Hazards and Controls Guide. In (pp. 35 p.).

United States Environmental Protection Agency (EPA). (2012). EPA's reanalysis of key issues related to dioxin toxicity and responses to NAS comments (Vol. Volume 1 (CAS No. 1746-01-06)). Washington DC, USA: U.S. Environmental Protection Agency.

United States Food and Drug Administration (FDA). (2014). Code of Federal Regulations. 21 CFR110. Available from: http://www.accessdata.fda.gov/scripts/cdrh/cfdocs/cfcfr/CFRSearch.cfm?CFRPart=110\&showFR=1

Usher, C. T., \& Daley, W. D. R. (2013). Development and evaluation of a vision based poultry debone line monitoring system. In Sensing for Agriculture and Food Quality and Safety V (Vol. 8721). Baltimore, MD.

Vaessen, H. A. M. G., Jekel, A. A., \& Wilbers, A. A. M. M. (1988). Dietary intake of polycyclic aromatic hydrocarbons. Toxicological \& Environmental Chemistry, 16(4), 281-294. http://dx.doi.org/10.1080/02772248809357267.

van Asselt, E. D., Marvin, H. J. P., Boon, P. E., Swanenburg, M., Zeilmaker, M., Mengelers, M. J. B., \& van der Fels-Klerx, H. J. (2016). Chemical and physical hazards in the Dairy Chain. Wageningen, NL: RIKILT Wageningen UR.

van Asselt, E. D., van der Spiegel, M., Noordam, M. Y., Pikkemaat, M. G., \& van der Fels-Klerx, H. J. (2013). Risk ranking of chemical hazards in food-A case study on antibiotics in the Netherlands. Food Research International, 54(2), 1636-1642. http://dx.doi.org/10.1016/j.foodres.2013.08.042.

van Bokhorst-van de Veen, H., Hazeleger, W., Nierop Groot, M., Vollebregt, M., \& Zwietering, M. (2015). Microbiologische gevaren in de pluimveevleesketen - Een literatuurstudie met additionele informatie van stakeholders. Wageningen, Netherlands: Wageningen UR Food \& Biobased Research.

van der Meulen, H. A. B., de Bont, C. J. A. M., Agricola, H. J., van Horne, P. L. M., Hoste, R., van der Knijff, A., Leenstra, F. R., van der Meer, R. W., \& de Smet, A. (2010). Schaalvergroting in de landen tuinbouw; Effecten bij veehouderij en glastuinbouw. Den Haag: LEI, onderdeel van Wageningen UR.

van der Spiegel, M. (2004). Measuring effectiveness of food quality management. Wageningen University.

van Horne, P. (2007). Production and consumption of poultry meat and eggs in the European Union. European Commission, project number SSPE-CT-2004-513737 "Healthy Poultry". http://www.healthy-poultry.org/Results\%20of\%20the\%20project/chapter3.pdf.

van Horne, P. L. M. (2013). Concurrentiekracht van de Nederlandse pluimveevleessector. Den Haag: LEI, onderdeel van Wageningen UR. 
van Horne, P. L. M., \& Bondt, N. (2014). Competitiveness of the EU poultry meat sector : International comparison base year 2013. The Hague: LEI Wageningen UR.

van Kreijl, C. F., \& Knaap, A. G. A. C. (2004). Ons eten gemeten: Gezonde voeding en veilig voedsel in Nederland: Bohn Stafleu Van Loghum.

van Leeuwen, S. P., \& de Boer, J. (2008). Brominated flame retardants in fish and shellfish - levels and contribution of fish consumption to dietary exposure of Dutch citizens to HBCD. Mol Nutr Food Res, 52(2), 194-203. http://dx.doi.org/10.1002/mnfr.200700207.

Van Rooij, J. G., Veeger, M. M., Bodelier-Bade, M. M., Scheepers, P. T., \& Jongeneelen, F. J. (1994). Smoking and dietary intake of polycyclic aromatic hydrocarbons as sources of interindividual variability in the baseline excretion of 1-hydroxypyrene in urine. Int Arch Occup Environ Health, 66(1), 55-65.

van Wijnen, J. H., Slob, R., Jongmans-Liedekerken, G., van de Weerdt, R. H. J., \& Woudenberg, F. (1996). Exposure to polycyclic aromatic hydrocarbons among Dutch children. Environmental Health Perspectives, 104(5), 530-534. http://dx.doi.org/10.2307/3432994.

Vass, M., Hruska, K., \& Franek, M. (2008). Nitrofuran antibiotics: A review on the application, prohibition and residual analysis. Veterinarni Medicina, 53(9), 469-500.

Waldron, A. C., \& Naber, E. C. (1974). Importance of Feed as an Unavoidable Source of Pesticide Contamination in Poultry Meat and Eggs .1. Residues in Feedstuffs. Poultry Science, 53(4), 13591371.

Wang, J. H. (2001). Determination of three nitroimidazole residues in poultry meat by gas chromatography with nitrogen-phosphorus detection. J Chromatogr A, 918(2), 435-438. http://dx.doi.org/10.1016/S0021-9673(01)00779-8.

Wisman, A. (2014). Ontwikkeling van het aantal bedrijven met pluimvee en aantal dieren. Bewerking van CBS cijfers statline. http://www.wageningenur.nl/nl/artikel/Kort-overzicht-economischbelang-Nederlandse-pluimveesector.htm Accessed November 10, 2015.

Wongtavatchai, J., McLean, L., Ramos, F., \& Arnold, D. (2004). WHO Food Additives series 53: Chloramphenicol.

World Health Organization (WHO). (2014a). Dioxins and their effects on human health. http://www.who.int/mediacentre/factsheets/fs225/en/ Accessed November 10, 2015.

World Health Organization (WHO). (2014b). First European outbreak of avian influenza A(H5N8) confirmed in poultry. http://www.euro.who.int/en/health-topics/communicablediseases/influenza/news/news/2014/11/first-european-outbreak-of-avian-influenza-ah5n8confirmed-in-poultry Accessed November 10, 2015.

World Health Organization (WHO), \& Food Agriculture Organization of the United Nations (FAO). (2015). Codex Alimentarius Commission: Procedural Manual. Rome, Italy: Secretariat of the Codex Alimentarius Commission Joint FAO/WHO Food Standards Programme. 1020-8070. Available from: ftp://ftp.fao.org/codex/Publications/ProcManuals/Manual_24e.pdf.

Xia, X., Li, X., Shen, J., Zhanc, S., Ding, S., \& Jiang, H. (2006). Determination of four nitroimidazoles in poultry and swine muscle and eggs by liquid chromatography/tandem mass spectrometry. $J$ AOAC Int, 89(1), 94-99.

Zeilmaker, M., Bokkers, B. G. H., \& Mengelers, M. J. B. (in preparation). Health impact assessment of dioxin toxicity: A global perspective.

Zeilmaker, M. J., Bokkers, B. G. H., te Biesebeek, J. D., Mengelers, M. J. B., \& Noorlander, C. W. (2014). Dietary intake and health risk assessment of polybrominated diphenyl ethers in the Netherlands based on data collected in 2004 and 2008. European Journal of Nutrition and Food Safety, 4(4), 535-557. http://dx.doi.org/10.9734/ejnfs/2014/6756. 


\section{Annex 1 Poultry Chain}

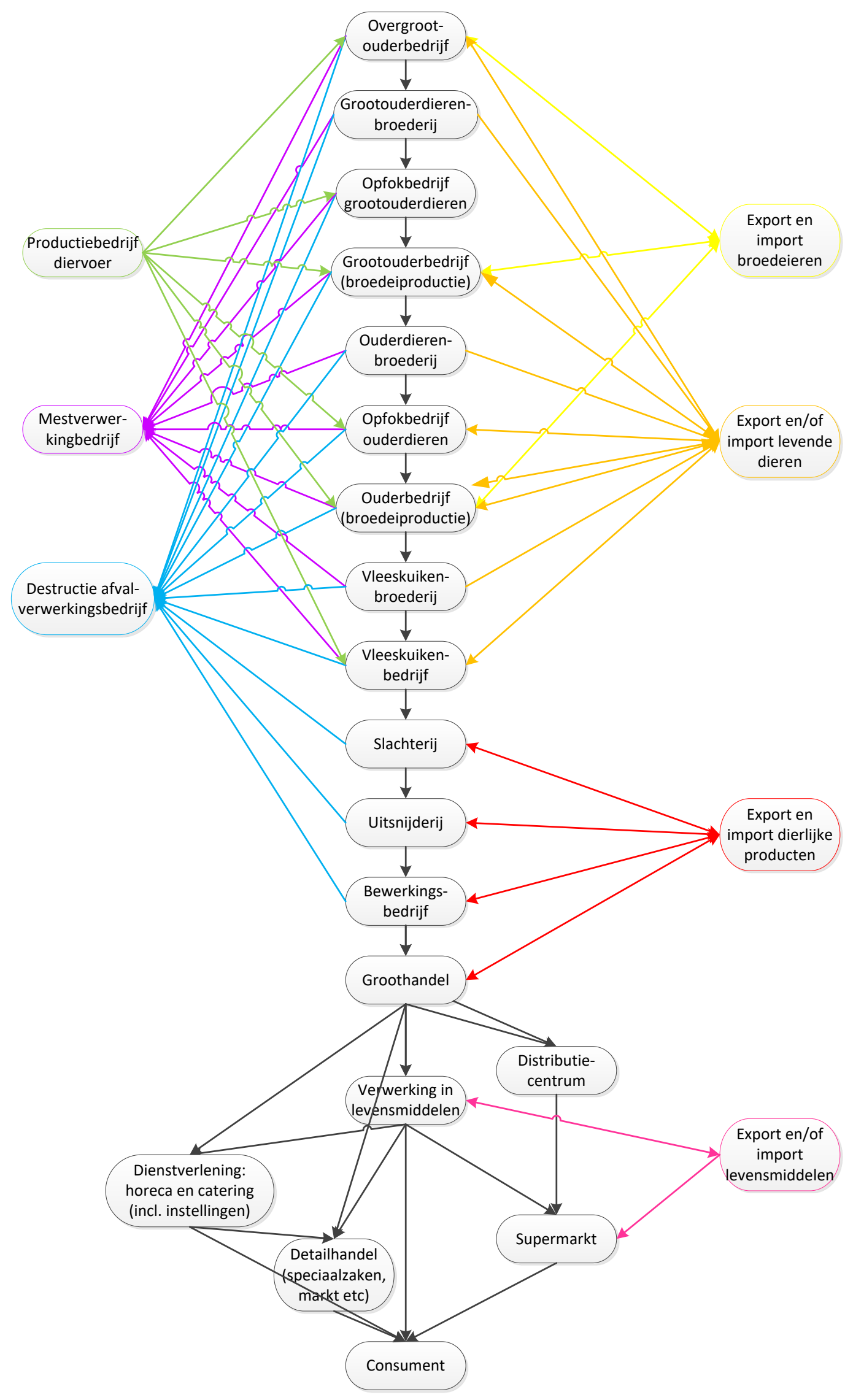




\section{Annex 2 RASFF notifications}

Table A2.1 Industrial contaminant notifications in RASFF.

\begin{tabular}{|c|c|c|c|c|c|c|}
\hline Reference & Notification type & Date of case & Last change & Product & Substance and Value & Countries concerned ${ }^{1)}$ \\
\hline 2011.ARI & border rejection & $24-3-2011$ & $24-3-2011$ & packaging of frozen turkey breast & diesel oil & $\begin{array}{l}\text { Israel (0) } \\
\text { United Kingdom }\end{array}$ \\
\hline 2011.1027 & $\begin{array}{l}\text { information for } \\
\text { follow-up }\end{array}$ & 29-7-2011 & 19-1-2012 & $\begin{array}{l}\text { Hatching eggs, day-old chicks and fattening chicks for } \\
\text { slaughter and chicken carcass }\end{array}$ & $\begin{array}{l}\text { suspicion of dioxins (in breeder chicken meat: } \\
33.68 ; 430.9 ; 116.4 \mathrm{pg} \text { WHO TEQ/g) }\end{array}$ & $\begin{array}{l}\text { Cape Verde (D) } \\
\text { Commission Services } \\
\text { France (D) } \\
\text { Portugal (D/O) } \\
\text { Spain (D) }\end{array}$ \\
\hline 2014.1267 & $\begin{array}{l}\text { information for } \\
\text { follow-up }\end{array}$ & $10-9-2014$ & $18-9-2014$ & Laying hens & suspicion of dioxins & $\begin{array}{l}\text { Belgium (D) } \\
\text { Netherlands (D/O) }\end{array}$ \\
\hline
\end{tabular}

1) $D=$ Distributed, $O=$ Origin. 
Table A2.2 Veterinary drugs: feed additive notifications in RASFF.

\begin{tabular}{|c|c|c|c|c|c|c|}
\hline Reference & Notification type & Date of case & Last change & Product & Substance and Value & Countries concerned ${ }^{1)}$ \\
\hline \multirow[t]{3}{*}{2009.0032} & information & 13-1-2009 & $6-4-2009$ & chicken livers pate $\&$ duck pate & residues of nicarbazin $(210 ; 140 \mu \mathrm{g} / \mathrm{kg}-\mathrm{ppb})$ & Belgium (O) \\
\hline & & & & & & Netherlands $(0)$ \\
\hline & & & & & & United Kingdom (D/O) \\
\hline \multirow[t]{2}{*}{2009.0227} & alert & $23-2-2009$ & $13-5-2009$ & frozen chicken livers & residues of nicarbazin $(6 ; 30 ; 20 \mu \mathrm{g} / \mathrm{kg}-\mathrm{ppb})$ & France \\
\hline & & & & & & United Kingdom (O) \\
\hline \multirow[t]{3}{*}{2009.0276} & information & $6-3-2009$ & $6-4-2009$ & chicken liver pate & residues of nicarbazin (dinitrocarbanilide: 310 & Belgium (O) \\
\hline & & & & & $\mu \mathrm{g} / \mathrm{kg}-\mathrm{ppb})$ & Netherlands $(\mathrm{O})$ \\
\hline & & & & & & United Kingdom (D) \\
\hline \multirow[t]{2}{*}{2009.0295} & information & $12-3-2009$ & $25-3-2009$ & frozen chicken meat & residues of nicarbazin $(7.6 \mu \mathrm{g} / \mathrm{kg}-\mathrm{ppb})$ & Brazil (O) \\
\hline & & & & & & Italy \\
\hline \multirow[t]{4}{*}{2009.0356} & alert & $26-3-2009$ & $25-8-2010$ & part-boned chicken breast & residues of nicarbazin $(270 \mu \mathrm{g} / \mathrm{kg}-\mathrm{ppb})$ & Denmark (D) \\
\hline & & & & & & Germany (O) \\
\hline & & & & & & United Kingdom (D) \\
\hline & & & & & & Vietnam (D) \\
\hline \multirow[t]{3}{*}{ 2009.APS } & border rejection & $27-3-2009$ & $1-9-2009$ & frozen chicken breast & residues of nicarbazin $(1.2 \mu \mathrm{g} / \mathrm{kg}-\mathrm{ppb})$ & Brazil (0) \\
\hline & & & & & & France \\
\hline & & & & & & Italy \\
\hline \multirow[t]{2}{*}{ 2009.BAV } & border rejection & $26-5-2009$ & 28-5-2009 & frozen chicken gizzards & residues of nicarbazin $(6.0 \mu \mathrm{g} / \mathrm{kg}-\mathrm{ppb})$ & Brazil (O) \\
\hline & & & & & & Bulgaria \\
\hline \multirow[t]{2}{*}{ 2009.BAU } & border rejection & $26-5-2009$ & $28-5-2009$ & frozen chicken gizzards & residues of nicarbazin $(5.95 \mu \mathrm{g} / \mathrm{kg}-\mathrm{ppb})$ & Brazil (O) \\
\hline & & & & & & Bulgaria \\
\hline \multirow[t]{3}{*}{2009.1731} & information & $14-12-2009$ & $13-1-2010$ & chilled young cockerel meat & residues of nicarbazin $(30 \mu \mathrm{g} / \mathrm{kg}-\mathrm{ppb})$ & Belgium (D) \\
\hline & & & & & & France $(0)$ \\
\hline & & & & & & Switzerland (D) \\
\hline 2010.BSE & border rejection & $7-10-2010$ & $24-11-2011$ & frozen poultry meat (Gallus gallus) & residues of nicarbazin $(10.25 \mu \mathrm{g} / \mathrm{kg}-\mathrm{ppb})$ & Brazil (O) Italy \\
\hline \multirow[t]{2}{*}{ 2012.ВCB } & border rejection & $21-5-2012$ & $25-6-2012$ & frozen salted chicken breast & unauthorized substance clopidol $(28.75 \mu \mathrm{g} / \mathrm{kg}-$ & Brazil (0) \\
\hline & & & & & $\mathrm{ppb})$ & Ireland \\
\hline \multirow[t]{2}{*}{ 2012.BEY } & border rejection & $11-6-2012$ & $25-6-2012$ & frozen salted chicken breast & unauthorized substance clopidol $(17.33 \mu \mathrm{g} / \mathrm{kg}-$ & Brazil (O) \\
\hline & & & & & $\mathrm{ppb})$ & Ireland \\
\hline \multirow[t]{2}{*}{ 2012.BFD } & border rejection & $12-6-2012$ & $16-7-2012$ & frozen salted chicken breast & unauthorized substance clopidol $(81.2 \mu \mathrm{g} / \mathrm{kg}$ - & Brazil (O) \\
\hline & & & & & $\mathrm{ppb}$ & Germany \\
\hline \multirow[t]{2}{*}{ 2012.BFC } & border rejection & $12-6-2012$ & $16-7-2012$ & frozen salted chicken breast & unauthorized substance clopidol ( $833 \mu \mathrm{g} / \mathrm{kg}$ - & Brazil (O) \\
\hline & & & & & $\mathrm{ppb})$ & Germany \\
\hline \multirow[t]{2}{*}{ 2012.BFB } & border rejection & $12-6-2012$ & $16-7-2012$ & frozen salted chicken breast & unauthorized substance clopidol $(147 \mu \mathrm{g} / \mathrm{kg}$ - & Brazil (O) \\
\hline & & & & & $\mathrm{ppb})$ & Germany \\
\hline
\end{tabular}




\begin{tabular}{|c|c|c|c|c|c|c|}
\hline Reference & Notification type & Date of case & Last change & Product & Substance and Value & Countries concerned ${ }^{1)}$ \\
\hline 2012.BFA & border rejection & $12-6-2012$ & $16-7-2012$ & in frozen salted chicken breast & $\begin{array}{l}\text { unauthorized substance clopidol (30.9 } \mathrm{\mu g} / \mathrm{kg} \text { - } \\
\text { ppb }\end{array}$ & $\begin{array}{l}\text { Brazil (O) } \\
\text { Germany }\end{array}$ \\
\hline 2012.BFW & border rejection & $14-6-2012$ & $16-7-2012$ & frozen salted chicken breast & $\begin{array}{l}\text { unauthorized substance clopidol (78.3 } \mu \mathrm{g} / \mathrm{kg} \text { - } \\
\mathrm{ppb} \text { ) }\end{array}$ & $\begin{array}{l}\text { Brazil (O) } \\
\text { Germany }\end{array}$ \\
\hline 2012.BHB & border rejection & $21-6-2012$ & $25-6-2012$ & frozen chicken breast fillet & $\begin{array}{l}\text { unauthorized substance clopidol }(310 \mu \mathrm{g} / \mathrm{kg} \text { - } \\
\mathrm{ppb} \text { ) }\end{array}$ & $\begin{array}{l}\text { Brazil }(0) \\
\text { United Kingdom }\end{array}$ \\
\hline 2012.BGZ & border rejection & $21-6-2012$ & $25-6-2012$ & frozen salted chicken breast & unauthorized substance clopidol $(11 \mu \mathrm{g} / \mathrm{kg}-\mathrm{ppb}$ & $\begin{array}{l}\text { Brazil }(0) \\
\text { Netherlands }\end{array}$ \\
\hline 2012.BIL & border rejection & $29-6-2012$ & $2-7-2012$ & frozen salted chicken breast fillets & $\begin{array}{l}\text { unauthorized substance clopidol }(27.1 \mu \mathrm{g} / \mathrm{kg} \text { - } \\
\mathrm{ppb} \text { ) }\end{array}$ & $\begin{array}{l}\text { Brazil (O) } \\
\text { Denmark } \\
\text { Germany }\end{array}$ \\
\hline 2012.BIZ & border rejection & $2-7-2012$ & $2-7-2012$ & frozen salted chicken breasts & $\begin{array}{l}\text { unauthorized substance clopidol }(116.25 \mu \mathrm{g} / \mathrm{kg} \text { - } \\
\mathrm{ppb} \text { ) }\end{array}$ & $\begin{array}{l}\text { Brazil }(0) \\
\text { Ireland }\end{array}$ \\
\hline 2012.BJI & border rejection & $3-7-2012$ & $16-7-2012$ & in frozen chicken breast & $\begin{array}{l}\text { unauthorized substance clopidol (48.5 } \mu \mathrm{g} / \mathrm{kg} \text { - } \\
\mathrm{ppb} \text { ) }\end{array}$ & $\begin{array}{l}\text { Brazil (O) } \\
\text { Germany }\end{array}$ \\
\hline 2012.BJT & border rejection & $5-7-2012$ & $20-12-2012$ & frozen salted chicken meat & $\begin{array}{l}\text { unauthorized substance clopidol }(27.85 \mu \mathrm{g} / \mathrm{kg} \text { - } \\
\mathrm{ppb})\end{array}$ & $\begin{array}{l}\text { Brazil }(0) \\
\text { Ireland }\end{array}$ \\
\hline 2012.BOJ & border rejection & $1-8-2012$ & $31-10-2012$ & frozen salted chicken meat & $\begin{array}{l}\text { unauthorized substance clopidol }(30.94 \mu \mathrm{g} / \mathrm{kg} \text { - } \\
\mathrm{ppb} \text { ) }\end{array}$ & $\begin{array}{l}\text { Brazil (0) } \\
\text { Ireland }\end{array}$ \\
\hline 2012.BOI & border rejection & $1-8-2012$ & $1-8-2012$ & frozen salted chicken meat & $\begin{array}{l}\text { unauthorized substance clopidol }(10.2 \mu \mathrm{g} / \mathrm{kg} \text { - } \\
\mathrm{ppb})\end{array}$ & $\begin{array}{l}\text { Brazil }(0) \\
\text { Ireland }\end{array}$ \\
\hline 2012.BQP & border rejection & $10-8-2012$ & 28-11-2013 & frozen chicken cuts and offal (Gallus gallus) & unauthorized substance clopidol & $\begin{array}{l}\text { Brazil (O) } \\
\text { Netherlands } \\
\text { Portugal (D) }\end{array}$ \\
\hline 2012.1244 & $\begin{array}{l}\text { information for } \\
\text { attention }\end{array}$ & $28-8-2012$ & $3-9-2012$ & frozen raw chicken meat & $\begin{array}{l}\text { unauthorized substance clopidol (19 } \mu \mathrm{g} / \mathrm{kg} \text { - } \\
\mathrm{ppb} \text { ) }\end{array}$ & $\begin{array}{l}\text { Israel }(O) \\
\text { United Kingdom (D) }\end{array}$ \\
\hline 2012.BTY & border rejection & $7-9-2012$ & $22-10-2014$ & frozen chicken from Brazil & $\begin{array}{l}\text { unauthorized substance clopidol }(22 \mu \mathrm{g} / \mathrm{kg} \text { - } \\
\mathrm{ppb})\end{array}$ & $\begin{array}{l}\text { Brazil (0) } \\
\text { Germany }\end{array}$ \\
\hline 2012.BVB & border rejection & $11-9-2012$ & $9-1-2014$ & frozen chicken meat (Gallus gallus) & $\begin{array}{l}\text { unauthorized substance clopidol }(30 \mu \mathrm{g} / \mathrm{kg} \text { - } \\
\mathrm{ppb} \text { ) }\end{array}$ & $\begin{array}{l}\text { Brazil (0) } \\
\text { Germany }\end{array}$ \\
\hline 2012.BWA & border rejection & $14-9-2012$ & 16-11-2012 & frozen whole chicken & $\begin{array}{l}\text { unauthorized substance clopidol }(1.7 \mu \mathrm{g} / \mathrm{kg} \text { - } \\
\mathrm{ppb})\end{array}$ & $\begin{array}{l}\text { Brazil (0) } \\
\text { Spain }\end{array}$ \\
\hline 2)2012.BWY & border rejection & $19-9-2012$ & 16-11-2012 & frozen chicken meat (Gallus gallus) & $\begin{array}{l}\text { unauthorized substance clopidol }(3.76 ; 5.53 \\
\mu \mathrm{g} / \mathrm{kg}-\mathrm{ppb})\end{array}$ & $\begin{array}{l}\text { Brazil (0) } \\
\text { Cyprus }\end{array}$ \\
\hline 2012.BWZ & border rejection & $19-9-2012$ & $10-4-2013$ & frozen chicken & unauthorized substance clopidol $(8 \mu \mathrm{g} / \mathrm{kg}-\mathrm{ppb})$ & $\begin{array}{l}\text { Brazil (0) } \\
\text { Germany }\end{array}$ \\
\hline
\end{tabular}




\begin{tabular}{|c|c|c|c|c|c|c|}
\hline Reference & Notification type & Date of case & Last change & Product & Substance and Value & Countries concerned ${ }^{1)}$ \\
\hline \multirow[t]{4}{*}{ 2012.BXA } & border rejection & $19-9-2012$ & $16-11-2012$ & frozen chicken & unauthorized substance clopidol ( $7 \mu \mathrm{g} / \mathrm{kg}-\mathrm{ppb})$ & Brazil (O) \\
\hline & & & & & & Germany \\
\hline & & & & & & Hungary \\
\hline & & & & & & Portugal \\
\hline \multirow[t]{4}{*}{ 3)2012.BYA } & border rejection & $26-9-2012$ & $7-5-2014$ & frozen chicken cuts and offal (Gallus gallus) & Salmonella Enteritidis (presence $/ 25 \mathrm{~g}$ ) and & Brazil (O) \\
\hline & & & & & unauthorized substance clopidol $(12 \mu \mathrm{g} / \mathrm{kg}-\mathrm{ppb}$ & Germany \\
\hline & & & & & & Hungary \\
\hline & & & & & & Portugal \\
\hline \multirow[t]{2}{*}{ 2012.BYF } & border rejection & $28-9-2012$ & $16-11-2012$ & frozen chicken cuts and offal (Gallus gallus) & unauthorized substance clopidol $(14 \mu \mathrm{g} / \mathrm{kg}$ - & Brazil $(0)$ \\
\hline & & & & & $\mathrm{ppb})$ & Germany \\
\hline \multirow[t]{3}{*}{ 2012.BYD } & border rejection & $28-9-2012$ & $9-11-2012$ & frozen chicken cuts and offal (Gallus gallus) & unauthorized substance clopidol ( $7 \mu \mathrm{g} / \mathrm{kg}-\mathrm{ppb})$ & Brazil (O) \\
\hline & & & & & & Germany \\
\hline & & & & & & Portugal \\
\hline \multirow[t]{2}{*}{ 2012.BZQ } & border rejection & $10-10-2012$ & $10-10-2012$ & frozen chicken cuts and offal (Gallus gallus) & unauthorized substance clopidol $(2.1 \mu \mathrm{g} / \mathrm{kg}$ - & Brazil (O) \\
\hline & & & & & $\mathrm{ppb})$ & Portugal \\
\hline \multirow[t]{2}{*}{ 2012.BZP } & border rejection & $10-10-2012$ & $10-10-2012$ & frozen chicken meat (Gallus gallus) & unauthorized substance clopidol ( $2 \mu \mathrm{g} / \mathrm{kg}-\mathrm{ppb})$ & Brazil (0) \\
\hline & & & & & & Spain \\
\hline \multirow[t]{2}{*}{ 2012.BZO } & border rejection & $10-10-2012$ & $10-10-2012$ & frozen chicken cuts and offal (Gallus gallus) & unauthorized substance clopidol $(1.5 \mu \mathrm{g} / \mathrm{kg}$ - & Brazil (O) \\
\hline & & & & & $\mathrm{ppb})$ & Spain \\
\hline \multirow[t]{2}{*}{ 2012.CAO } & border rejection & $16-10-2012$ & $28-11-2013$ & frozen chicken liver (Gallus gallus) & unauthorized substance clopidol $(18 \mu \mathrm{g} / \mathrm{kg}-\mathrm{ppb}$ & Brazil (O) \\
\hline & & & & & & Germany \\
\hline \multirow[t]{2}{*}{ 2012.CBN } & border rejection & $19-10-2012$ & $23-10-2012$ & frozen poultry & unauthorized substance clopidol (presence) & Brazil (0) \\
\hline & & & & & & Spain \\
\hline \multirow[t]{2}{*}{ 2012.CB] } & border rejection & $19-10-2012$ & 23-10-2012 & frozen poultry meat & unauthorized substance clopidol (presence) & Brazil (O) \\
\hline & & & & & & Spain \\
\hline \multirow[t]{2}{*}{ 2012.CME } & border rejection & $5-12-2012$ & $7-12-2012$ & frozen cuts and offal poultry meat & unauthorized substance clopidol $(3.0 \mu \mathrm{g} / \mathrm{kg}$ - & Brazil (O) \\
\hline & & & & & $\mathrm{ppb})$ & Portugal \\
\hline \multirow[t]{2}{*}{ 2012.CPK } & border rejection & $20-12-2012$ & $6-5-2013$ & frozen poultry cuts & unauthorized substance clopidol & Belgium \\
\hline & & & & & & Israel (O) \\
\hline \multirow[t]{3}{*}{ 2013.ABJ } & border rejection & $3-1-2013$ & $6-5-2013$ & frozen chicken breast & unauthorized substance clopidol $(0.5 ; 2 ; 5$ & Belgium \\
\hline & & & & & $\mu \mathrm{g} / \mathrm{kg}-\mathrm{ppb})$ & France \\
\hline & & & & & & Israel $(0)$ \\
\hline \multirow[t]{2}{*}{2013.0318} & information for & $8-3-2013$ & $19-6-2013$ & frozen whole chicken & unauthorized substance clopidol $(6.3 \mu \mathrm{g} / \mathrm{kg}-$ & Argentina $(0)$ \\
\hline & attention & & & & $\mathrm{ppb})$ & Germany (D) \\
\hline \multirow[t]{2}{*}{ 2013.AWB } & border rejection & $30-4-2013$ & $6-5-2013$ & frozen chicken "Gallus gallus" & unauthorized substance clopidol $(5.92 \mu \mathrm{g} / \mathrm{kg}$ - & Argentina $(0)$ \\
\hline & & & & & $\mathrm{ppb})$ & Cyprus \\
\hline
\end{tabular}




\begin{tabular}{|c|c|c|c|c|c|c|}
\hline Reference & Notification type & Date of case & Last change & Product & Substance and Value & Countries concerned ${ }^{1}$ ) \\
\hline 2013.1138 & alert & $16-8-2013$ & $16-10-2013$ & frozen turkey cutlets & $\begin{array}{l}\text { unauthorized substance clopidol }(37.3 \mu \mathrm{g} / \mathrm{kg} \text { - } \\
\mathrm{ppb} \text { ) }\end{array}$ & $\begin{array}{l}\text { Austria (D) } \\
\text { Commission Service } \\
\text { Germany (D) } \\
\text { Israel (O) }\end{array}$ \\
\hline 2013.BOZ & border rejection & $9-9-2013$ & $28-11-2013$ & frozen turkey breast (Meleagris gallopavo) & $\begin{array}{l}\text { unauthorized substance clopidol }(91 \mu \mathrm{g} / \mathrm{kg} \text { - } \\
\mathrm{ppb})\end{array}$ & $\begin{array}{l}\text { Germany } \\
\text { Israel }(0)\end{array}$ \\
\hline 2013.BPZ & border rejection & $16-9-2013$ & $23-9-2013$ & frozen turkey (Meleagris gallopavo) & $\begin{array}{l}\text { unauthorized substance clopidol }(97 \mu \mathrm{g} / \mathrm{kg} \text { - } \\
\mathrm{ppb})\end{array}$ & $\begin{array}{l}\text { Germany } \\
\text { Israel }(0)\end{array}$ \\
\hline 2013.BPW & border rejection & $16-9-2013$ & $16-9-2013$ & frozen turkey meat (Meleagris gallopavo) & $\begin{array}{l}\text { unauthorized substance clopidol ( } 38 \mu \mathrm{g} / \mathrm{kg} \text { - } \\
\mathrm{ppb} \text { ) }\end{array}$ & $\begin{array}{l}\text { Germany } \\
\text { Israel }(0)\end{array}$ \\
\hline 2013.BRF & border rejection & $27-9-2013$ & $27-9-2013$ & frozen raw turkey breast (Meleagris gallopavo) & unauthorized substance clopidol $(20 \mu \mathrm{g} / \mathrm{kg}$ - ppb & $\begin{array}{l}\text { Israel }(0) \\
\text { United Kingdom }\end{array}$ \\
\hline 2013.BSS & border rejection & $4-10-2013$ & $4-10-2013$ & turkey cutlets and thighs (Meleagris gallopavo) & unauthorized substance clopidol & $\begin{array}{l}\text { Belgium } \\
\text { Israel }(0)\end{array}$ \\
\hline 2013.1569 & $\begin{array}{l}\text { information for } \\
\text { attention }\end{array}$ & $28-11-2013$ & $17-9-2014$ & frozen raw chicken breast & $\begin{array}{l}\text { unauthorized substance clopidol }(20 \mu \mathrm{gg} / \mathrm{kg} \text { - } \\
\mathrm{ppb} \text { ) }\end{array}$ & $\begin{array}{l}\text { Brazil (O) } \\
\text { Commission Services } \\
\text { United Kingdom (D) }\end{array}$ \\
\hline 2013.1592 & alert & $2-12-2013$ & $3-1-2014$ & frozen turkey breast & $\begin{array}{l}\text { unauthorized substance clopidol }(10 \mu \mathrm{g} / \mathrm{kg} \text { - } \\
\mathrm{ppb} \text { ) }\end{array}$ & $\begin{array}{l}\text { Ireland (D) } \\
\text { Israel (O) } \\
\text { United Kingdom (D) }\end{array}$ \\
\hline 2013.1726 & alert & $23-12-2013$ & $3-1-2014$ & frozen turkey breasts & $\begin{array}{l}\text { unauthorized substance clopidol ( } 32 \mu \mathrm{g} / \mathrm{kg} \text { - } \\
\mathrm{ppb} \text { ) }\end{array}$ & $\begin{array}{l}\text { Ireland (D) } \\
\text { Israel (O) } \\
\text { United Kingdom (D) }\end{array}$ \\
\hline 2013.1733 & $\begin{array}{l}\text { information for } \\
\text { attention }\end{array}$ & $27-12-2013$ & $27-12-2013$ & frozen turkey breast & $\begin{array}{l}\text { unauthorized substance clopidol }(53 \mu \mathrm{g} / \mathrm{kg} \text { - } \\
\mathrm{ppb} \text { ) }\end{array}$ & $\begin{array}{l}\text { Israel (O) } \\
\text { United Kingdom (D) }\end{array}$ \\
\hline 2014.0116 & alert & $27-1-2014$ & $27-1-2014$ & frozen chicken breast fillets & $\begin{array}{l}\text { unauthorized substance clopidol }(10 \mu \mathrm{g} / \mathrm{kg} \text { - } \\
\mathrm{ppb} \text { ) }\end{array}$ & $\begin{array}{l}\text { Brazil (O) } \\
\text { Netherlands (O) } \\
\text { United Kingdom (D) }\end{array}$ \\
\hline
\end{tabular}

\footnotetext{
1) $D=$ Distributed, $O=$ Origin
}

2) Reported in the meat and meat products (other than poultry) product category.

3) Reference overlaps with another hazard category. 
Table A2.3 Veterinary drugs: residues of VMPs in RASFF.

\begin{tabular}{|c|c|c|c|c|c|c|}
\hline Reference & Notification types & Date of case & Last change & Product & Substance and Value & Countries concerned ${ }^{1)}$ \\
\hline \multirow[t]{2}{*}{2009.0643} & information & $25-5-2009$ & $25-5-2009$ & turkey breast fillets & presence of bacterial inhibitor & Germany (D) \\
\hline & & & & & & Poland (D/O) \\
\hline \multirow[t]{4}{*}{2009.1337} & information & $12-10-2009$ & $12-10-2009$ & chicken meat & prohibited substance nitrofuran (metabolite) & Belgium (D) \\
\hline & & & & & furazolidone (AOZ) $(A O Z>M R P L \mu g / k g-p p b)$ & France $(0)$ \\
\hline & & & & & & Netherlands $(0)$ \\
\hline & & & & & & United Kingdom (O) \\
\hline \multirow[t]{9}{*}{2009.1725} & alert & $11-12-2009$ & $3-1-2011$ & frozen chicken breast fillets & unauthorized substance sulphaquinoxaline (412 & Austria (D) \\
\hline & & & & & $\mu \mathrm{g} / \mathrm{kg}-\mathrm{ppb})$ & Brazil (0) \\
\hline & & & & & & Commission Services \\
\hline & & & & & & Denmark (D) \\
\hline & & & & & & France \\
\hline & & & & & & Germany $(0)$ \\
\hline & & & & & & Luxembourg $(D)$ \\
\hline & & & & & & Netherlands (D) \\
\hline & & & & & & Spain \\
\hline \multirow[t]{2}{*}{ 2)2012.AWD } & border rejection & $16-4-2012$ & $16-7-2012$ & frozen steamed chicken breasts & residue level above $M R L$ for toltrazuril $(340 \mathrm{mg} / \mathrm{kg}$ & China $(0)$ \\
\hline & & & & & $-\mathrm{ppm})$ & United Kingdom \\
\hline \multirow[t]{2}{*}{ 3)2012.BKL } & border rejection & $10-7-2012$ & $11-7-2012$ & frozen poultry meat & cyromazine $(70.5 \mu \mathrm{g} / \mathrm{kg}-\mathrm{ppb})$ and residue level & China $(0)$ \\
\hline & & & & & above MRL for toltrazuril (422 $\mu \mathrm{g} / \mathrm{kg}-\mathrm{ppb})$ & Ireland \\
\hline \multirow[t]{2}{*}{2012.1192} & information for & $20-8-2012$ & $10-9-2012$ & chilled chicken breast & residue level above MRL for doxycycline ( 230 & Poland (O) \\
\hline & attention & & & & $\mu \mathrm{g} / \mathrm{kg}-\mathrm{ppb})$ & Slovakia $(D / O)$ \\
\hline \multirow[t]{6}{*}{2012.1197} & alert & $21-8-2012$ & $25-9-2012$ & frozen mechanically separated poultry meat & prohibited substance chloramphenicol $(0.88 \mu \mathrm{g} / \mathrm{kg}$ & Albania (D) \\
\hline & & & & & $-\mathrm{ppb})$ & Armenia (D) \\
\hline & & & & & & Commission Services \\
\hline & & & & & & Germany (D) \\
\hline & & & & & & Italy $(\mathrm{D} / \mathrm{O})$ \\
\hline & & & & & & Netherlands (D) \\
\hline \multirow[t]{3}{*}{2012.1552} & information for & $8-11-2012$ & $21-10-2013$ & frozen salted halves of skinless boneless chickens & residue level above MRL for doxycycline & Belgium (D) \\
\hline & follow-up & & & & & Brazil (0) \\
\hline & & & & & & Germany (D) \\
\hline 2012.1747 & $\begin{array}{l}\text { information for } \\
\text { follow-up }\end{array}$ & $19-12-2012$ & $19-12-2012$ & chicken breast fillets & $\begin{array}{l}\text { residue level above MRL for lasalocid ( } 25 \mu \mathrm{g} / \mathrm{kg} \text { - } \\
\text { ppb) }\end{array}$ & $\begin{array}{l}\text { Belgium }(D / O) \\
\text { Luxembourg }(D)\end{array}$ \\
\hline
\end{tabular}


Netherlands (D)

Romania (D)

Switzerland (D)

United Kingdom ( $D$ )

4)2013.0923 $\begin{aligned} & \text { information for } \\ & \text { attention }\end{aligned} \quad$ 2-7-2013 2-8-2013 chilled chicken breasts

residue levels above MRL for the sum of

Poland (D/O)

Bulgaria (D)

$(313 \mu \mathrm{g} / \mathrm{kg}-\mathrm{ppb})$

Commission Services

Denmark (D)

Hungary (D)

Poland (O)

Slovakia (D)

2013.0985 alert 12-7-2013 27-8-2013 frozen poultry thigh fillets

residue level above MRL for doxycycline $(>300$

Bulgaria (D)

Czech Republic (D)

France (D)

Hungary $(D)$

Poland (D/O)

Romania (D)

Slovakia (D)

\begin{tabular}{lllll}
\hline 2013.0988 & alert & $12-7-2013$ & $15-7-2013$ & frozen chicken thigh fillets \\
\hline 2013.1185 & $\begin{array}{l}\text { information for } \\
\text { follow-up }\end{array}$ & $29-8-2013$ & $26-9-2013$ & chicken meat products \\
& & & & \\
\hline
\end{tabular}

residue level above MRL for doxycycline (243; 315 Czech Republic (D) $\mu \mathrm{g} / \mathrm{kg}-\mathrm{ppb})$ Poland (O)

from animals which have not undergone sufficient Czech Republic (D)

withdrawal periods for veterinary medicines Poland (D/O)

(doxycycline)

Slovakia (D)

United Kingdom (D) 


\begin{tabular}{|c|c|c|c|c|c|c|}
\hline Reference & Notification types & Date of case & Last change & Product & Substance and Value & Countries concerned ${ }^{1)}$ \\
\hline \multirow[t]{5}{*}{2013.1467} & alert & $7-11-2013$ & 29-11-2013 & frozen salted chicken breast & residue level above MRL for doxycycline (172 & Brazil (0) \\
\hline & & & & & $\mu g / k g-p p b)$ & Czech Republic (D/O) \\
\hline & & & & & & Denmark (0) \\
\hline & & & & & & Netherlands $(0)$ \\
\hline & & & & & & Slovakia (D/O) \\
\hline \multirow[t]{3}{*}{2013.1520} & information for & $19-11-2013$ & $13-8-2014$ & frozen chicken meat preparation & residue level above MRL for doxycycline ( 246 & Brazil (O) \\
\hline & attention & & & & $\mu \mathrm{g} / \mathrm{kg}-\mathrm{ppb})$ & Commission Services \\
\hline & & & & & & Netherlands (D) \\
\hline \multirow[t]{2}{*}{2013.1643} & alert & $11-12-2013$ & $18-12-2013$ & fresh chicken meat & residue level above MRL for doxycycline (>200 & Belgium (D) \\
\hline & & & & & $\mu g / k g-p p b)$ & Netherlands $(0)$ \\
\hline \multirow[t]{3}{*}{${ }_{4)}^{2} 2013 . \mathrm{CDH}$} & border rejection & $17-12-2013$ & $9-1-2014$ & frozen salted chicken breasts & residue levels above MRL for tetracycline ( $>100$ & Belgium \\
\hline & & & & & $\mu \mathrm{g} / \mathrm{kg}-\mathrm{ppb})$ and for doxycycline & Brazil (0) \\
\hline & & & & & & Commission Services \\
\hline \multirow[t]{5}{*}{2014.0613} & alert & $5-5-2014$ & $6-8-2014$ & chilled chicken & residue level above MRL for doxycycline (146 & Belgium (D/O) \\
\hline & & & & & $\mu \mathrm{g} / \mathrm{kg}-\mathrm{ppb})$ & France (D) \\
\hline & & & & & & Germany (D) \\
\hline & & & & & & Ireland (D) \\
\hline & & & & & & Netherlands (D) \\
\hline \multirow[t]{10}{*}{2014.1680} & information for & $8-12-2014$ & 9-3-2015 & frozen duck legs & residue level above MRL for doxycycline (139 & Belgium (D) \\
\hline & follow-up & & & & $\mu g / k g-p p b)$ & Canada (D) \\
\hline & & & & & & Commission Services \\
\hline & & & & & & France (D) \\
\hline & & & & & & Hong Kong (D) \\
\hline & & & & & & Hungary (D) \\
\hline & & & & & & Malta (D) \\
\hline & & & & & & Portugal (D) \\
\hline & & & & & & Slovakia (D) \\
\hline & & & & & & United States (D) \\
\hline \multicolumn{7}{|c|}{ 1) $\mathrm{D}=$ Distributed, $\mathrm{O}=$ Origin. } \\
\hline \multicolumn{7}{|c|}{ 2) Reported in the meat and meat products (other than poultry) product category. } \\
\hline \multicolumn{7}{|c|}{ 3) Reference overlaps with another hazard category. } \\
\hline \multicolumn{7}{|c|}{ 4) Multiple hazards reported within the same hazard category. } \\
\hline
\end{tabular}


RIKILT Wageningen University \& Research P.O. Box 230

6700 AE Wageningen

The Netherlands

$\mathrm{T}+31(0) 317480256$

www.wur.eu/rikilt

RIKILT report 2017.001
The mission of Wageningen University and Research is "To explore the potential of nature to improve the quality of life." Under the banner Wageningen University \& Research, Wageningen University and the specialised research institutes of the Wageningen Research Foundation have joined forces in contributing to finding solutions to important questions in the domain of healthy food and living environment. With its roughly 30 branches, 5,000 employees and 10,000 students, Wageningen University \& Research is one of the leading organisations in its domain. The unique Wageningen approach lies in its integrated approach to issues and the collaboration between different disciplines. 



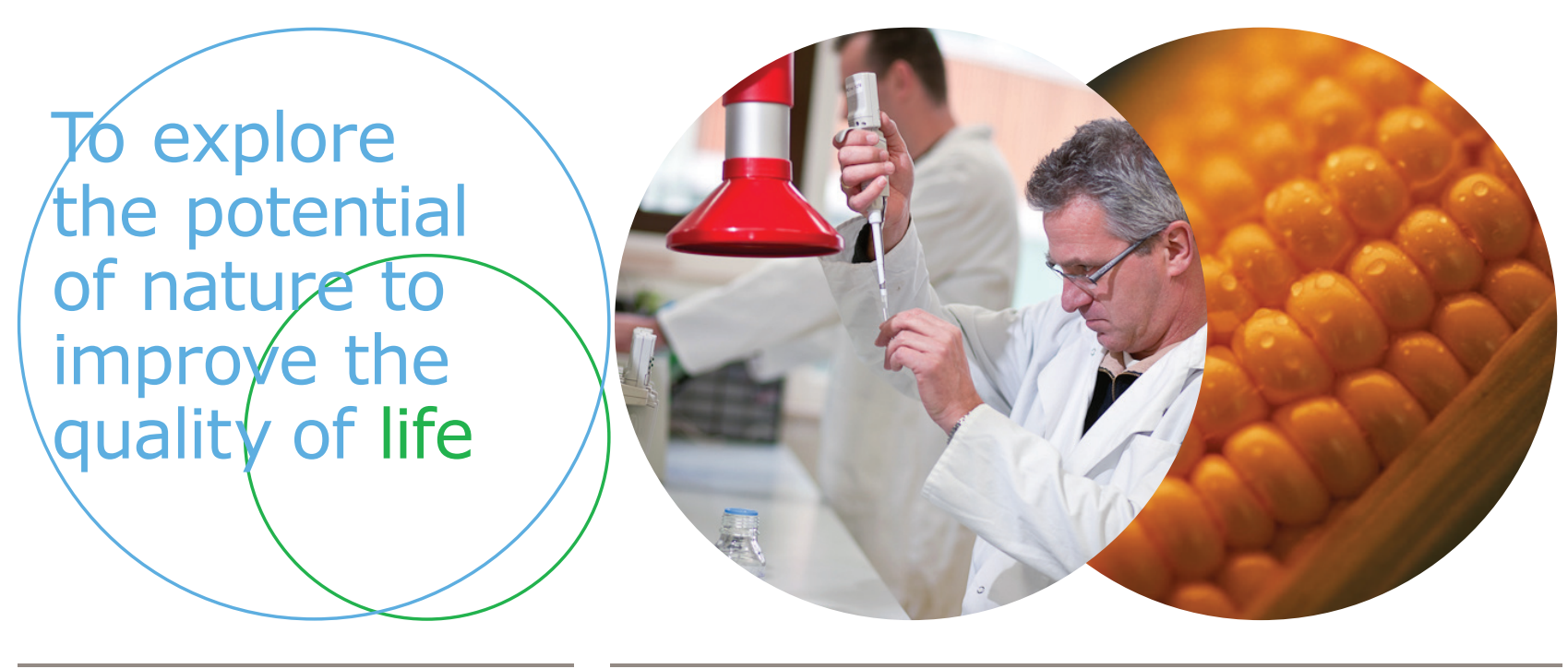

RIKILT Wageningen University \& Research P.O. Box 230

6700 AE Wageningen

The Netherlands

T +31 (0)317480256

www.wur.eu/rikilt

Report 2017.001
The mission of Wageningen University and Research is "To explore the potential of nature to improve the quality of life". Under the banner Wageningen University \& Research, Wageningen University and the specialised research institutes of the Wageningen Research Foundation have joined forces in contributing to inding solutions to important questions in the domain of healthy food and living environment. With its roughly 30 branches, 5,000 employees and 10,000 students, Wageningen University \& Research is one of the leading organisations in its domain. The unique Wageningen approach lies in its integrated approach to issues and the collaboration between different disciplines. 